\title{
PALEO
}

Revue d'archéologie préhistorique

$22 \mid 2011$

Varia

\section{Le mammouth de la Madeleine (Tursac, Dordogne)}

Dans son siècle et aujourd'hui

The mammoth of La Madeleine (Tursac, Dordogne) in its century and today

\section{Patrick Paillet}

\section{OpenEdition}

\section{Journals}

Édition électronique

URL : http://journals.openedition.org/paleo/2143

DOI : $10.4000 /$ paleo.2143

ISSN : 2101-0420

Éditeur

SAMRA

Édition imprimée

Date de publication : 1 décembre 2011

Pagination : 223-270

ISSN : $1145-3370$

\section{Référence électronique}

Patrick Paillet, « Le mammouth de la Madeleine (Tursac, Dordogne) », PALEO [En ligne], 22 | 2011, mis en ligne le 17 avril 2012, consulté le 07 juillet 2020. URL : http://journals.openedition.org/paleo/2143 : DOl : https://doi.org/10.4000/paleo.2143

\section{(c)}

PALEO est mis à disposition selon les termes de la licence Creative Commons Attribution - Pas d'Utilisation Commerciale - Pas de Modification 4.0 International. 


\title{
LE MAMMOUTH DE LA MADELEINE (Tursac, Dordogne) dans son siècle et aujourd'hui
}

\author{
Patrick PAILLET ${ }^{(1)}$
}

Pendant que les aristocrates de Solutré, du haut de leur abrupt rocher, nid d'aigle digne de ces féodaux en herbe, planaient sur la contrée environnante ; pendant qu'ils caracolaient sur leurs montures, brandissant leurs lances de pierre, agitant leurs sagaies, parcourant à fond de train le plat pays, toujours en chasse, quelque fois en guerre, rêvant déjà peut-être conquêtes et batailles, songeries funestes, habituelles à toute chevalerie, même à la chevalerie sauvage ; pendant que ce grand monde piaffait, criait, hurlait, les doux Girondins d'Aquitaine, sur les bords calmes de la Vézère, à l'abri des rochers de Bruniquel et de Laugerie Basse, assis à l'ombre des grands arbres, bercés par le doux murmure des ondes claires sur le sable fin de la rive, cachés à tous les regards, les doux Girondins d'Aquitaine, plus grands de cent coudées que les futurs Césars de Bourgogne, inventaient l'Art. (Henri du CLEUZIOU, 1887, La création de l'homme et les premiers âges de l'humanité, Flammarion, Paris, p. 247)

\begin{abstract}
Résumé : Le mammouth gravé sur ivoire de La Madeleine (Tursac, Dordogne) appartient sans conteste à notre mémoire scientifique collective. Depuis 1865, il n'est quasiment pas un ouvrage de vulgarisation ou un traité de préhistoire qui ne mentionne son existence, qui n'en montre une image ou qui ne précise les conditions et l'importance de sa découverte. L'antiquité de l'Homme et sa coexistence préhistorique ou « antédiluvienne » avec des animaux aujourd'hui disparus trouvent en partie leur affirmation et s'enracinent même dans cette plaque d'ivoire découverte si fortuitement un jour de mai 1864. L'objet est rare, il est exceptionnel même et pourtant, quel paradoxe, il est si mal connu. Les images abondent, souvent de piètre qualité et les commentaires les plus fantasques inondent les livres. Aucune monographie ne lui avait été consacrée jusqu'à aujourd'hui. Nous proposons de l'étudier en le réinsérant dans le cours de l'Histoire et de mesurer son rôle dans l'agitation intellectuelle du XIX ${ }^{\text {ème }}$ siècle. Nous montrerons ce que doit la Préhistoire à cette squame d'ivoire et nous en décrirons l'influence sur les esprits, tant positive que négative. Nous achèverons enfin notre propos par une analyse détaillée de l'objet et de sa représentation en les replaçant dans le contexte paléolithique régional de l'art pariétal et de l'art mobilier.
\end{abstract}

Mots-clés : art mobilier, Mammouth, La Madeleine, Magdalénien, ivoire.

Key-words: Portable art, Mammoth, La Madeleine, Magdalenian, Ivory.

\section{Abridged english version}

The mammoth of La Madeleine (Tursac, Dordogne) in its century and today.

\section{Introduction}

The mammoth is the symbol for all disappeared species. The discovery of an engraved mammoth on ivory from La Madeleine in may, 1864, has been essential because it constitutes the assertion of the contemporaneity of man and mammoth.

(1) Muséum national d'histoire naturelle, Département de Préhistoire - Bâtiment des collections n¹40, 43 rue Buffon - 75005 Paris paillet@mnhn.fr 


\section{A great debate in XIXth century : the antiquity of man and its contemporaneity with disappeared species}

In XIXth century, the study of man and its place in Prehistory is trusted to geologists and palaeontologists. The first works in France and Wales between 1812 and 1850 yet reveal the coexistence of man with disappeared fossil species. But the most convincing proof of this contemporaneity are given by the researches and publications of J. Boucher de Perthes in the Somme valley and of E. Lartet in Aurignac and Massat, even thought E. de Beaumont, perpetual secretary of the Science Academy, is still denying it.

\section{Men and artists - the role of art objects}

The first prehistoric art objects discovered by E. Lartet, H. Christy and P. de Vibraye (fig. 1) in Les Eyzies region in 1863-1864 testify the great antiquity of art and the aesthetic abilities of their creators. The discovery of the ivory from La Madeleine is a decisive step in this recognition.

\section{The mammoth of La Madeleine and its place in a wider debate: pros and cons}

This art masterpiece is exceptional as it conjugates the representation and the ivory of the mammoth - which isn't the case of the bored stick (fig. 2) or the "wanton Venus" from Laugerie-Basse and the mammoth-shaped spear thrower or the reindeer couple from Bruniquel (fig. 3 and fig. 4) But all these objects also prove definitely the authenticity of prehistoric art and its antiquity, equivalent to the one of the disappeared fossil species. The most inveterate detractors of antiquity of man and its coexistence with fossil animals are part of the Science Academy: they will systematically invoke falsification and fields alterations.

\section{The mammoth of La Madeleine : history, context and circumstances of the discovery}

The discovery of the ivory from La Madeleine takes place in May, 1864, about a year after the first researches made in Perigord by Lartet and Christy. It is realized in presence of $\mathrm{E}$. Lartet and the palaeontologists $\mathrm{E}$. de Verneuil and $\mathrm{H}$. Falconer. A first tracing of the object is published in 1865 (fig. 5).

\section{The archaeological context of the discovery}

Unfortunately we don't have any indication on the archaeological context and the topographic and stratigraphic localization of the object. Lartet and Christy have tested the central part of the slhelter, where it is the most existent (fig. 6). For J.-M. Bouvier, the object must come from the Upper Magdalenian horizon.

\section{Its place in the 1867 Universal Exhibition}

The ivory is presented in the Champ de Mars Palace in Paris during the 1867 Universal Exhibition. It is disposed in the middle of a showcase gathering more than 50 Palaeolithic art objects.

\section{The mammoth from La Madeleine and its first descriptions}

Since the first publication, a lot of descriptions of this mammoth have been published. The mane strikes first all the critics. The authors also mentions details such as the raised tail, the large and powerful trump, the great curved defences and even the anal valve, an inconspicuous but very characteristic detail. The attitude and dynamism of the animal have also raised a lot of commentaries.

\section{The frozen examples from Siberia}

The hairs from the mammoth of La Madeleine makes us think of the frozen animals coming from the ices of Siberia. But in the XIXth century, there isn't any example with skin, muscles or grease. In 1864, the only mammoth that can be used as a comparison comes from Adams and have been discovered in 1799 near the mouth of the Lena river (fig. 7).

\section{Falsifications}

The mammoth of La Madeleine have attracted a lot of forgers. We know several objects discovered in the XIXth century in USA, such as the Holly Oak shell (Delaware) (fig. 8), whose drawing was inspired by a reproduction of La Madeleine published by C. Rau (fig. 9), the Lenape Stone (fig. 10) and elephant-shaped limestone pipes (fig. 11 and fig. 12). The engraved mammoth on a fossil bone from Old Vero Site in Florida (fig. 13) has been recently discovered and is currently analysed. In Europe, La Madeleine ivory has also been more or less copied (fig. 14 and fig. 16).

\section{The mammoth from La Madeleine today - a brief anatomic presentation of a disappeared specie}

The mammoth's morphology is remarkable. The animal is round and characteristic because of its massive appearance. The back is designed by a prominent hump. The loins are in a great declivity towards the back quarters. Between the upper parts of the skull and of the back, the nape depression marks a angle, sometimes very deep. This anatomical segment make the mammoth very recognizable in its environment and also in the most schematic graphic expression. The eye, when presented 
as a circle or oval, is frequently expressive. Next to the orbit, the front part is prominent. On the other side, the tail is small. The trump is vertically straight towards the ground and its extremity forms two lips. These appendix are very exceptionally represented. Finally, even though the difficulty of the representation of the defences seen sideways, their remarkable dimensions and curve are frequently exaggerated.

The mammoth is very hairy. A woolly fur is covering the body and completed with straight long hairs on the chicks, the down lip, the members, the belly, the back, the chest and the shoulders.

\section{The support}

Beside several alterations traces, the external part of the defence is smooth and compact and well conserved. The ivory was already fossil when engraved: the plate (fig. 18) can't be detached from fresh ivory. The piece is slightly curved. The defence from La Madeleine clearly presents this morphology and some ivory plates of more or less equivalent thickness can be seen (fig. 19).

\section{The mammoth and its tracings}

This masterpiece have been frequently published and copied. In general, the drawings aren't faithful to the figure. They are copies more or less interpreted (fig. 20 and fig. 21). The published page in 1865 will be copied dozens of times (Fig. 22). It is even sometimes reproduced the wrong way (fig. 23 and fig. 24). In the XIXth century, the only valuable tracing is due to A. de Mortillet (fig. 25). It is reproduced in more recent books (fig. 26 to fig. 30). Our article is the occasion of a new analysis and a new graphic recording of the figure and its support.

\section{Description and analysis - conservation place}

This masterpiece is kept in the department "Histoire de la Terre" (Palaeontology gallery) of the Muséum national d'Histoire naturelle, Paris, France.

\section{Conservation state}

The engraved surface, corresponding to the first ivory layer under the cement, is slightly fissured with lots of superficial alterations traces (some chipping may be recent) (fig. 31 and fig. 32).

\section{Description}

The ivory is $24.8 \mathrm{~cm}$ long, $10.6 \mathrm{~cm}$ wide and $1.8 \mathrm{~cm}$ of maximal thickness (fig. 33). The mammoth is engraved in a massive yet dynamic attitude (fig. 34 and fig. 35). The head as well as the front part of the body are very precise (fig. 36). The head is massive, high and short. The eye is finely incised, without pupil. The trump is long and thick. The mouth is closed but the pointed bottom lip can be seen next to the base of the trump. The fur is given by long parallel or crossed incisions. Some very long hairs can be remarked on the chin and the chest. The defences are long with an important curve. The animal's massive body is projected towards the front and seems elongated. The treatment of the body and the legs isn't as well as the front part. The back forms a good arch. It is inclined towards the back part and present a light angle next to the loins. The back part continues with a thick tail, rather long and raised up (fig. 37). The anal valve is represented. There is only one back leg. The members are joined by a straight belly line, parallel to the back line.

\section{Another mammoth in La Madeleine?}

Another mammoth have been mentioned in La Madeleine. The engraving on a bone spatula shows only the back part of the animal. It was discovered by L. Capitan and D. Peyrony (fig. 38). The object comes from the middle Madgalenian layers. It measures $51 \mathrm{~mm}$ long, $19 \mathrm{~mm}$ wide and $3 \mathrm{~mm}$ of thickness. Beside the representation of a fur, the figure is blur and we consider it as unspecified.

\section{Conclusion}

The mammoth of La Madeleine is one of the most completed of the Palaeolithic corpus of representations. It is together static and dynamic and its drawings is very valuable. It constitutes the first known portrait of a mammoth and is one of the most faithful. This object is unique and its discovery have helped the science, proving definitively the contemporaneity of men and disappeared animal species. 


\section{Introduction}

Au XIX siècle, et aujourd'hui encore, le mammouth est le symbole de l'animal antédiluvien et plus généralement des espèces disparues. II a joué un rôle essentiel dans la découverte de l'homme fossile, la recherche de ses origines et l'affirmation de son ancienneté. L'existence du mammouth est d'abord affaire de paléontologue au début du $\mathrm{XIX}^{e}$ siècle. Nul ne songe alors à lui imaginer une quelconque contemporanéité avec les premiers hommes. Vers 1860 , les preuves de la coexistence de l'homme et du mammouth s'accumulent et en mai 1864, la démonstration finale en est établie avec la découverte exceptionnelle du mammouth gravé sur ivoire de La Madeleine. Cette œuvre, l'une des rares figurations mobilières de mammouth en Périgord (une quinzaine de figures recensées sur plus de 300 mammouths pariétaux dans cette région), occupe une place à part, centrale pour ne pas dire capitale, dans la Préhistoire du $\mathrm{XIX}^{\mathrm{e}}$ siècle mais plus globalement dans l'histoire de notre discipline. Le sujet, un mammouth aux nombreux détails anatomiques figurés et l'objet, une portion d'ivoire de mammouth, sont emblématiques. Sur cette gravure, c'est toute la Préhistoire moderne qui a conquis droit de cité (Bouvier 1977 - p. 57). Sa célébrité ne se mesure pas tant dans la force expressive de l'animal figuré ou dans son éventuelle dimension esthétique que dans le rôle singulier et fondamental qu'on lui a fait jouer depuis sa découverte sous les coups de pioches des ouvriers d'Édouard Lartet et Henry Christy. Le document est capital car il permet de démontrer que l'homme et le mammouth ont été contemporains. II donne de cet animal antédiluvien emblématique la première des images connues et il prouve également que son auteur, l'homme fossile, a été capable de produire une pensée et un art véritables. Mais, pour prendre toute la mesure du rôle joué par le mammouth de La Madeleine, il convient de se plonger un peu dans l'agitation des premiers débats sur l'antiquité de l'homme qui touchent en cette moitié de $\mathrm{XIX}{ }^{e}$ siècle le monde académique, scientifique et religieux.

\section{1 - Un grand débat au XIXe siècle : l'antiquité de l'homme et sa contemporanéité avec les espèces animales disparues}

La tradition chrétienne, vivace et bien ancrée dans la société du XIXe siècle, veut que l'homme, façonné à l'image de Dieu, soit apparu tardivement. La courte chronologie biblique en constitue le cadre historique rigide.

Pour inventer la Préhistoire, il faut donc reconnaître et prouver la haute antiquité de l'homme. Cela implique de s'opposer aux conceptions de Georges Cuvier pour qui l'espèce humaine est apparue après la dernière catastrophe qui a modifié la surface du globe et permis la plus récente création animale. Par conséquent, il n'est pas concevable d'en découvrir les vestiges dans les terrains géologiques. Cuvier est hostile à la notion d'homme fossile et une grande partie de l'establishment français lui est fidèle.

... Tout porte à croire que l'espèce humaine n'existait point dans les pays où se découvrent les os fossiles, à l'époque des révolutions qui ont enfoui ces os ... (Cuvier édit. 1985 p. 125)

Evidemment, le cadre étriqué des temps bibliques ne se prête pas à une telle (r)évolution conceptuelle. II faut le détruire. Ce sont les géologues et les paléontologistes qui vont s'y consacrer les premiers en trouvant des vestiges interrogeant la place de l'homme à des époques " géologiques » où il est encore insoupçonné. Les découvertes de vestiges humains, d'hommes fossiles selon l'expression de ces scientifiques soucieux de s'affranchir du dogme religieux ou créationniste, dans des terrains géologiques contenant les ossements d'espèces disparues comme le mammouth, le rhinocéros laineux ou l'ours des cavernes se multiplient dans les premières décennies du XIX siècle.

Les travaux pionniers conduits notamment par François Jouannet en Dordogne à partir de 1812 (Ecorneboeuf, Pech de l'Azé, Combe-Grenal, Badegoule), William Buckland au Pays de Galles (grotte de Paviland) en 1822, Paul Tournal dans l'Aude (grottes de Bize) en 1826, Philippe-Charles Schmerling en Belgique (grottes d'Engis) en 1830, Auguste Aymard dans le Velay (Volcan Denise) en 1844 ou Jean-Baptiste Noulet en Haute-Garonne (site de I'Infernet à Clermont-le Fort) en 1851-1853, révèlent progressivement la coexistence de l'homme, ou plutôt de certaines de ses productions (silex taillés), et des espèces disparues sans pour autant affirmer sa très haute antiquité. Ces découvertes plongent la plupart des auteurs dans une certaine perplexité.

En effet, l'homme fossile des géologues ou des paléontologistes n'est déjà plus l'homme antédiluvien des théologiens, mais il s'en rapproche encore par l'âge qui peut lui être attribué.

Finalement, avant 1859, date de naissance officielle de la Préhistoire, Jacques Boucher de Perthes est le seul auteur à proclamer la haute antiquité de l'homme sur l'échelle des temps géologiques. II l'affirme depuis que des outils taillés ont été découverts dès 1842 dans la couche à ossements de mastodontes (mammouth et rhinocéros) de la sablière de Menchecourt-lès-Abbeville dans la Somme (Richard 1992 ; Boucher de Perthes 1857) et le consigne dans les trois éditions des Antiquités celtiques et antédiluviennes. Mais, entre la première - 1847-1849 - et la seconde édition - 1857, il substitue la théorie du déluge au profit d'une théorie des glaciations. Voilà qui témoigne d'une certaine modernité de sa pensée.

Lors de fouilles réalisées à Brixham (Devonshire, Angleterre) en 1858, Hugh Falconer (géologue et paléontologiste écossais) et Joseph Prestwich (géologue anglais) découvrent des outils de pierre associés à des ossements d'espèces animales disparues. En 1859, ils viennent à Abbeville pour comparer ces découvertes avec celles que Boucher de Perthes y a faites. Leurs observations les persuadent de la contemporanéité de l'homme et des espèces animales disparues. De retour en Angleterre, ils convainquent le célèbre géologue anglais Charles Lyell qui admet alors explicitement la très haute antiquité de l'homme et sa contemporanéité avec les animaux disparus lors d'un discours devant la British 
Association for the Advancement of Science (Lyell 1860). L'homme fossile devient I'homme préhistorique ou quaternaire et la conversion de Lyell rallie une partie du monde savant. En France, le discours de Lyell n'est pas sans écho. Les géologues et paléontologistes Albert Gaudry et Édouard Lartet sont les premiers à reconnaître les travaux de Boucher de Perthes. À l'Académie des Sciences, ils prennent la défense de l'homme quaternaire contre les opinions du Secrétaire perpétuel de l'institution, le géologue Elie de Beaumont. $\mathrm{Ce}$ dernier, imperturbablement attaché à la pensée de Cuvier, fait effectivement valoir des arguments troublants comme l'absence d'ossements humains assurément associés aux nombreux vestiges de leurs industries supposées (silex taillés). Cette absence conforte ses partisans, opposés ou réticents à la notion d'homme fossile. Nombre de disciples de Cuvier ont abandonné la prudence naturelle de ce dernier dans ses conclusions sur l'homme. ... Mais je n'en veux pas conclure que l'homme n'existait point du tout avant cette époque. II pouvait habiter quelques contrées peu étendues, d'où il a repeuplé la terre après ces événemens terribles ... (Cuvier édit. 1985 - p. 126). Ils refusent l'idée de l'antiquité de l'homme alors que les découvertes se multiplient et que la valeur des travaux de Boucher de Perthes est reconnue. L'attitude d'Elie de Beaumont et la vive résistance qu'il organise au sein de l'Académie des Sciences sont caricaturales. Jusqu'à sa mort en 1874, il refuse de se rallier aux idées nouvelles et son dogmatisme va peser de tout son poids contre cette reconnaissance. Les idées qui dérangent sont même parfois censurées. Ainsi, la première communication de Lartet à l'Académie des Sciences (1860) est soumise à veto et n'est pas publiée dans les Comptes Rendus de séances. Ces idées nouvelles ne parviennent pas à ébranler les foyers de résistance scientifique. L'homme fossile reste aux yeux des réfractaires un fait douteux car il est découvert dans des sites (grottes ou plein-air) dont la stratigraphie est incertaine et mal assurée. Le remaniement des terrains constitue un argument invariablement avancé pour nier l'authenticité de l'homme fossile. À peine accepte-t-on qu'il puisse avoir été contemporain ou très proche dans le temps des grands mammifères éteints, mais on n'en tire aucune conclusion quant à son ancienneté géologique. Pourtant, Édouard Lartet a déjà présenté à l'Académie (séance du 19 mars 1860) une note sur l'ancienneté géologique de l'espèce humaine dans l'Europe occidentale. Mais elle n'est pas publiée, comme signalé plus haut, par la volonté d'Elie de Beaumont. Dans une addition en séance du 23 avril 1860, Lartet évoque les traces laissées par l'homme fossile sur certains ossements d'animaux disparus à Massat (Ariège) et à Aurignac (Haute-Garonne) et démontre de la manière la plus convaincante l'association de faunes anciennes et d'instruments anthropiques en os, bois de renne et silex. Ce texte constitue une synthèse d'un article plus important publié en 1861 dans les Annales des Sciences Naturelles (Lartet 1861b). II met alors en place l'argumentation qu'il développera trois ans plus tard avec les découvertes d'art mobilier faites en Périgord, puis avec le mammouth de La Madeleine.

Le premier épisode qui convainc une majorité de chercheurs est la découverte, en mars 1863, d'une mâchoire humaine dans le diluvium inférieur de la carrière de Moulin-Quignon, près d'Abbeville. Finalement, la conversion de la communauté scientifique française à la Préhistoire semble s'effectuer sur une trouvaille qui s'avère plus tard n'être qu'une mâchoire humaine récente frauduleusement introduite dans des couches connues pour anciennes par un ouvrier payé pour découvrir des fossiles. Pourtant, après une enquête diligentée par les scientifiques anglais et français sur l'authenticité de la mâchoire, le zoologiste français Henri Milne Edwards conclu qu' ... enfin il paraît résulter aussi des recherches de M. Boucher de Perthes, ainsi que des observations de plusieurs autres paléontologistes, parmi lesquels je citerai en première ligne Schmerling, Tournal, $M$. Lartet et $M$. de Vibraye, que les anciens habitants de ce qui est aujourd'hui la France étaient contemporains du mammouth ou Elephas primigenius, $d u$ Rhinoceros tichorhinus, et de quelques autres animaux remarquables dont les espèces sont éteintes (Milne Edwards 1863 - p. 933).

Comme le relate la revue philosophique, scientifique et littéraire la Voie Nouvelle en 1866... La question de l'ancienneté de l'homme tend de plus en plus vers une solution bien différente des premières hypothèses...(p. 50-51) (Anonyme 1866).

La trouvaille de Moulin-Quignon n'est pas isolée. En 1864, le Marquis Paul de Vibraye apporte de nouvelles preuves de l'existence de l'homme dans le centre de la France à une époque où s'y trouvaient aussi divers animaux qui de nos jours n'habitent pas cette contrée (Comptes Rendus des Séances de l'Académie des Sciences, séance du 24 février 1864). II signale que ... sur quelques points de ces stations humaines [...] on retrouve les dépouilles d'animaux appartenant aux races éteintes ... L'an dernier j'ai cru devoir explorer plus scrupuleusement encore la grotte des Fées (Arcy-sur-Cure). Le point capital était d'établir incontestablement la coexistence de l'homme, des races éteintes et des espèces ayant opéré leur migration vers le Nord. Mes dernières fouilles m'ont apporté la confirmation du premier de ces deux faits ... Voici le cinquième exemple en six années d'ossements humains retirés de cette couche inférieure (Arcy) et recueillis sur des points éloignés, mais toujours en relation directe avec les races éteintes et dans les mêmes conditions d'enfouissement, sans aucune trace d'un remaniement postérieur ... (1864 - p. 413)

\section{1 - La naissance de la Préhistoire}

L'invention de la Préhistoire coïncide avec la reconnaissance de l'évolution biologique des êtres vivants dont la théorie a pris forme d'abord dans la Philosophie zoologique de Jean-Baptiste Lamarck (1809) puis, le 24 novembre 1859, dans L'Origine des espèces par le moyen de la sélection naturelle, ou la préservation des races favorisées dans la lutte pour la vie de Charles Darwin (Darwin 1859 ; Groenen 1994 ; Coye 1997). La Préhistoire de la seconde moitié du XIX siècle devient alors un véritable laboratoire de transformisme ou d'évolutionnisme appliqué. Les inventeurs de la Préhistoire se font les chantres du progrès dont la marche est supposée inexorable et à laquelle leur science contribue. La Préhistoire doit témoigner du progrès de l'homme et de son esprit. Elle doit aussi montrer que l'humanité a évolué et qu'elle a une histoire. Pour cela, il lui faut en élaborer le 
cadre chronologique. Les paléontologues et les préhistoriens s'y attachent, notamment Édouard Lartet, auteur d'une première chronologie "paléontologique ", mais, qui voit dès 1864 , tout l'intérêt de mieux décrire les armes et outils en pierre pour établir une distinction chronologique entre les diverses stations de l'âge de la pierre dans le Périgord (Lartet et Christy 1864 - p. 8). Gabriel de Mortillet également, le plus radical et le plus positiviste d'entre eux, défend l'idée d'une ascension non spirituelle de l'homme préhistorique et élabore plusieurs chronologies archéologiques successives (Bon 2009).

\section{2 - Hommes et artistes Le rôle des objets d'art}

On vient de voir le rôle joué par l'association des restes humains, même s'ils ne sont pas toujours authentiques, des silex taillés et des animaux disparus dans la reconnaissance de l'antiquité de l'homme et de sa contemporanéité avec les espèces fossiles. Mais, qu'en est-il des œuvres d'art dont les premiers témoignages remarquables (art mobilier) sont découverts en cette moitié de XIX ${ }^{\circledR}$ siècle ? Quelle place occupent-elles dans le débat sur l'ancienneté de l'homme et sur sa coexistence avec les animaux éteints ? Les objets d'art gravés ou sculptés en os, ivoire ou bois de renne exhumés en grand nombre, notamment par Édouard Lartet et Henry Christy dans la région des Eyzies en 1863-1864, contribuent à démontrer l'antiquité préhistorique de l'art et les capacités esthétiques de son auteur, l'homme fossile. Pour autant, ces objets, de mieux en mieux contextualisés archéologiquement, vont-ils réellement peser dans le débat qui agite alors le monde savant ? Les fameuses " pierres-figures » découvertes dans la Somme par Jacques Boucher de Perthes sont censées incarner la sensibilité immanente du premier homme insufflée lors de sa création (Bon 2009). Ce ne sont en fait que des lusi naturae qui ont un effet désastreux dans les esprits et perdent toute pertinence scientifique, dès 1860 (Cohen et Hublin 1989). Les interprétations proposées par Boucher de Perthes (animaux ou visages humains naturels ou vaguement retouchés) ne convainquent pas les milieux officiels et contribuent même à alimenter l'atmosphère de suspicion qui entoure les premières découvertes de vrais objets d'art, aidés en cela par la publication de faux grossiers supposés découverts dans la grotte du Chaffaud (Brouillet et Meillet 1864-1865). Les travaux discrets et les quelques publications confidentielles du Marquis de Vibraye ne suscitent pas davantage de vraies réactions. Ce dernier note pourtant au début de l'année 1864 que ... l'homme s'associe par sa dépouille aux races éteintes; l'homme enfin se fait révélateur de sa propre existence en reproduisant lui-même son image (p. 416). II doit alors penser à la « vénus » dite « impudique » qu'il découvre en 1863 au début de ses recherches à Laugerie-Basse (fig. 1).

Édouard Lartet et Henry Christy publient également en 1864 dans la Revue Archéologique leurs premières découvertes d'objets gravés et sculptés des temps préhistoriques en Périgord. II s'agit d'une publication majeure, une sorte de manifeste de la préhistoire de l'art mobilier. Les auteurs soulignent qu' ... une race humaine [...] a vécu dans cette région qui fut plus tard le Périgord, en même temps que le renne, l'aurochs, le bouquetin, le chamois, etc. ... Leurs objets de parure, leurs ustensiles ornés de façon si diverse et quelquefois avec une régularité symétrique, témoignent de, leurs instincts de luxe et d'un certain degré de culture des arts. Leurs dessins et leurs sculptures nous en fournissent une manifestation plus élevée, par la manière dont ils ont réussi à reproduire la figure des animaux leurs contemporains ... Personne, nous le supposons, ne songera à contester la valeur de ces déductions; elles ressortent d'évidences matérielles ... (1864 - p. 262-263). ... La chasse et la pêche fournissaient amplement aux besoins de ces aborigènes, et leur laissaient ainsi les loisirs d'une existence peu tourmentée. Or, si la nécessité est mère de l'industrie, on peut dire aussi que les loisirs d'une vie facile enfantent les arts (1864 - p. 264).

Le texte est capital mais il ne fournit pas encore les arguments les plus imparables contre les détracteurs académiques. Le tournant décisif, scientifique, conceptuel,

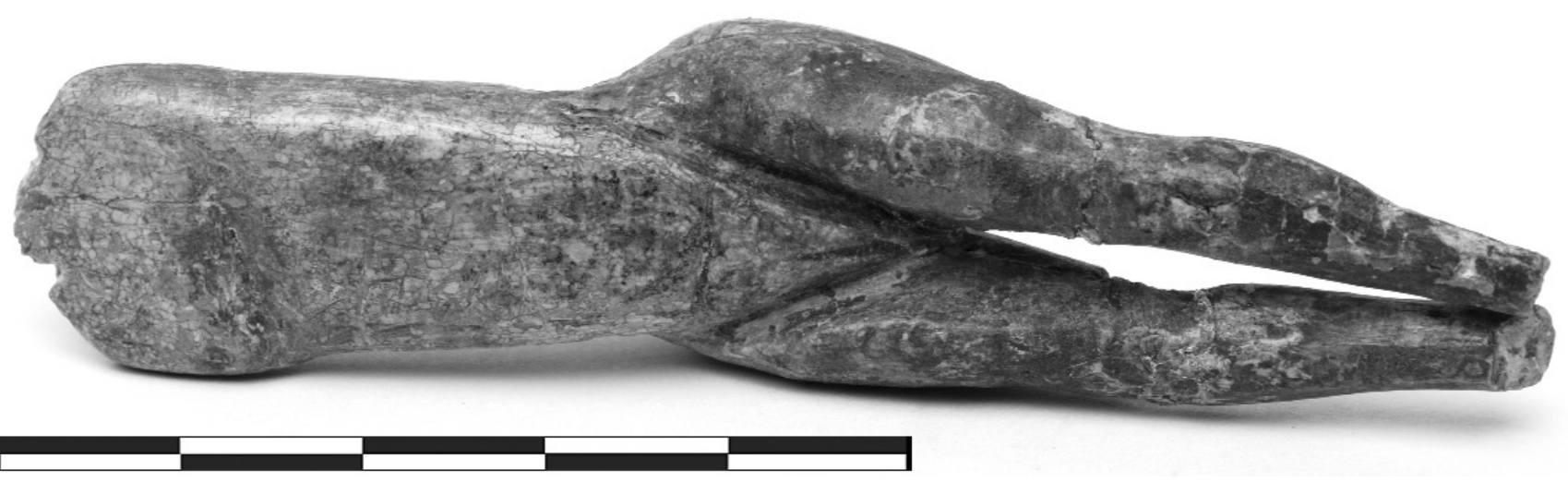

Figure 1 - Figuration féminine sculptée en ivoire ou Vénus dite «impudique ", Laugerie-Basse (Dordogne). (c) Cliché " Département de Préhistoire », Musée de l'Homme, Muséum national d'histoire naturelle.

Figure 1 - Feminine representation carved out in ivory, said " wanton Venus », Laugerie-Basse (Dordogne). () Image " Département de Préhistoire ", Musée de l'Homme, Muséum national d'histoire naturelle. 
culturel même, est réellement pris en mai 1864 lors de la découverte à La Madeleine de fragments d'ivoire de mammouth gravés d'une figure représentant cet animal. Publiée en 1865, cette découverte d'art mobilier constitue le deuxième épisode qui décide une majorité de chercheurs en Europe et dans le monde après la "vraiefausse " mâchoire de Moulin-Quignon. Finalement, il est cocasse qu'un objet d'art, somme toute assez ordinaire par sa facture, succède à un fossile extraordinaire, puisqu'il n'est pas fossile. Dès lors, on voit se multiplier dans les ouvrages et la presse grand public, parfois même sous la plume des scientifiques, des pages dithyrambiques et fleuries sur les artistes sauvages:

... Mais l'homme qui menait dans ces cavernes la vie de troglodyte ne maniait pas seulement la taille avec habileté, il réussissait, avec ses outils de pierre, à ciseler et à fouiller l'ivoire et le bois de renne, ainsi que l'établissent les curieux spécimens rapportés du Périgord [...] il avait déjà l'instinct du dessin, et il figurait [...] l'image des animaux dont il était entouré ...

... Jamais on n'eût pu attendre, dans ces œuvres de purs sauvages, une telle hardiesse et une telle sûreté de dessin, une si fière tournure, une imitation si vraie de la nature vivante, une telle propriété dans la reproduction des attitudes spéciales à chaque espèce animale; on n'eût jamais osé prévoir que le sol des cavernes où vivaient les hommes contemporains du renne et du mammouth rendrait des sculptures et des dessins à la pointe, dans lesquels il y a de la grandeur et du style ... alors qu'il n'était point encore sorti de l'état le plus sauvage, déjà l'homme se montrait artiste et avait l'instinct du beau ...(Anonyme Gazette des Beaux-Arts 1867a - p. 499-500).

Les premières œuvres d'art authentiques sont ... un indice de progrès qu'on s'attend peu sans doute à trouver dans ces époques sauvages, c'est que déjà il se rencontrait des artistes cultivant le dessin et la sculpture ... (Bourlot 1868 p. 25-26).

Pour Gabriel de Mortillet ... dans leurs gravures et sculptures primitives, on remarque un sentiment si vrai des formes et des mouvements, qu'il est presque toujours possible de déterminer l'animal représenté et de rendre compte de l'intention de l'artiste ? II y a beaucoup de naïveté, c'est l'enfance de l'art, mais c'est incontestablement de l'art, de l'art bien réel ...(1868 p. 474). Il y a loin, bien loin de là aux ébauches informes que font nos enfants, et surtout aux ridicules caricatures produites par certains faussaires... (Mortillet 1867b p. 701).

La construction changeante de l'image de l'homme primitif est marquée par les interrogations au sujet de l'existence et de la signification de l'art préhistorique. Dès lors, on se demande si cet homme est capable d'un sentiment du beau, s'il produit des images simplement pour imiter le réel ou si son art est la manifestation d'une pensée religieuse.

\section{3 - Le mammouth de La Madeleine et sa place dans le grand débat}

\section{1 - Les partisans}

Jusqu'au mois de mai 1864, de nombreuses preuves de l'existence de l'homme en des temps anciens et dans des contrées habitées par le renne et d'autres animaux qui n'y vivent pas de nos jours sont déjà acquises. Elles suffisent même à conforter l'intime conviction de la plupart des scientifiques éclairés. En 1864, Henri Milne Edwards rappelle que ... s'il fallait ajouter de nouvelles évidences à celles déjà fournies pour la preuve de la contemporanéité de l'homme et du Renne dans ces régions devenues notre France centrale et méridionale, nous pourrions mentionner des bois assez nombreux de cet animal à la base desquels on distingue des entailles faites en en détachant la peau ... Nous n'avons pas trouvé ses ossements dans les dolmens et autres sépultures dites celtiques, où se trouvent fréquemment associés des restes d'animaux sauvages et domestiques ... il n'en est pas moins probable que cette disparition (Renne) remonte à une phase des temps préhistoriques antérieure à l'introduction des races domestiques et à l'emploi des métaux dans notre Europe occidentale (1864 - p. 401-408). La même année, Édouard Lartet et Henry Christy ajoutent à propos des restes de renne qu'... on ne les a pas non plus observés dans les tourbières de France, ni sous les pilotis des lacs de la Suisse; et nulle part, que nous sachions, dans l'Europe centrale, les restes de cet animal n'ont été rencontrés en association avec des produits métalliques de l'industrie humaine (1864 - p. 33-34). Voilà un argument qui devrait ébranler les sceptiques. Ces mêmes auteurs poussent alors le raisonnement plus loin encore et osent des rapprochements presque inédits jusqu'alors.

... Sans même tenir compte des recherches personnelles que nous avons pu faire dans cette voie, il existe aujourd'hui, soit en France, soit en Angleterre, un nombre très considérable d'observations toutes concordantes, toutes vérifiées et contrôlées par des hommes éminents et des plus compétents ; ajoutons, pour nous servir des expressions de notre ami, M. Boucher de Perthes, par des hommes de science et de conscience. En sorte que cette vérité tant contestée de la coexistence de l'homme avec les grandes espèces éteintes (Elephas primigenius, Rhinoceros tichorhinus, Hyaena spelaea, Ursus spelaeus), etc., nous paraît désormais inattaquable, et définitivement acquise à la science (1864 - p. 34-35). Lartet et Christy suggèrent même l'existence d'un homme très ancien contemporain d'espèces archaïques comme l'éléphant antique, le rhinocéros de prairie ( $D$. hemitœchus), mais également l'éléphant méridional et le rhinocéros étrusque. Les stries, les incisions ou les entailles présentes sur certains ossements découverts par Jules Desnoyers en 1863 à Saint-Prest (Eure-et-Loir) (Desnoyers 1863) et dans la vallée de l'Arno (Toscane, Italie) sont attribuées à l'action de l'homme. On sait aujourd'hui que ce n'est pas le cas. Mais les auteurs reconnaissent honnêtement qu'aucun silex taillé, objet d'art ou d'industrie humaine, aucun indice de l'existence de l'homme n'a été retrouvé associé à ces vestiges fauniques (1864 - p. 35-36). 
La découverte de l'ivoire de La Madeleine constitue selon Édouard Lartet un ... fait [qui] n'ajoutera rien aux convictions déjà acquises sur la coexistence de l'homme avec l'Éléphant fossile (El. primigenius) et les autres grands Herbivores ou Carnassiers que les géologues considèrent comme ayant vécu dans les premières phases de la période quaternaire. Cette vérité d'évidence rétrospective se déduit aujourd'hui d'un si grand nombre d'observations concordantes et de faits matériels d'une signification tellement manifeste, que les esprits les moins préparés à l'admettre ne tardent pas à l'accepter dans toute sa réalité, dès qu'ils veulent bien prendre la peine de voir, et, après cela, de juger en conscience ... (Lettre de M. Lartet, relative à une lame d'ivoire fossile trouvée dans un gisement ossifère du Périgord, et portant des incisions qui paraissent constituer la reproduction d'un Éléphant à longue crinière, $1865 a$ - p. 310). De cette première publication, il ressort clairement que, même si la conviction de Lartet est déjà acquise depuis quelques années, plus rien ni personne ne peut s'opposer désormais à cette évidence parfaitement démontrée : l'homme fossile a vécu dans des temps reculés et côtoyé des animaux aujourd'hui disparus. Le dernier des détracteurs, le plus obstiné des opposants sera ... réduit à se taire et à laisser parler devant lui l'homme fossile sans élever la moindre protestation ...
(Quatrefages 1896 - p. 108). L'homme paléolithique a côtoyé le mammouth et la découverte de La Madeleine en apporte la preuve définitive. ... Le raisonnement est imparable dans sa simplicité : le mammouth est un animal assurément disparu depuis longtemps. Ceci est prouvé et admis. Seul, un homme qui avait vu un mammouth vivant a pu [...] faire cette gravure. Donc l'homme est antérieur à la disparition du mammouth ... (Bouvier 1977 - p. 56). Cette trouvaille condense même toutes les preuves. ... Par quelques traits de gravures et à cent cinquante siècles de distance, un Magdalénien anonyme révolutionne les idées et rend caducs les dogmes les mieux admis ... (Bouvier 1977 - p. 56).

Elle conjugue simultanément le sujet et le support, la représentation et l'ivoire de mammouth. L'animal est reproduit sur sa propre dépouille. II n'en faut pas plus pour convertir durablement le monde scientifique et le public. En effet, une simple représentation de mammouth inscrite sur un autre type de support, comme la tête décorant un bâton percé en bois de renne de Laugerie-Basse (de Vibraye $1865 \mathrm{a}$ et 1865b) (fig. 2) ou le mammouth-propulseur également sur bois de renne découvert par M. Peccadeau de I'Isle et Victor Brun en 1866 à Bruniquel (fig. 3), n'y auraient pas totalement suffit. La présence d'ivoire ou de

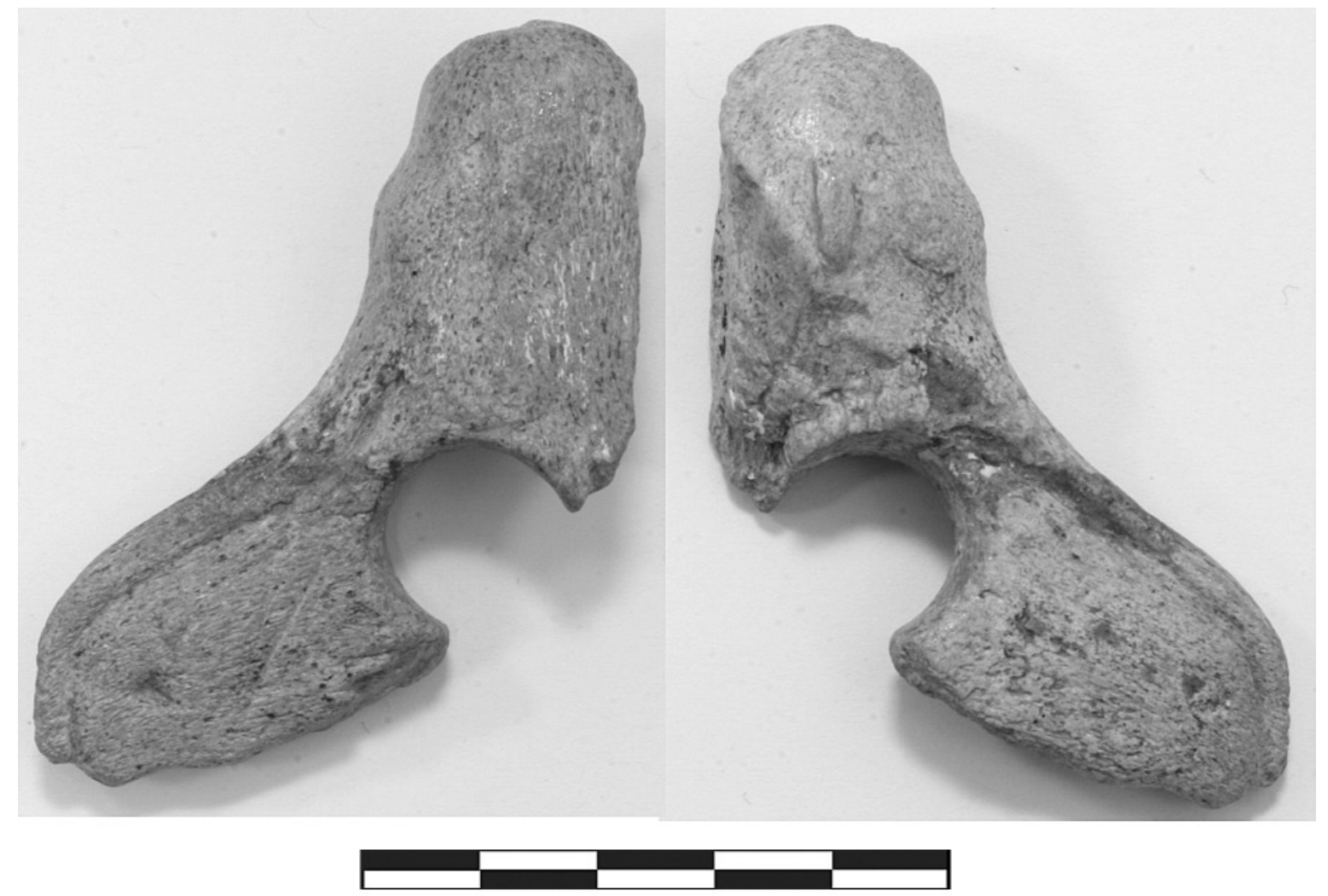

Figure 2 - Tête de mammouth gravée sur bâton percé en bois de renne, Laugerie-Basse (Dordogne). @ Cliché Patrick Paillet (2009) avec l'autorisation du «Département de Préhistoire », Musée de l'Homme, Muséum national d'histoire naturelle.

Figure 2 - Mammoth head, engraved on a bored stick in reindeer antler, Laugerie-Basse (Dordogne). () Image Patrick Paillet (2009) with authorization of the "Département de Préhistoire ", Musée de l'Homme, Muséum national d'histoire naturelle 


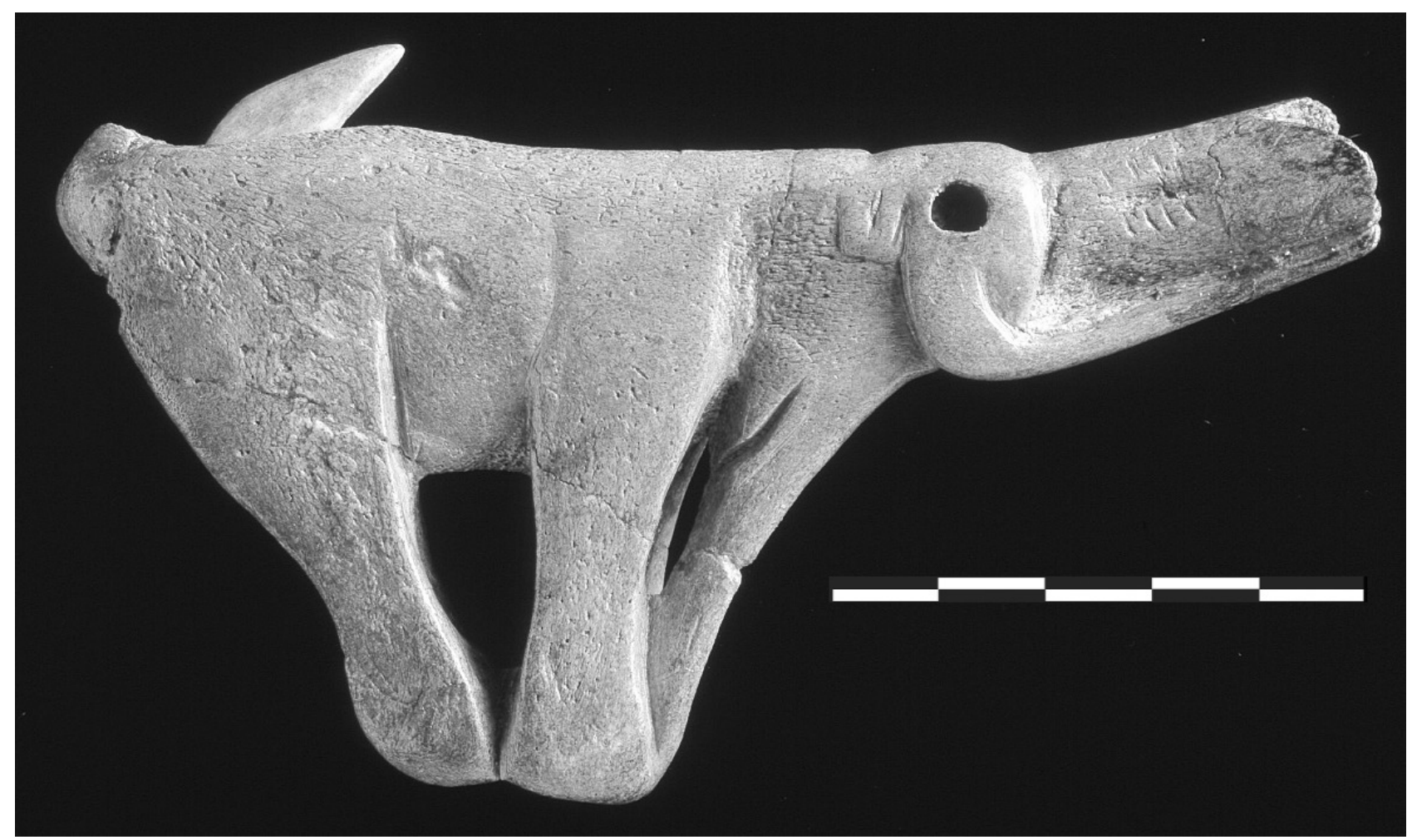

Figure 3 - Mammouth sculpté sur extrémité de propulseur en bois de renne, Bruniquel (Tarn-et-Garonne). (c) Cliché British Museum.

Figure 3 - Mammoth carved out on the extremity of a spear thrower in reindeer antler, Bruniquel (Tarn-et-Garonne). @ Image British Museum.

restes osseux de mammouths associés aux vestiges des industries de l'homme constituent une preuve insuffisante aux yeux des détracteurs, tout comme l'emploi de l'ivoire comme support d'autres représentations, humaines (" vénus impudique » - Laugerie-Basse) ou animales (couple de rennes sculptés - abri Montastruc à Bruniquel) (fig. 4).

Paul de Vibraye rejoint les conclusions d'Édouard Lartet et considère que ses propres découvertes à Arcy-sur-Cure, dès 1860 , et à Laugerie-Basse, entre 1863 et 1865 ... sont de nature à lever définitivement tous les doutes relatifs à la contemporanéité de l'homme et du Mammouth ... (1865a - p. 404). En guise d'hommage au personnage discret qu'était le marquis de Vibraye et à son œuvre scientifique, Émile Cartailhac rappelle qu' ... il fut très utile à la cause de la vérité de voir un savant respecté comme le marquis de Vibraye, appartenant au parti le plus conservateur, apporter son adhésion à l' " homme fossile ». En ce temps-là c'était un acte de courage ... (1907 - p. 1). De Vibraye s'est opposé aux plus ardents détracteurs et notamment au Docteur Eugène Robert. II estime qu'il eût été facile de répondre à la communication de Robert (1863a et 1863b) ... puisqu'en 1860, après quatre ans de fouilles où [il avait] constamment rencontré l'Éléphant, [il recueillait] pour la première fois, dans les grottes d'Arcy-sur-Cure, une sorte de marque de chasse en ivoire, d'un travail assez achevé ... Deux années se passèrent, et les recherches entreprises en 1863, 1864 et 1865, dans les stations du Périgord, [lui] procurèrent d'assez nombreux débris de défense, dont quatorze présentaient les indices incontestables d'un travail humain. L'année 1863 [lui] avait notamment fourni cette statuette de femme à laquelle on n'a consacré qu'une trop fugitive attention ... (de Vibraye 1865a - p. 399-400).

Cette communication, intitulée Sur la reproduction en bois de Renne d'une tête (présumée) de Mammouth et sur quelques morceaux d'ivoire travaillé provenant plus particulièrement des stations du Périgord, est publiée deux semaines seulement après la lecture de la lettre de Lartet en séances de l'Académie des Sciences. Émile Cartailhac attire l'attention sur le mot présumée mis entre parenthèses et indique qu' ... il est formellement contredit par le texte imprimé à la suite. II n'est pas de l'auteur ; il fut imposé par le secrétariat de l'Académie (1907 - p. 2). On le voit, quand l'Académie n'est pas convaincue, elle censure (Lartet) ou manipule (de Vibraye). Et pourtant, la nouvelle découverte de Paul de Vibraye (plus précisément de son ouvrier M. Franchet) ne souffre d'aucune contestation et corrobore d'une certaine manière celle de Lartet. Un an tout juste après l'ivoire de la Madeleine, il découvre à Laugerie-Basse une extrémité de bâton percé ornée d'une tête de mammouth. ... Un heureux hasard me fit découvrir au mois de mai de cette année, dans un des foyers de l'Augerie basse, la représentation d'un animal qui me sembla ne pouvoir être qu'un Éléphant. Des appréciateurs compétents et non prévenus en ont jugé de même. C'était donc, une fois le fait acquis, une démonstration suffisante 


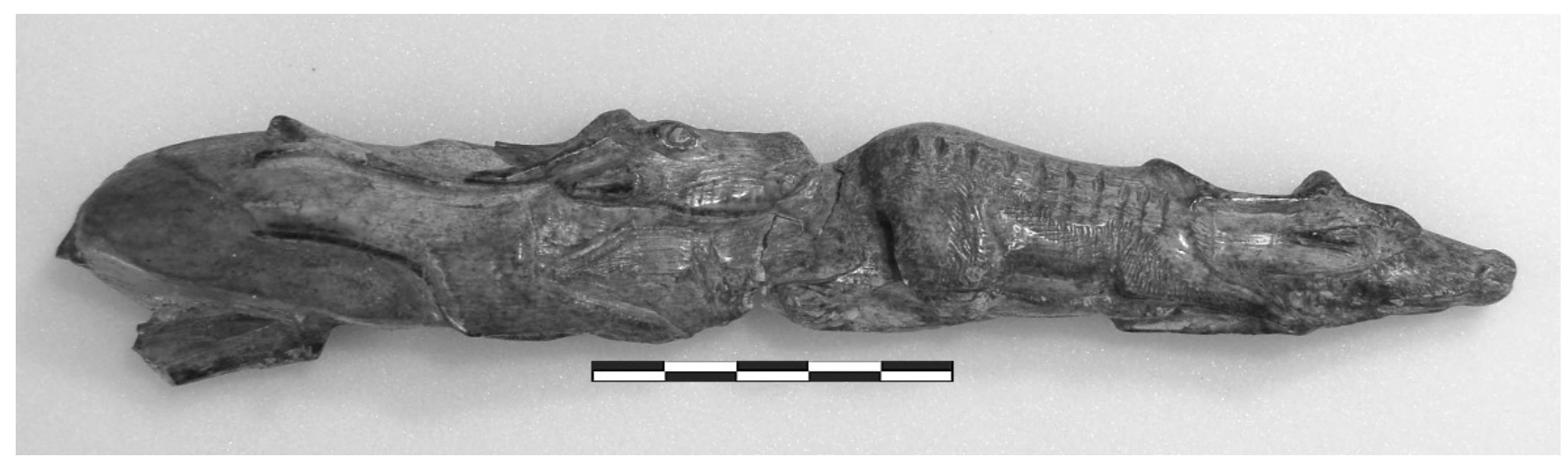

Figure 4 - Rennes sculptés sur baguette d'ivoire, Bruniquel (Tarn-et-Garonne). @ Cliché British Museum.

Figure 4 - Reideers carved on ivory baguette, Bruniquel (Tarn-et-Garonne). (@ Image British Museum.

de la contemporanéité de l'homme et du grand Proboscidien ... (1865a - p. 400). Cette petite pièce de Laugerie-Basse, le magnifique propulseur de Bruniquel, découvert en 1866, et la désormais célèbre plaque d'ivoire de la Madeleine scellent définitivement l'authenticité de l'art préhistorique et prouvent son antiquité, égale à celle des espèces animales disparues.

En 1867, lors de la deuxième Exposition Universelle tenue à Paris, ces trois pièces historiques figurent en place d'honneur, au centre de la grande salle dédiée à L'Histoire du travail, dans une belle vitrine plate et parmi 48 autres curiosités de l'art des cavernes présentées à l'admiration du grand public. II s'agit d'une consécration pour ces objets qui constituent ... la plus belle réponse à la pensée de Cuvier et de son défenseur, Elie de Beaumont. (Bon 2009 - p. 48).

\section{2 - Les détracteurs}

C'est à l'Académie des Sciences, foyer de résistance à l'homme préhistorique, que sévissent les détracteurs les plus acharnés de l'antiquité de l'homme et de sa coexistence avec les animaux fossiles. Les démonstrations de Boucher de Perthes ne suscitent d'abord de la part de la science officielle que dénégations, railleries et dédain. Elie de Beaumont, qui conduit les réfractaires, n'admet pas que l'homme ait pu être contemporain du mammouth et se demande même si les silex taillés ne sont pas d'origine romaine. II refuse en premier lieu les conclusions de Boucher de Perthes et s'attaque ensuite aux hypothèses de Lartet. Je ne crois pas que l'espèce humaine ait été contemporaine de l'Elephas primigenius. Je continue à partager à cet égard l'opinion de M. Cuvier. L'opinion de Cuvier est une création du génie ; elle n'est pas détruite ... (de Beaumont 1863 - p. 935).

Les dénégations ou les suspicions puisent leur origine dans deux types d'arguments majeurs : le remaniement des terrains et la falsification. Le premier de ces arguments, comme nous l'avons signalé plus haut, est systématiquement convoqué. L'association stratigraphique entre la faune et les produits de l'industrie de l'homme est contestée à cause de la nature détritique supposée du diluvium dont les éléments ont pu être récoltés à des niveaux différents ou dans des couches d'âges divers. Eugène Robert, un des plus tenaces opposants, se refuse en 1863 (1863a, $1863 \mathrm{~b}$ et 1863c) à se rallier au témoignage de la mâchoire humaine découverte à Moulin-Quignon, qui constitue alors une réponse à l'absence des fossiles humains dans le diluvium. ... Quant aux ossements humains qui paraissent devoir accompagner les silex taillés à Abbeville ... je fais remarquer qu'il n'est pas rare d'en rencontrer à SaintAcheul dans le fond des sablières, et qui proviennent évidemment des couches supérieures dans lesquelles on peut voir encore des sépultures gallo-romaines ... (Robert 1863b - p. 1122).

Par ailleurs, Eugène Robert soutient que ... l'absence complète d'objets en ivoire travaillé et même d'ivoire non travaillé dans les gisements celtiques [témoigne] que les habitants primitifs des Gaules n'ont jamais été contemporains des grandes espèces perdues de Pachydermes ... (1863a, p. 955). Mais, dans cette même note publiée (in extenso et sans aucune censure) dans les Comptes Rendus des Séances de l'Académie des Sciences, Robert écrit aussi que ... lorsque les Celtes se rendaient sur les bords de la Somme ou de toute autre rivière pour se tailler des haches avec les pierres que les eaux charriaient, ils durent parfois rencontrer, au milieu des cailloux roulés, des défenses d'éléphants arrachées au véritable diluvium ; mais comme cet ivoire était déjà profondément altéré par le poids des siècles qui avaient passé dessus, ils ne cherchèrent pas à en tirer parti. C'est pour la même raison qu'ils délaissèrent aussi ces grands ossements de Pachydermes qui gisent dans les mêmes atterrissements, après les avoir sans doute essayés avec leurs instruments de pierre tranchants, ainsi que le témoigneraient des empreintes de coups de hache qu'on s'est plu à voir sur d'aucuns de ces ossements ... (1863a p. 956). II lui faut bien tenir compte des découvertes faites par de Vibraye et Lartet. Mais il ajoute, pour achever sa démonstration, que ... rien, jusqu'à présent, ne démontre, suivant nous, qu'il faille reculer ou changer la place que les illustres Cuvier et Brongniart lui ont assignée dans l'échelle de la création. (1863a - p. 957). Décidément les créationnistes ont la dent dure. II renouvelle ses 
observations et ses réfutations en 1864 en invoquant les remaniements du terrain et l'absence absolue de ... toute représentation, soit d'Éléphant, soit de Rhinocéros, soit d'Hippopotame, etc. (p. 674). Cette note est publiée dans les Comptes Rendus de la séance du 11 avril 1864, soit un mois avant la découverte du Mammouth de La Madeleine.

L'argument de la falsification est également avancé par les réfractaires et non sans raison véritable. Nous développerons plus loin la question des faux mammouths inspirés de l'animal de la Madeleine, mais avant même la découverte de ce dernier, Eugène Robert, toujours lui, signale qu'il a recueilli à Amiens et Abbeville ... un grand nombre de silex dont la taille remonte certainement à une époque très reculée (j'insiste sur ce point, afin de ne pas confondre les pierres façonnées anciennement avec celles que les ouvriers ne se font aucun scrupule de vous présenter comme telles après les avoir préparées euxmêmes), et dont les arêtes sont si fraîches, qu'on éprouve la plus grande répugnance à supposer qu'ils ont dû subir le même sort que les matériaux dits du diluvium ; en d'autres termes, qu'ils sont contemporains des ossements fossiles de mammifères ... (1863b - p. 1122).

Les fausses pièces sont nombreuses et la pratique est courante à l'époque. On fabrique de faux objets et on les introduit dans de vrais sites archéologiques. Les critiques les plus vives touchent donc à l'antiquité des objets découverts. L'art mobilier n'y échappe pas et le rôle joué par A. Meillet au Chaffaud est funeste. Des opposants tenaces, allemands pour la plupart, Ludwig Lindenschmidt (directeur du Musée de Mayence) en tête, adressent à l'attention des découvertes de Lartet et Christy des critiques radicales. Selon certains, parmi tous les objets d'art découverts, il n'y en a pas un qui ne soit pas un faux.

... Quant à la plaque d'ivoire où l'on a cru trouver l'image sculptée d'un mammouth vivant [...] l'auteur de cette découverte pourrait bien avoir été victime d'une mystification. (Anonyme, La Revue Catholique 1867c - p. 638). Cette attitude résolument suspicieuse sert ceux qui refusent l'art préhistorique par principe. L'ancienneté attribuée aux œuvres d'art de la Préhistoire n'est pas compatible avec leur propre qualité d'exécution. II est difficile d'accepter que les gravures et sculptures d'animaux remontent à des temps si anciens, puisqu'elles ne s'accordent pas avec l'état de barbarie inculte dans lequel les savants les plus orthodoxes se représentent les peuplades aborigènes, privées de l'usage des métaux et des autres ressources les plus élémentaires de nos civilisations modernes (Lartet et Christy 1864). ... Nous ferons simplement remarquer que le progrès et la perfection dans les arts ne se manifestent pas toujours en conformité des gradations chronologiques. II y a deux mille ans et plus que Phidias et Praxitèle réalisaient, sur l'ivoire et sur le marbre, leurs plus sublimes conceptions de beauté idéale ; depuis lors, l'art moderne s'est trouvé réduit à les prendre pour modèles, sans pouvoir les surpasser ni peutêtre même les égaler... (Lartet et Christy 1864 - p. 264).

Les efforts d'imagination de ces mêmes savants sont sans limite. À propos du mammouth de La Madeleine, l'abbé Moigno, mathématicien français, pousse le raisonnement jusqu'à l'absurde en indiquant que ... ce dessin, que nous avons eu entre les mains, rajeunit considérablement et l'homme des cavernes et l'éléphant barbu ; si tant est qu'il faille admettre leur coexistence, l'un et l'autre seraient certainement postérieurs à l'homme des dolmens (Anonyme, La Voie Nouvelle 1866 - p. 50).

L'antiquité attribuée à l'art mobilier est également mise en doute par la nature même des représentations animales figurées, comme est contestée l'antiquité de l'homme par la nature des faunes qui lui sont associées. Avant la découverte du mammouth de La Madeleine, premier représentant d'un bestiaire disparu, et avant la mise au jour de restes osseux et de dents de ce grand pachyderme assurément associés aux vestiges des activités de l'homme ou transformés par ce dernier, le renne est le seul animal qui, dans ses vestiges ou ses représentations, donne un cachet d'ancienneté aux diverses stations préhistoriques fouillées. Cela n'est pas suffisant et les détracteurs objectent que le renne, cité par César, et les autres animaux actuels, n'ont pas été antédiluviens. En tous cas, ils n'ont pas disparu de nos contrées depuis si longtemps. Ils cohabitent même avec l'homme encore de nos jours. Lartet et Christy répondent à cette objection : ...

Sans doute, César a parlé du renne, mais sur simple ouïdire ; et il a soin d'ajouter que, chez ces mêmes Germains qui lui fournirent ces vagues renseignements de l'existence du renne dans la forêt d'Hercynie, aucun n'avait pu atteindre les limites de cette forêt, après une marche de soixante jours, ni dire où elle commençait. Si, plus tard, lorsque, sous les premiers empereurs, l'influence romaine s'étendit à toute la Germanie, le renne eût encore existé, même dans les parties extrêmes de cette contrée, nul doute qu'on ne l'eût vu figurer dans les jeux du cirque, où l'on rassemblait, à grands frais, les animaux des régions les plus lointaines. Rien ne nous dit que les anciens aient connu le renne autrement que par les récits obscurs des Scythes et des Germains. Les Gaulois eux-mêmes ne l'ont pas figuré dans leurs monnaies, sur lesquelles on retrouve leurs animaux indigènes et aussi le lion, dont ils avaient emprunté l'image aux médailles grecques. (1864 - p. 263).

On le voit, les détracteurs ont plus d'une corde à leur arc mais ils rencontrent à chaque fois de solides contradicteurs. Le mammouth de La Madeleine en 1864, puis celui de Laugerie-Basse en 1865 et, enfin, celui de Bruniquel en 1866 ruinent définitivement l'édifice construit par les mystifiés de l'Académie des Sciences (Mortillet 1865).

À la fin du XIX siècle, de rares et pathétiques attardés continuent à prétendre que l'homme fossile est une invention de la Science. Nous ne résistons pas au plaisir de reproduire les délires d'un de ces plus fameux rétrogrades qu'est Lucien Darville. Dans un ouvrage au titre évocateur (Le roman de la science), l'auteur affirme que les ... prétendus troglodytes [de la Vézère] ... n'étaient autres que des chrétiens qui se cachaient [momentanément dans les grottes pour se mettre à l'abri des persécutions]. Les ébauches de gravures sur os ou sur ivoire qu'ils nous ont laissés ... étaient tout bonnement des signes distinctifs de leur état de chrétiens, et leur servaient de titres de reconnaissance auprès de leurs coreligionnaires se réfugiant comme eux dans les grottes. En retrouvant ces sculptures grossières, nos savants partent encore en 
guerre et nous affirment gravement que ce sont des gravures sur bois de renne et sur défenses de mammouth, au lieu de reconnaître simplement qu'il s'agit d'ivoire ou de bois de cerf ... [ils ne parlent] ni de l'usage auquel elles étaient destinées, ni du sens mystérieux qui y était attaché, car, pour s'expliquer cela, il faut posséder à fond l'histoire de l'Église à l'époque des persécutions ... (1893 - p. 165). Magnifiques conclusions desquelles nous ne saurions ôter la description du mammouth de La Madeleine dénommé ... Béhémoth [qui] est le nom donné à l'éléphant image de la force de Dieu. Ce mot est un pluriel emphatique pris pour Béem, de même qu'Elohim est pris pour Ell, au commencement de la Genèse. (1893 - p. 168). C'est encore le registre des créationnistes d'aujourd'hui.

\section{4 - Le mammouth de La Madeleine : histoire, contexte et circonstances de la découverte}

En séance du lundi 21 août 1865, Henri Milne Edwards communique à l'Académie des Sciences une lettre d'Édouard Lartet dans laquelle sont exposés I'historique et les conditions de la découverte d' une lame d'ivoire fossile trouvée dans un gisement ossifère du Périgord, et portant des incisions qui paraissent constituer la reproduction d'un éléphant à longue crinière. (1865a - p. 309-311). Le texte, parfois avec de très légères modifications de détails, est également publié en 1865 dans les Annales des Sciences Naturelles (1865b - p. 353-355, pl. XVI), accompagné du premier relevé historique de l'objet (fig. 5), exécuté probablement à partir du moulage crayonné par Augustus Wollaston Franks à la demande de Lartet et dans les Matériaux pour l'histoire primitive et philosophique de l'Homme (1865c - p. 46-48). II est repris dans les Reliquiae Aquitanicae (1865-1875 - chap. XIX, p. 206-208).

La découverte a lieu en mai 1864, soit un peu moins d'un an après les premières recherches entreprises en Périgord par Lartet et Christy. Elle se déroule lors d'une excursion conduite par Édouard Lartet dans les sites de la région à la demande et en présence des paléontologistes Édouard de Verneuil et Hugh Falconer. Contrairement à ce qui est parfois signalé dans la littérature, Henry Christy n'est pas présent lors de cette visite. II décède près de 4 mois avant la première publication.

... On continuait alors les fouilles au gisement de la Madelaine, qui avait déjà fourni un certain nombre de ces figures d'animaux gravées sur os ou sur bois de Renne, et dont quelques-unes ont été mises, l'année dernière, sous les yeux de l'Académie. Au moment de notre arrivée, les ouvriers avaient nouvellement mis à découvert cinq fragments éclatés d'une lame d'ivoire un peu épaisse (" assez mince » dans la publication de 1875), qui avait dû être anciennement détachée d'une assez grosse défense d'Éléphant (« de taille moyenne » dans la version de 1875). Après avoir rejoint ces morceaux par les points de repère que fournissaient les anfractuosités des cassures, je montrai au Dr Falconer de nombreuses lignes ou traits de gravure peu profonde, dont l'ensemble ainsi rapproché paraissait accuser des formes animales. L'œil exercé du célèbre paléontologiste qui a le mieux étudié les Proboscidiens y reconnut aussitôt une tête d'Éléphant. (Lartet 1865a - p. 309)

Falconer identifie d'autres détails de l'animal, notamment à hauteur du cou, comme ces lignes verticales qui évoquent les longs poils caractéristiques du mammouth. Entre la découverte au mois de mai 1864 et sa publication en août 1865 , Lartet va prendre le temps de consulter, de réunir les avis des uns et des autres, de soumettre l'objet aux examens les plus scrupuleux et de rassembler enfin les observations analogues. II montre les fragments d'ivoire gravés aux personnes les plus compétentes, écrit-il. Parmi elles, citons Jules Desnoyers, l'archéologue, historien et géologue qui a publié en 1863 les indices matériels de la coexistence de l'homme avec l'Elephas meridionalis dans

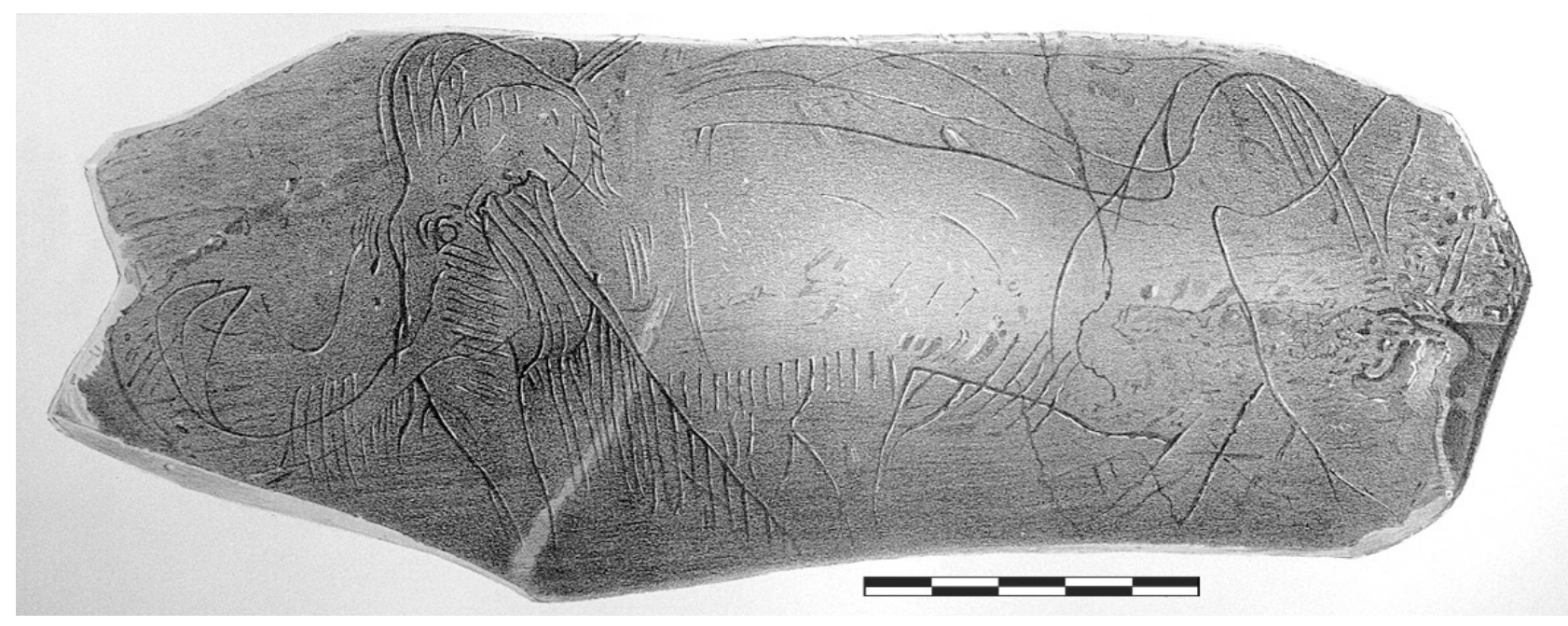

Figure 5 - Premier relevé du mammouth de La Madeleine (É. Lartet 1865b).

Figure 5 - First tracing of the La Madeleine mammoth (É. Lartet 1865b) 
un terrain des environs de Chartres (Saint-Prest), mais aussi Armand de Quatrefages, le célèbre biologiste, zoologiste et anthropologue, adversaire attentif du darwinisme et Adrien de Longpérier, Conservateur des antiquités égyptiennes, grecques et romaines du musée du Louvre, un des opposants notoires à l'authenticité et l'antiquité de l'art préhistorique (Reinach 1928). Tous les experts ne sont pas acquis d'emblée à sa cause. Ce sont donc des avis contrastés que sollicitent Lartet pour mieux faire valoir et reconnaître sa découverte. Et ... c'est donc, en réalité, l'opinion de ces savants éminents, celle de M. Falconer, et la vôtre aussi, Monsieur [Milne Edwards], qui se produira devant l'Académie, autant que la mienne propre. (Lartet 1865a - p. 310). Augustus Wollaston Franks, directeur de la Société des antiquaires de Londres et futur conservateur du Département d'antiquités et d'ethnographie du British Museum, apporte également sa contribution en analysant un moulage de la pièce et en effectuant une première lecture des gravures. C'est une belle victoire pour Lartet.

\section{1 - Le contexte archéologique de la découverte}

Les premières publications de Lartet et Christy n'apportent pas d'indications sur le contexte archéologique précis de la découverte et sur sa situation topographique et stratigraphique. Lartet indique même que les fragments ont été exhumés avant son arrivée. Les scientifiques présents n'ont pas été les témoins directs de la découverte. Un doute subsiste donc sur l'origine de l'objet, même si quelques auteurs affirment qu'il provient d'une couche parfaitement intacte (Bandi et Maringer 1952) ou très bien repérée (Foucault 2005). Louis Capitan et Denis Peyrony publient en 1928 de précieuses informations sur la localisation et l'extension des fouilles de Lartet et Christy : L'exploration du grand abri, situé au fond du pré, fut commencée en 1863 par Lartet et Christy. Sur ce point, les couches archéologiques étaient presqu'en surface ; aussi les premiers travaux se firent aisément ... [p. 12] ... Lartet et Christy avaient atteint partout la base des couches archéologiques, sauf dans le fond d'une cuvette près du bloc calcaire B du plan. Grâce à un article paru dans la Revue archéologique de 1864, il nous a été permis de limiter leurs travaux d'une manière précise. Partant du côté Est, de la lettre $L$ gravée sur la paroi de l'abri, ils s'étendaient au fond de ce dernier sur une longueur de 15 mètres et sur une largeur de 7 mètres en moyenne. (Capitan et Peyrony 1928 - p. 13-15). Lartet et Christy ont sondé la zone centrale de l'abri où il est le plus marqué (fig. 6). Selon Jean-Marc Bouvier ... les niveaux archéologiques affleurent presque la surface et les premiers coups de pioches sont fructueux (1977 - p. 40). L'objet doit provenir selon lui des niveaux attribués au Magdalénien VI (supérieur).

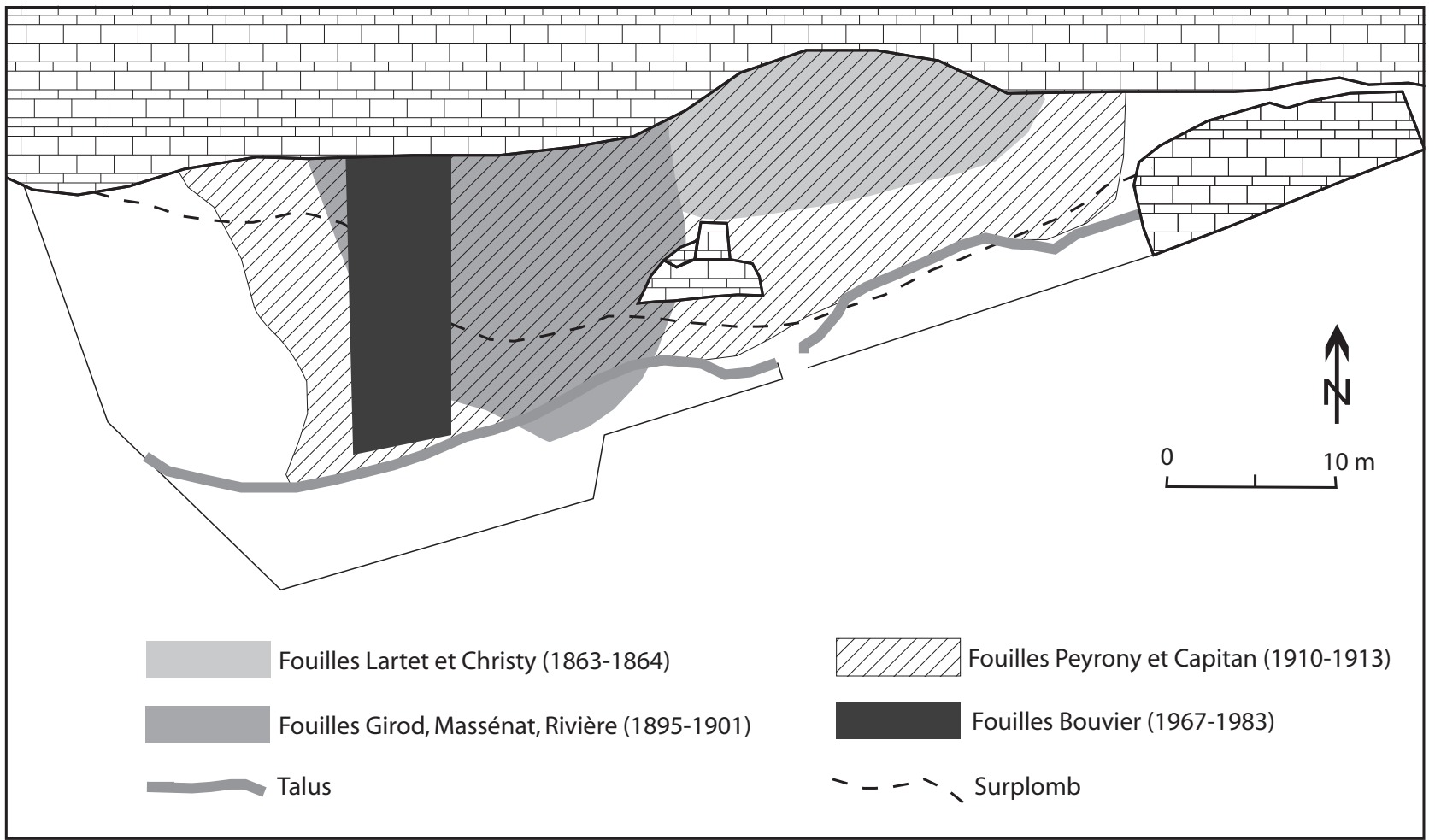

Figure 6 - Plan de l'abri de La Madeleine (DAO, Patrick Paillet).

Figure 6 - map of La Madeleine shelter (drawing, Patrick Paillet). 


\section{2 - Sa place à l'exposition universelle de 1867}

Si la situation exacte des fragments d'ivoire dans l'abri de La Madeleine n'est pas connue, on sait en revanche quelle a été la place que Lartet et Mortillet leur ont réservé au Palais du Champ de Mars à Paris lors de l'exposition universelle de 1867 (et non de 1889 comme parfois indiqué dans la littérature). ... Le génie de Lartet et Christy a été d'interpréter correctement ce document "où l'un de nos lointains ancêtres a inscrit lui-même et de façon charmante, la preuve décisive de son antiquité géologique » (M. Boule). Mais plus cruciale encore que la récolte du document et sa «lecture » correcte, apparaît la publicité qui lui fut donnée par publication et par l'exposition (Bouvier 1977 - p. 40).

La vitrine qui contient ... l'exposition de l'art à l'époque du renne ou seconde époque des cavernes ... (Mortillet 1867a - p. 24) rassemble 51 pièces estimées à un million de francs par un amateur, somme qu'il offrait si on voulait lui céder la collection. La vitrine plate, où sont présentées les œuvres d'art, occupe le centre de la première salle qui s'ouvre sur le grand vestibule du palais autour d'un jardin central, point de départ de l'exposition française de l'Histoire du Travail ( $1^{\text {̀re }}$ salle consacrée à la Préhistoire $: L a$ Gaule avant l'emploi des métaux) ... Les personnes qui parcouraient, à l'exposition universelle de 1867, la belle galerie de l'Histoire du travail, ne pouvaient manquer de remarquer une magnifique collection de ces productions artistiques des anciens âges. On n'y comptait pas moins de cinquante et une pièces, envoyées par divers amateurs, et qui étaient pour la plupart extrêmement curieuses. C'étaient d'abord diverses représentations du mammouth, lequel existait encore au commencement de l'époque du renne ... (Figuier 1876 - p. 162). L'organisation de cette salle a été confiée à une commission présidée par Édouard Lartet et composée de Jules Desnoyers, Paul de Vibraye, Jules Charvet et Gabriel de Mortillet. Elle est organisée chronologiquement et regroupe les collections de nombreux chercheurs et inventeurs (Lartet, Christy, de Vibraye, Bourgeois, Peccadeau de l'Isle, Brun, Filhol, Garrigou, Robert, Delaunay, Cartailhac et Costa de Beauregard notamment). La première vitrine plate, si bien mise en valeur au milieu de la dizaine de travées thématiques, rassemble pour la première fois des ... pièces, de découverte toute récente, qui en partie ne sont pas encore publiées ... c'est là un produit exclusivement français, qui n'a pas encore été rencontré ailleurs, et qui, même en France, se trouve jusqu'à présent groupé sur une partie assez limitée du sud-ouest de la France. On dirait presque que, dans ces temps reculés, le sentiment artistique avait apparu et s'était développé sur un point très restreint, sans se répandre dans les populations voisines de mêmes mœurs, de même civilisation ... [...] Les matières employées par les artistes de l'époque du renne sont parfois des plaques de pierres plus ou moins schisteuses ; parfois aussi l'ivoire provenant des défenses de mammouth ou diverses portions d'os; mais la plus ordinaire, la plus habituelle, est le bois de renne. Plus de la moitié des pièces sont gravées ou sculptées sur bois de renne (Mortillet $1867 a$ - p. 24).

La plaque d'ivoire gravée de La Madeleine est placée au milieu de la vitrine. On ne voit qu'elle quand on arrive face à cet "écrin ", entourée des figures de mammouths de Laugerie-Basse et de Bruniquel. Les œuvres exposées dans cette vitrine ... forment un ensemble important pour l'étude de ces époques dites antéhistoriques, et la Commission, en les mettant sous les yeux du public, est heureuse de rendre hommage aux recherches de ces savants distingués et à l'excellent concours qu'ils ont bien voulu lui prêter; de même que c'est aux soins de M. Lartet, de MM. Mortillet et Jules Desnoyers, du marquis de Vibraye, de MM. Bertran et Colomb qu'elle doit l'excellente classification qui a permis d'apprécier à leur juste valeur ces monuments qui peuvent être considérés comme les essais élémentaires de l'homme, et qui constituent le premier échelon de l'Histoire du Travail. (Exposition universelle - Rapports du Jury international 1868 - p. 150 et Linas 1868). Cette vitrine constitue aux yeux de Mortillet la démonstration la plus convaincante de la contemporanéité de l'homme et du renne (animal émigré), du tigre des cavernes, du grand ours et du mammouth (animaux éteints).

\section{5 - Le mammouth de La Madeleine et ses anciennes descriptions}

Depuis la publication princeps (Comptes Rendus des séances de l'Académie des Sciences, 1865) de multiples descriptions du mammouth de La Madeleine ont été publiées, notamment au $\mathrm{XIX}^{\mathrm{e}}$ siècle, tantôt par des scientifiques confirmés comme Gabriel de Mortillet ou Émile Cartailhac, tantôt par des auteurs moins inspirés qui se copient ou s'inspirent mutuellement. Ils reconnaissent unanimement l'espèce éteinte à longue crinière, le mammouth ou Éléphant des temps glaciaires (Elephas primigenius). L'esquisse ou le dessin est parfois qualifié de grossier ou de rudimentaire (Anonyme, La Voie Nouvelle 1866 - p. 50 ; Anonyme, La Production Animale et Végétale $1867 \mathrm{~b}$ - p. 4 ; Ménard 1882 - p. 545 et Woodward cité par Lartet et Christy 1865-1875 - p. 168) et la main qui l'a exécutée est dite même fort inexpérimentée (Anonyme, Gazette des Beaux-Arts 1867a - p. 500). Gabriel de Mortillet ajoute enfin qu'il s'agit d'une simple gravure, ... nous pouvons même dire une ébauche de gravure (1890p. 24) et Louis Figuier d'une ... esquisse au trait (1876 p. 162).

Mais généralement les auteurs reconnaissent la qualité de l'exécution. C'est ... une pièce tout à fait hors ligne ... selon Émile Cartailhac (1889 - p. 72), exécutée ... avec fermeté et finesse (Bandi et Maringer 1952 - p. 19). Certains manifestent même un enthousiasme peu commun pour l'époque. Henri du Cleuziou dit de l'art de La Madeleine qu'il ... est en progrès sur celui des modernes les plus fougueux ... Voyez ce mammouth [écrit-il] il est d'une réalité saisissante (1887 - p. 254). L'artiste primitif est remarquable mais il ne lui manque ... que les matières et les procédés appropriés à l'art du dessin (Le Hon 1867 p. 70). L'animal est gravé ... avec finesse et exactitude pour Paul Gervais (1867 - p. 26).

Les auteurs soulignent aussi l'abondance, la qualité des détails figurés et les caractères les plus saillants de l'animal. Sur cette antique gravure on retrouve tous les traits du mammouth (Quatrefages 1896 - p. 108), dont la 
silhouette aux proportions exactes est dite imposante. C'est la crinière qui frappe d'abord tous les observateurs. L'ensemble des textes publiés indique que les longs poils ou longs crins sont caractéristiques du mammouth. La crinière est ample et touffue et les longs poils sont hardiment tracés (Cartailhac 1889 - p. 73). Elle retombe le long du cou et pend entre la trompe et les jambes jusqu'aux genoux. La région inférieure du corps, le cou et le dos sont couverts d'une épaisse toison qui ressemble à celle du lion. D'autres détails corporels sont soulignés comme la queue relevée, touffue ou garnie de longs crins. Elle est retroussée en forme de fouet. Le front est dit tantôt large et bombé, tantôt haut et creux. La trompe, longue et puissante, tombe droit. Les défenses sont grandes et fort recourbées. Le garrot est élevé et domine une ligne dorsale plus basse et en pente. D'autres auteurs signalent enfin la petite taille de l'œil et de l'oreille. Jean-Marc Bouvier ajoute même que l'artiste a fignolé ... ajoutant les paupières à l'œil, indiquant les longs poils de la tête et les jarres du poitrail, la queue fouettant l'air et même le clapet anal, tous détails familiers à celui qui a vu le Mammouth vivant mais à lui seul (1977 - p. 40). Le clapet anal, détail discret mais très caractéristique du mammouth, est également évoqué par le Docteur Léon Pales : ... I/ semble bien en effet que l'artiste paléolithique ait voulu représenter la valvule anale, mais il en a exagéré les dimensions et l'a figurée très relevée. Comme l'animal paraît marcher à vive allure, il me semble que ce relèvement exagéré de la queue a été voulu par l'artiste. C'était peut-être l'attitude de combat du Mammouth ... Le relevé publié par Lartet et Christy est, malheureusement, erroné et l'énorme valvule précitée a disparu dans le relevé précis qu'en fit Breuil (1989 - p. 67).

L'attitude de l'animal et ses allures ont également suscité de nombreux commentaires. Certains auteurs pensent que l'animal a été reproduit en vive allure (Pales 1989) ou en pleine course (Bourlot 1868) ... L'artiste qui a reproduit ce mammouth a été frappé de l'allure, à la fois singulière et imposante, de cet animal quand il fuyait devant les chasseurs. II en a saisi, sur l'ivoire, la grande silhouette, le mouvement plein de vie et les caractères les plus saillants. On distingue jusqu'à deux repentirs dans la partie dorsale qu'il n'avait pas assez bombée. La crinière est figurée, et la queue, également garnie de crins, est relevée comme on le voit chez certains ruminants quand ils sont animés par la course (Le Hon 1867 - p. 70). D'autres auteurs y voient plutôt un ...croquis de trois éléphants marchant à la file. Celui du milieu était seul visible en totalité (Büchner 1872 p. 114). Henry Woodward, géologue et paléontologue britannique, cité par Lartet et Christy (1865-1875 - p. 168), suggère ... que l'attitude de l'animal ainsi que la position verticale de la trompe pourraient bien s'accorder avec l'idée d'un éléphant parmi une harde descendant au clair de lune pour boire, et que les doubles lignes déroutantes pourraient s'expliquer par une tentative, de la part de l'artiste, de représenter le reste de la harde. Quand l'éléphant court, ou quand il est alarmé, sa trompe est toujours dressée. Cette interprétation fait l'objet d'une critique très documentée de la part de René de SaintPérier (1920). Afin de mieux analyser l'attitude du mammouth de La Madeleine, il fait appel au témoignage du géographe français Édouard Foà, aventurier et chasseur d'éléphant d'Afrique. Ce dernier affirme que ... chaque fois qu'il y a du danger et que l'Éléphant se jette sur un ennemi, il replie sa trompe et la rentre avec soin, laissant ses défenses bien en avant ... (p. 283). L'observation est donc diamétralement opposée à celle de Woodward. Selon de Saint-Périer l' ... attitude du mammouth n'a point été fidèlement représentée par les artistes quaternaires, s'il faut en croire les chasseurs qui ont observé l'Éléphant d'Afrique actuel dans son milieu naturel (p. 283). Le mammouth gravé de La Madeleine ferait exception à la règle.

... Sur la gravure de la Madeleine nous ne voyons qu'une partie de la trompe, dont l'extrémité, non figurée, pouvait être repliée. En tout cas, elle est protégée par les défenses, comme [...] dans la charge. D'autre part, la tête baissée de l'animal, sa queue levée, l'action puissante que dénote le mouvement violent du membre postérieur [...] font penser au début de la charge, alors que l'Éléphant, furieux, va foncer sur le chasseur, commence à ramener sa trompe en arrière des défenses et se porte en avant par une impulsion énergique de son arrière-train ... (Saint-Périer 1920 - p. 284). L'auteur en conclu, à l'inverse de l'interprétation de Joseph Bourlot (1868) où l'animal fuit le chasseur, que le mammouth de La Madeleine est représenté ... chargeant un chasseur ou un animal qui l'attaque, scène que les artistes quaternaires ont dû avoir souvent l'occasion d'observer ... L'observation moderne ..., ajoute-t-il, ... confirme le réalisme sincère de l'art déjà si parfait de ces lointains chasseurs (p. 285). Le fait est que l'animal semble bien figuré en mouvement comme l'atteste la queue relevée en crosse et l'extension des membres postérieurs. II semble même ... que deux trompes et plusieurs défenses, au tracé filiforme, aient été figurées ... (Vialou 1995 - p. 89). Nous allons voir plus loin si cet artifice graphique vise à traduire l'idée du mouvement de l'animal.

\section{6 - Les modèles congelés en Sibérie}

Les commentaires des premiers auteurs s'appuient invariablement ou presque sur les découvertes d'individus congelés faites dans le nord de la Sibérie. Ce sont bien les modèles de l'artiste de La Madeleine qui sont alors découverts dans les glaces et qui aident à l'interprétation de la première image de l'animal qui nous est donnée à voir. La découverte d'un mammouth, conservé intact dans les glaces du nord de la Sibérie, nous a appris que cet animal était recouvert d'une laine épaisse et de forts longs poils, tandis que tous les éléphants actuels sont à peau nue (Mortillet 1868 - p. 465). Il a donc été possible ..., nous dit René Verneau, ... de reconstituer avec la plus grande vérité l'éléphant dont on rencontrait les ossements dans presque toute l'Europe, et on a pu se rendre compte de l'exactitude de l'œuvre exécutée par l'artiste de la Dordogne (Verneau 1890 - p. 161). Le pelage du mammouth de La Madeleine est semblable à l'épaisse fourrure et aux longues soies des animaux congelés extraits des terres glacées de Sibérie. Mais c'est à peu près tout ce qui peut être dit des vestiges miraculeusement préservés dans les glaces, contrairement à ce qu'écrit René de Saint-Périer (1920) sur l'exactitude du mammouth de La Madeleine. Elle a été reconnue ... lorsque des découvertes récentes de mammouths, conservés dans les terrains glacés de Sibérie, ont permis d'examiner la configuration des parties molles de cet éléphant (p. 284). 
En effet, ce sont plus souvent des fragments de corps, des lambeaux de peau et de chair putréfiées, des touffes de poils, des défenses et des ossements plus ou moins en connexion qui sont découverts à l'époque. II faudra attendre le $X X^{e}$ siècle pour que soient récoltés des animaux à peu près complets, prélevés dans de bonnes conditions et surtout épargnés par les découvreurs eux-mêmes, les charognards, les chiens et la nature. Les savantes descriptions de Henry Woodward, publiées dans le Geological Magazine (1864, 1868 et 1869) s'appuient sur des vestiges osseux. Le seul individu qui, à l'époque de la découverte, aurait pu servir utilement aux comparaisons était le célèbre mammouth d'Adams, découvert en 1799 près de l'embouchure de la Léna et extrait quelques années plus tard après qu'il eut subi les outrages de l'homme et des animaux (disparition de la plupart des parties molles) (fig. 7). Gabriel de Mortillet donne sur cette découverte d'excellentes précisions.

... Plusieurs individus ont été successivement rencontrés gelés sur les côtes de la Sibérie. Le plus célèbre est celui signalé par Adams. II fut découvert par un Tungouze, en 1799, vers l'embouchure de la Léna. II était pris dans un bloc de glace impure qui ne fondit que lentement, car deux ans plus tard Adams trouva encore le cadavre à la même place. Malheureusement les lakoutes pour nourrir leurs chiens, et les animaux sauvages pour se repaitre, avaient déchiré et détruit en grande partie les chairs. Le squelette a été transporté au Musée de Pétersbourg, ainsi que ce qui restait de la peau ... La peau n'a été conservée que sur la tête et autour des pieds. Ces découvertes de cadavres encore entiers ont montré que le mammouth, au lieu d'avoir une peau nue comme les éléphants actuels, était recouvert d'une épaisse fourrure. Cette fourrure se composait de deux espèces de poils. II y avait des soies brunes semblables aux crins des chevaux, mais plus raides. Ces soies avaient une longueur de 32 à $40 \mathrm{~cm}$, sur le cou elles étaient plus abondantes et encore plus allongées. Elles formaient une crinière retombante dont les éléments atteignaient et dépassaient même $70 \mathrm{~cm}$ de long. Ces crins formaient aussi à la queue un fouet long et bien fourni. La seconde espèce de poils était une manière de laine, fine, douce, frisée, fauve clair, qui recouvrait tout le corps, formant une toison épaisse de 11 à $13 \mathrm{~cm}$. Le mammouth était donc habillé de manière à pouvoir supporter les grands froids (1890 - p. 26-27). Voilà qui est clair. Au $\mathrm{XIX}$ siècle, les quelques vestiges de mammouths congelés ne servaient finalement qu'à habiller de touffes de poils plus ou moins longues et denses les rares squelettes plus ou moins complets connus par ailleurs. Peau, graisse et muscles ne viendront que plus tard parfaire le portrait de l'espèce disparue (Cohen 2004).

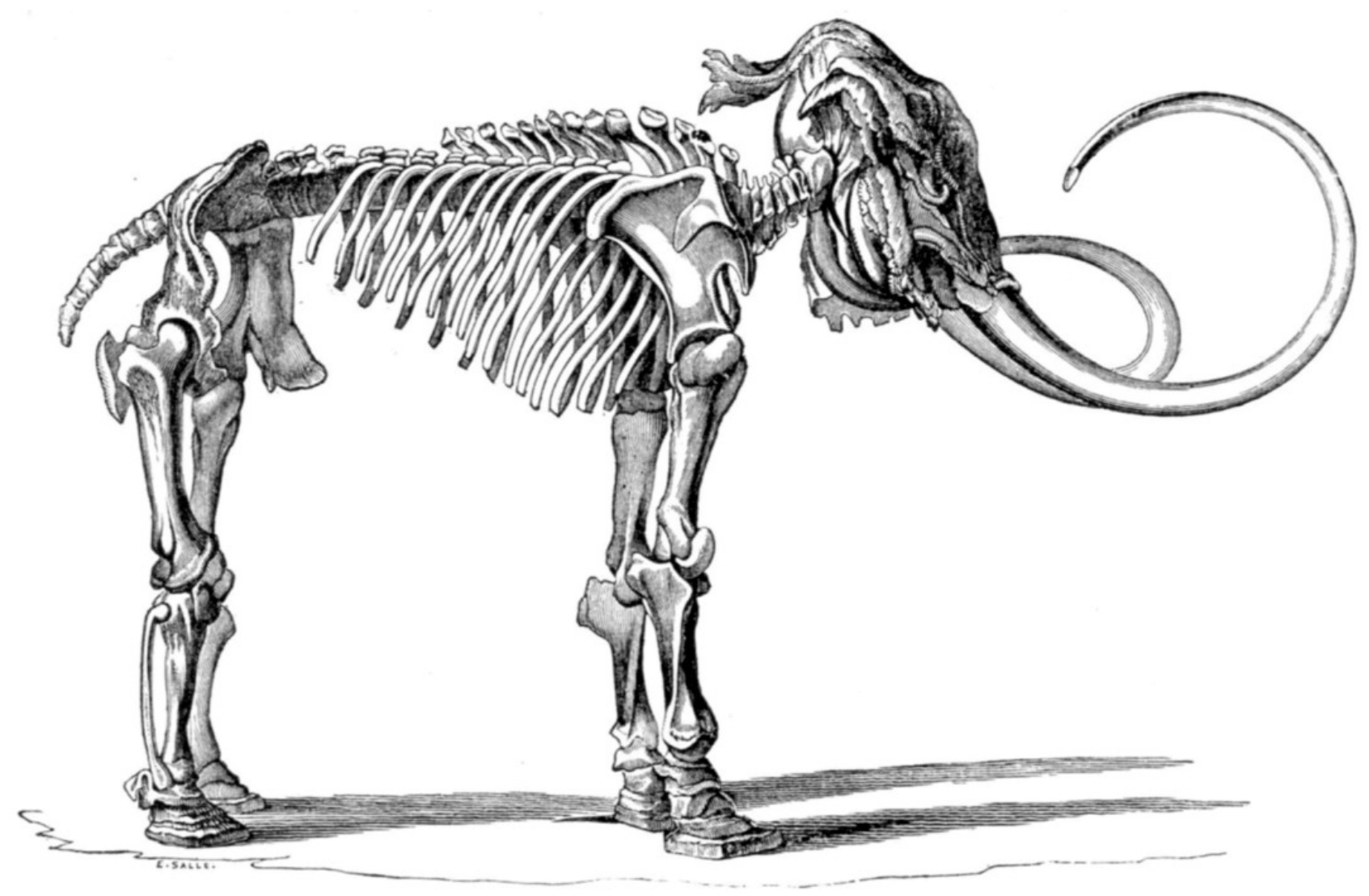

Figure 7 - Reconstitution du squelette du mammouth d'Adams (Saint-Pétersbourg). Dessin d'après Charles Rau (1876).

Figure 7 - Reconstitution of the skeleton of the Adams mammoth (St-Petersbourg). Drawing after Charles Rau (1876) 


\section{7 - Faux et usage de faux}

Nous avons vu plus haut combien a été néfaste l'influence des faux objets archéologiques dans l'évolution des idées au XIX siècle. Les falsifications opposent un argument sévère à la reconnaissance même de l'antiquité de l'homme et de sa coexistence avec certains animaux fossiles. La question des faux n'est donc pas anodine. Elle est même fondamentale pour la Préhistoire à ses débuts (Piveteau 1928 ; Griffin et al. 1988).

Une pièce archéologique comme l'ivoire gravé de La Madeleine ne pouvait échapper aux falsificateurs pour une raison essentielle : l'animal figuré. Le mammouth, espèce éteinte depuis des millénaires, figure symbolique de la Préhistoire, est un gage d'antiquité. L'association des restes osseux de mammouths et de l'homme ou des vestiges de son activité constitue un indice fort. La représentation par l'homme de ce même animal devient une preuve capitale, un argument d'autorité en quelque sorte. Le mammouth de La Madeleine sera donc copié, généralement avec certaines libertés. Peu de temps après la découverte, Lartet confie à M. Stahl (chef des ateliers de moulages du Muséum national d'histoire naturelle) le soin de réaliser une réplique de l'original. Des fac-similés vont alors circuler. La première note de Lartet est publiée en 1865 dans plusieurs revues, lui assurant ainsi une plus large diffusion : une grande publicité est donnée à l'objet. Des moulages, bien souvent de mauvaise qualité, sont tirés par centaines et envoyés dans les musées et institutions scientifiques du monde entier. L'image est maintenant diffusée et va inspirer les faussaires. Pour prouver la contemporanéité de l'homme et du mastodonte ou du mammouth, pour prouver simplement l'existence d'un homme préhistorique américain d'âge paléolithique, des représentations de mammouths, plus ou moins inspirées du modèle périgourdin, sont mises au jour aux États-Unis.

L'agitation des archéologues américains porte rapidement ses fruits. Le premier objet découvert outre-Atlantique est un pendentif en coquillage marin (Busycon sinistrum) gravé d'une figure de mammouth (fig. 8). Hilborne T. Cresson (chercheur associé au Peabody Museum de l'Université d'Harvard) signale qu'il a été découvert en 1864, en sa présence, par un certain M. W.L. Surault. L'objet, dont on dit qu'il a autant de valeur que le mammouth de La Madeleine, aurait été collecté en surface d'un champ cultivé, près du site archéologique de Holly Oak (Naaman's Creek, Delaware). II se trouvait associé à des restes humains, des outils taillés, des ossements animaux et des charbons. La découverte n'est signalée qu'en 1890 par Frederic Ward Putman, naturaliste et archéologue américain, conservateur au Peabody Museum of Archaeology de l'Université d'Harvard, qui relate les propos de Cresson (1890 - p. 467-469).

Selon Thomas Wilson, conservateur du département d'archéologie préhistorique de l'United States National Museum (musée précédant le Smithsonian à Washington), l'animal ressemble beaucoup à celui de La Madeleine. II ajoute que son aspect ne laisse aucun doute sur son ancienneté « paléoindienne » et l'on n'y observerait pas de traces d'un travail récent. De semblables représentations de mammouth, cette espèce éteinte des temps préhistoriques, ont été découvertes en Amérique. Je ne connais aucune raison pour que ces gravures ne jouissent pas d'un crédit égal à celui qui fut accordé aux mêmes manifestations artistiques en Europe, relativement à l'antiquité de l'homme (Wilson 1898 - p. 380). André Vayson de Pradenne est beaucoup plus mesuré. Pour lui ... le fragment de coquille paraît en effet ancien d'après son altération superficielle. Mais que dire du dessin ? Ne se réduit-il pas à quelques traits où l'imagination voit ce qu'elle veut? S'agit-il d'une figuration voulue et dans ce cas qu'elle garantie offre cette trouvaille pour la technique? (1932 - p. 138). Ce coquillage, conservé à la Smithsonian Institution, tombe ensuite dans l'oubli pour ne réapparaître qu'à la seconde moitié du XX' siècle. En 1976, il est publié dans la revue Science et en fait même la couverture (p. 756-761). Les auteurs (John C. Kraft et Ronald A. Thomas) n'excluent pas qu'il puisse s'agir d'un faux mais concluent tout de même que la pièce peut être attribuée à la fin du Pléistocène ou même encore à la période Sangamon (dernier interglaciaire). On frise l'hérésie ! Aucune réflexion n'est menée sur le contexte même de la découverte et ses conditions. On est bien loin finalement de la datation ${ }^{14} \mathrm{C}$-AMS obtenue à Zurich en 1986 sur un micro-échantillon du coquillage qui fournit la date de $1530 \pm 100$ ans BP. En dates calibrées cela donne 885 ans $A D$, soit entre 700 et 1000 ans AD compte-tenu du sigma d'erreur. L'objet est bien archéologique, mais son décor a été réalisé à la fin des années 1880 , vraisemblablement par Cresson lui-même. Selon JeanLoïc Le Quellec (2009) le procédé qui consiste à se procurer ... de véritables pièces archéologiques pour les modifier à leur gré [est] courant chez les meilleurs faussaires (p. 121). Des comparaisons stylistiques avec un mauvais relevé du mammouth de La Madeleine publié aux États-Unis par Charles Rau (1876) montrent de très nombreuses similitudes (fig. 9). La découverte a été manifestement antidatée à 1864, pour qu'elle apparaisse contemporaine de celle de La Madeleine. Dans cette affaire, il n'y a guère de doute sur la culpabilité de Hilborne T. Cresson qui était un voleur de pièces archéologiques et qui a même été exclu pour cela des fouilles conduites par le Peabody en 1891, avant de se suicider en 1894.

Un autre objet célèbre est la pierre dite Lenape Stone (fig. 10). Selon Le Quellec (2009 - p. 121) elle ressemble à un gorgerin amérindien (sorte de protège-cou) qui est un élément de parure poli et percé (deux trous de suspension), porté sur la poitrine ou servant de pendentif et souvent trouvé en contexte funéraire. La forme de l'objet, en schiste ardoisier, est assez répandue en Amérique. Il est constitué de deux morceaux, supposés avoir été découverts en 1872 (plus grand fragment) et en 1881 sur une ferme du village de Doylestown (Bucks County) en Pennsylvanie par un jeune fermier, Barnard Hansell. L'inventeur vend l'objet en 1881 au Colonel Henry D. Paxson. II est aujourd'hui conservé au Mercer Museum de Doylestown. La pièce est publiée en 1885 par Henry Chapman Mercer, archéologue et ethnologue américain et conservateur au Musée de Philadelphie (1885). Ce dernier confie plus tard à Thomas Wilson qu'il ne voit aucune raison de nier l'authenticité de la Lenape Stone. La pièce est ornée sur une face d'un mammouth poursuivi par des chasseurs dont un est muni d'un arc et d'une flèche et sur l'autre face de figures 

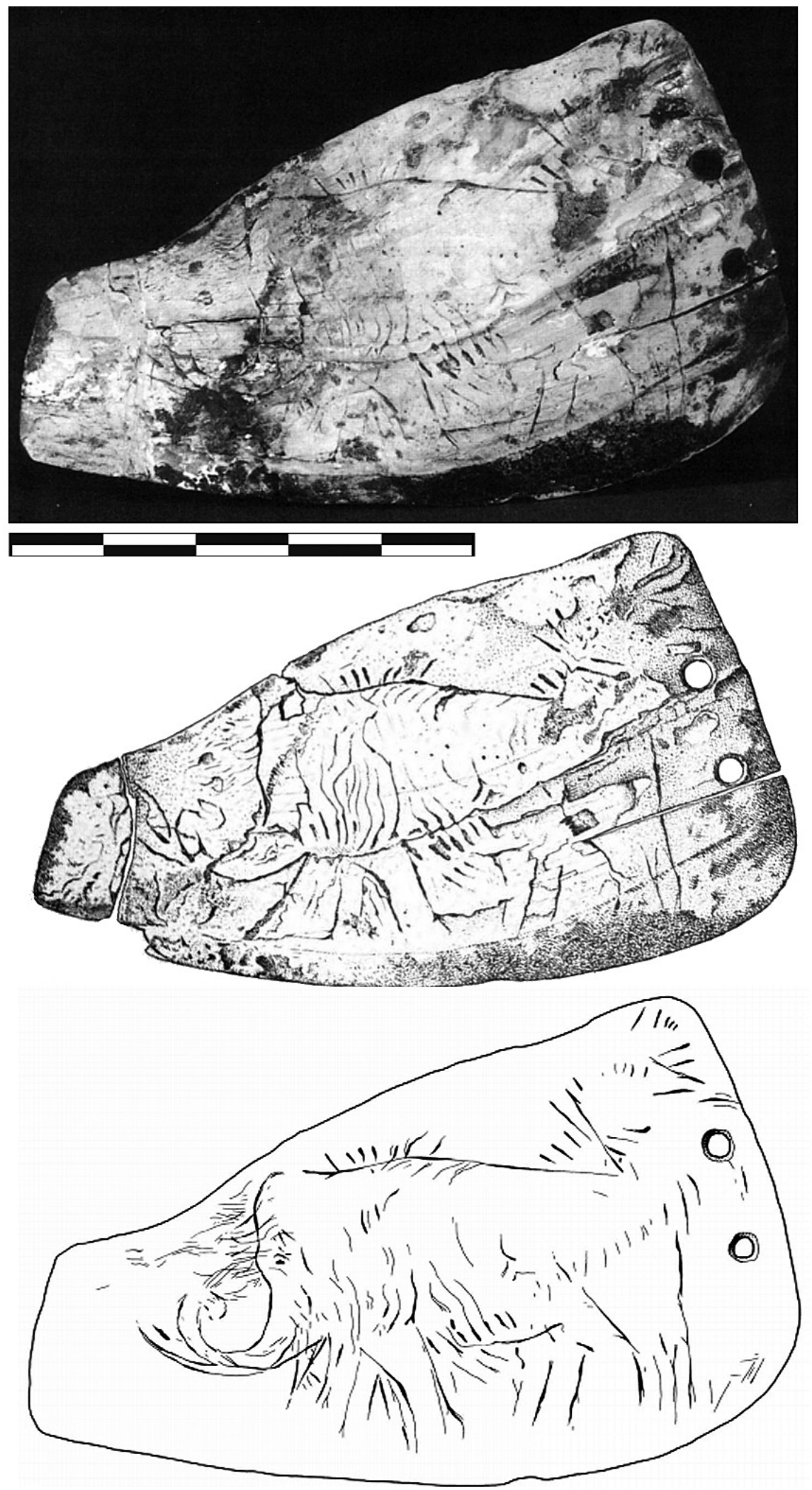

Figure 8 - Faux « mammouth » gravé sur un coquillage marin, Holly Oak (Delaware, Etats-Unis). (C) Cliché et relevé Thomas Wilson (1898).

Figure 8 - Fake « mammoth » engraved on a marine shell, Holly Oak (Delaware, USA) @ Image and tracing Thomas Wilson (1898). 


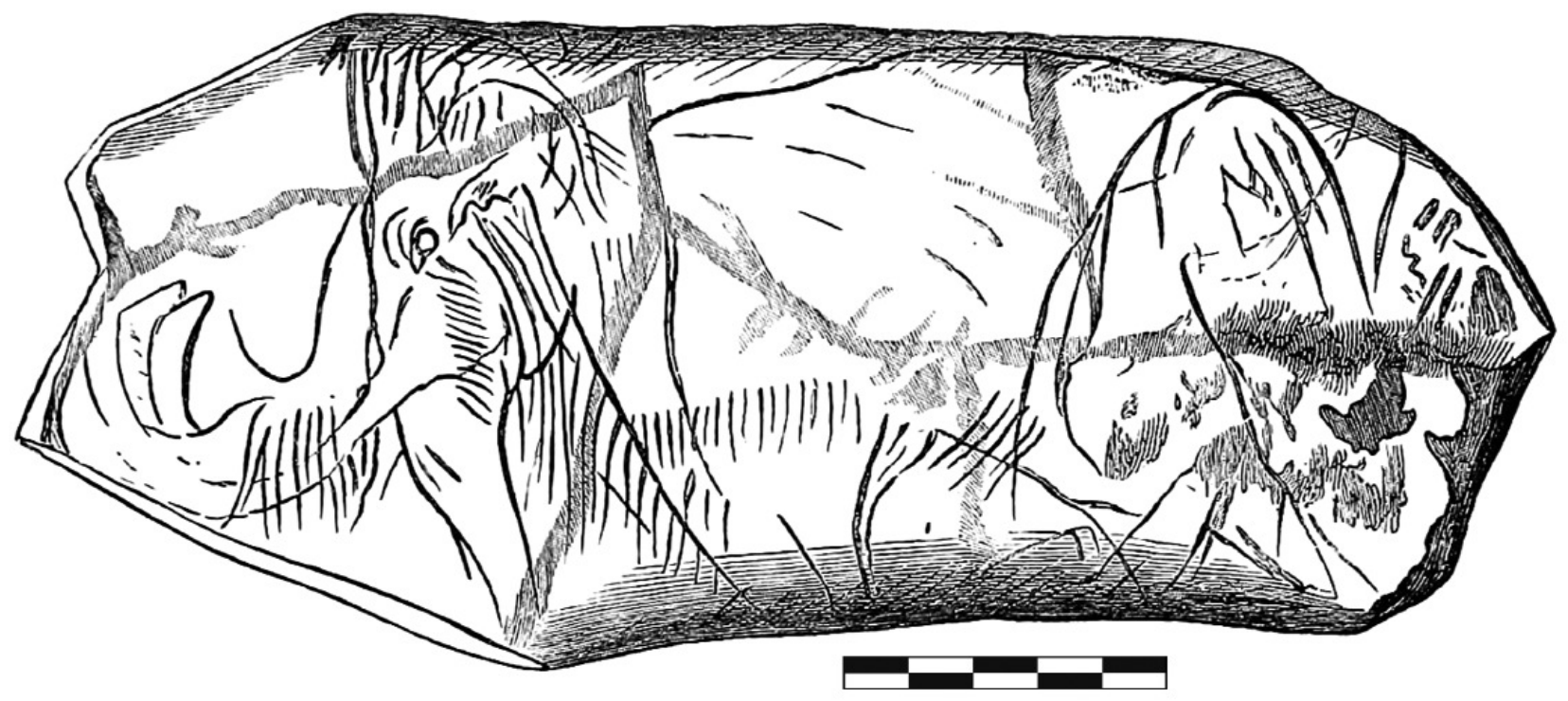

Figure 9 - Le Mammouth de La Madeleine. Relevé Charles Rau (1876).

Figure 9 - La Madeleine mammoth. Tracing Charles Rau (1876).

animales (cerf, tortue, poisson, oiseau, serpent) et d'objets stylisés (pipe, tomahawk, étoile, calumet, etc.). Selon Vayson de Pradenne (1932) l'objet ressemble beaucoup par son mode de fabrication à ... des pendentifs récents alors qu'[il] devrait appartenir à une période ancienne ... (p. 138). Par ailleurs le décor lui semble franchement suspect. II écrit que ... le fait que seule parmi ses semblables elle porte un dessin gravé de ce genre ; l'aspect même du dessin qui par ses caricatures humaines stylisées, par la représentation d'un paysage complet, par quelques détails comme l'œil du mammouth, par la figuration fantaisiste du soleil, de la lune et des étoiles, évoque beaucoup plus le travail d'un mystificateur moderne que celui d'un artiste quaternaire. En face de ces graves présomptions, pour les combattre, qu'y a-t-il ? Les dires d'un individu inconnu qui a soi-disant trouvé la pièce à la surface du sol. C'est plus qu'insuffisant. On notera le récit de la découverte en deux fois, donné comme gage de sincérité mais après coup (p. 138). II nous semble clair que les prétendues gravures quaternaires américaines ne méritent pas le même crédit que celles trouvées en France (p. 138). Spectacle extraordinaire que celui gravé sur la Lenape Stone. On y voit tout un paysage dominé par un soleil, une lune et des étoiles, peuplé de sapins, de tipis et de chasseurs armés d'arc et de lances, affrontant un terrible mammouth. Mais de qui se moque-t-on ? H. Carvill Lewis, Professeur de Minéralogie à l'Académie des Sciences Naturelles de Philadelphie, examine l'objet en 1884 et conclut que la plaquette est authentique mais que le dessin du mammouth est directement inspiré de la pièce d'ivoire découverte à La Madeleine. II suffit de retourner l'animal vers la gauche pour se rendre compte de la ressemblance. F.W. Putman déplore le traitement subi par l'objet qui empêche toute analyse. Quant à M.E. Wadsworth, il suggère l'utilisation d'un outil métallique et montre que les traits gravés sont certainement récents. Ces témoignages sont publiés par Mercer en appendice de sa publication de 1885 et confirment, s'il en était besoin, que le décor de la Lenape Stone est une falsification.

Que penser enfin des deux têtes de pipes en calcaire sculptées de figures "éléphantines 》 (elephant pipes) découvertes dans le comté de Louisa dans l'lowa, l'une dans un champ en 1872-1873 (fig. 11) et l'autre dans un tertre amérindien en 1880 (fig. 12) ? Les conditions obscures de ces deux découvertes, ... à une époque où la question de l'ancienneté relative de l'homme et du mammouth en Amérique du Nord était toujours au cœur de vifs débats ... (Le Quellec 2009 - p. 127), ne font nullement douter. II s'agit de faux ou d'images mal interprétées. Le style particulièrement maladroit de la première figuration découverte hors de tout contexte archéologique, le fait que la seconde figure nous semble être un animal indéterminé et enfin, l'absence totale de restes osseux, de dents et d'ivoire de mammouths parmi les milliers d'objets sculptés découverts lors de la fouille des tertres ôtent tout intérêt archéologique ou plutôt toute dimension préhistorique à ces objets.

La quête du mammouth, du mastodonte ou de l' « éléphant impérial » devient une obsession et on ne compte plus les gravures rupestres de la région de Moab (Utah), les " tertres-géoglyphes » de l'lowa ou du Wisconsin et même les sculptures et bas-reliefs mayas ou olmèques ainsi interprétés. Comme le souligne Jean-Loïc Le Quellec (2009), cette poignée d'œuvres ou d'ouvrages mal analysées est utilisée par les créationnistes américains dans leur combat contre l'évolutionnisme (p. 105). 

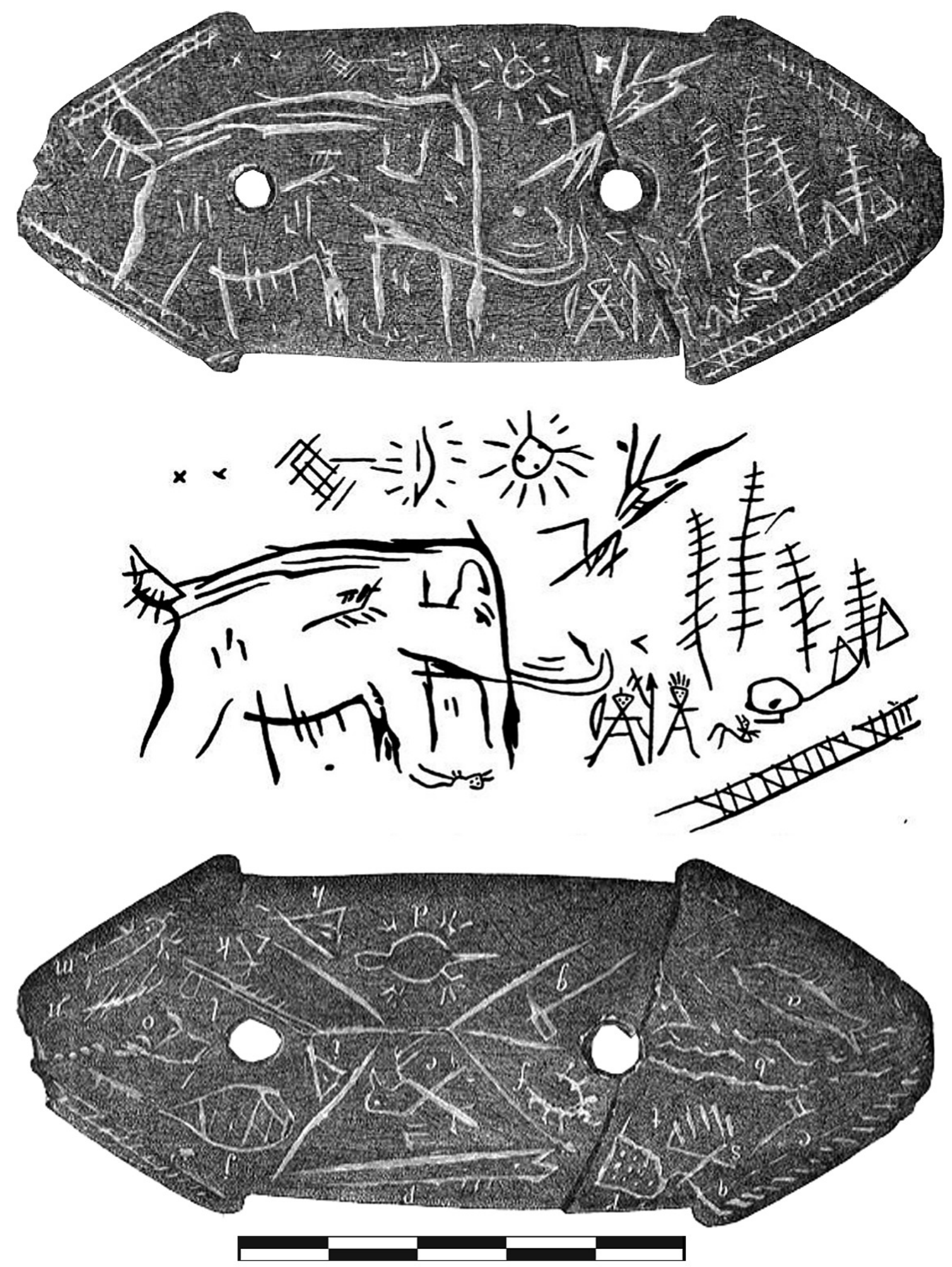

Figure 10 - Faux « mammouth » et autres représentations gravés sur schiste, Lenape Stone (Pennsylvanie, Etats-Unis). (C) Clichés et relevé Henry Chapman Mercer (1885).

Figure 10 - Fake " mammoth » and other engraved figures on a slate, Lenape Stone (Pennsylvania, USA). ( I Images and tracing Henry Chapman Mercer (1885). 


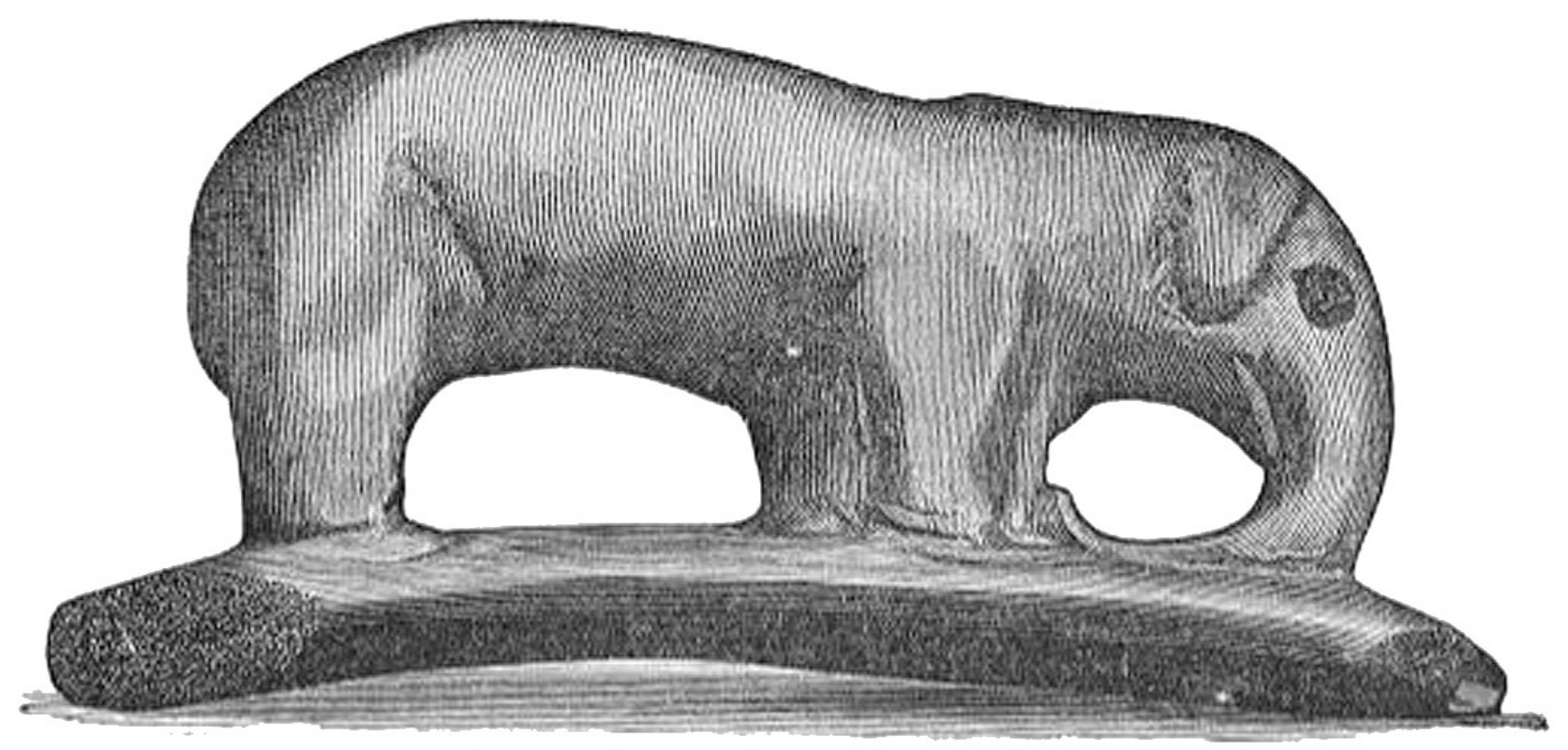

Figure 11 - Pipe en calcaire sculptée d'une fausse figure " éléphantine » (Elephant pipe) (lowa, Etats-Unis). Dessin Henry Chapman Mercer (1885).

Figure 11 - Elephant pipe on limestone (lowa, USA). Drawing Henry Chapman Mercer (1885).

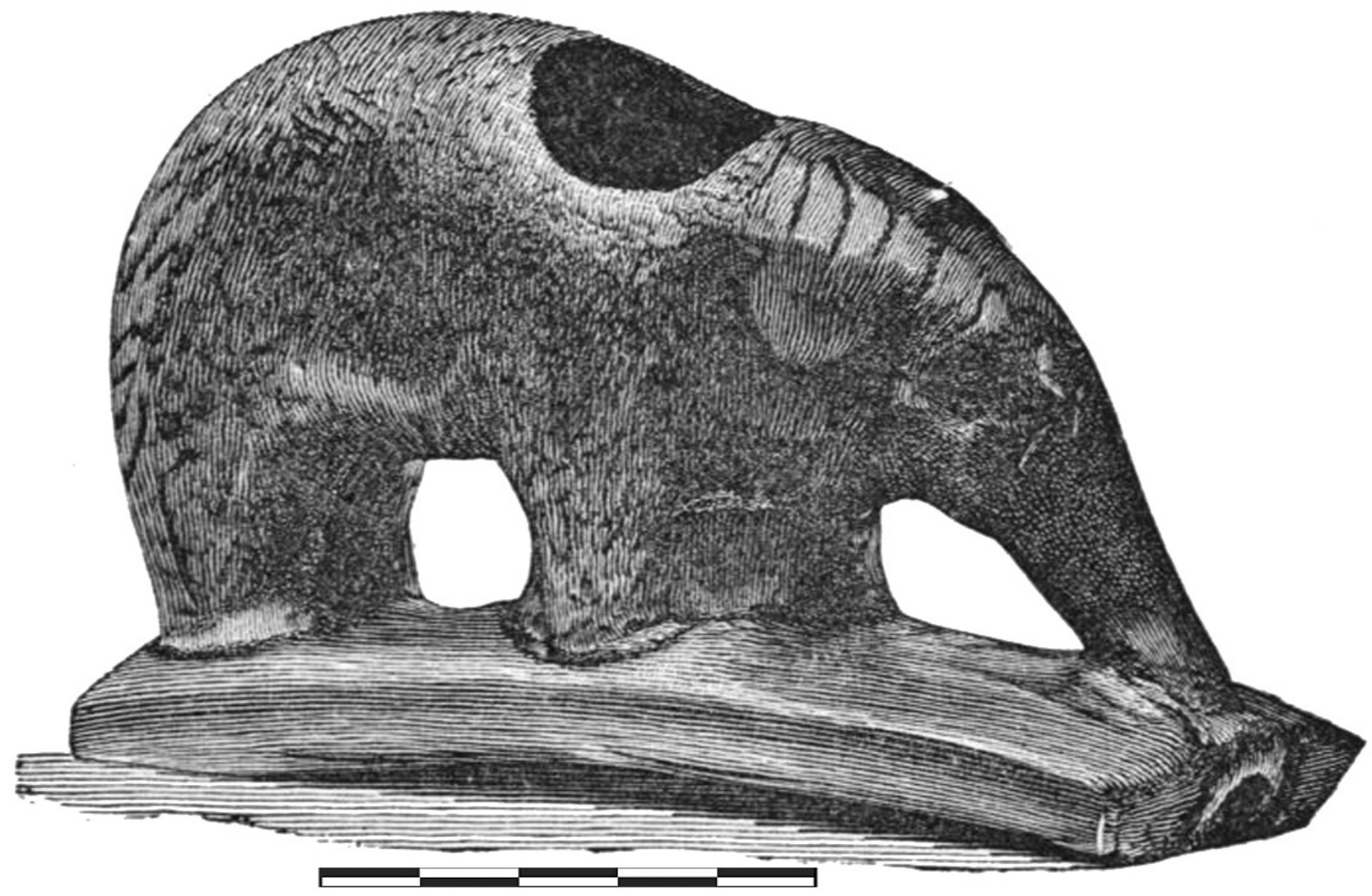

Figure 12 - Pipe en calcaire sculptée d'une figure dite « éléphantine » (Elephant pipe) (lowa, Etats-Unis). Dessin Henry Chapman Mercer (1885).

Figure 12 - Elephant pipe on limestone (lowa, USA). Drawing Henry Chapman Mercer (1885). 
Voilà 146 ans que le mammouth de La Madeleine a été découvert et rien encore en Amérique du Nord. Toutes les tentatives d'escroqueries ont échoué. Force est de reconnaître que les paléoindiens de culture Clovis, qui ont chassé le mammouth, ne l'ont jamais représenté. Enfin, le croyait-on jusqu'en février 2009, date à laquelle était annoncée la découverte d'une gravure de mammouth (bien entendu !) dans le site paléoindien de Old Vero Site (Vero Beach) en Floride (fig. 13). Le site est connu depuis 1915 pour avoir livré des restes d'animaux fossiles et d'humains datés d'environ 13000 ans, ainsi que quelques artefacts lithiques et osseux et même deux morceaux de défense d'Éléphantidés et un fragment d'os portant des marques intentionnelles (?) (Sellards 1916). La gravure de mammouth récemment identifiée est exécutée sur un fragment d'os long d'un animal appartenant à la faune pléistocène (mammouth, mastodonte ou paresseux géant).
Enfin une représentation d'un animal disparu est au rendez-vous avec un support fossile. Les dateurs n'ont qu'à bien se tenir. Mais là encore, des doutes sérieux subsistent sur l'authenticité de cette gravure dont on a fait d'emblée sur internet le plus vieil objet d'art d'Amérique et, très naturellement de son auteur, le plus vieil artiste des Amériques. II est d'abord regrettable que les conditions de la découverte ne soient pas scientifiquement réunies, comme souvent en pareil cas. L'objet aurait été découvert dans le canal principal de Vero Beach en 2005 par un certain James Kennedy, collectionneur et chasseur de « trésors » paléontologiques. De quoi éveiller quelques soupçons. Finalement, la chasse aux œuvres d'art préhistorique américaines réussit plus aux «innocents » qu'aux professionnels. L'objet a été expertisé plus d'une fois et plusieurs méthodes de micro-analyses modernes (REE - analyse des éléments traces et EDS - spectrométrie

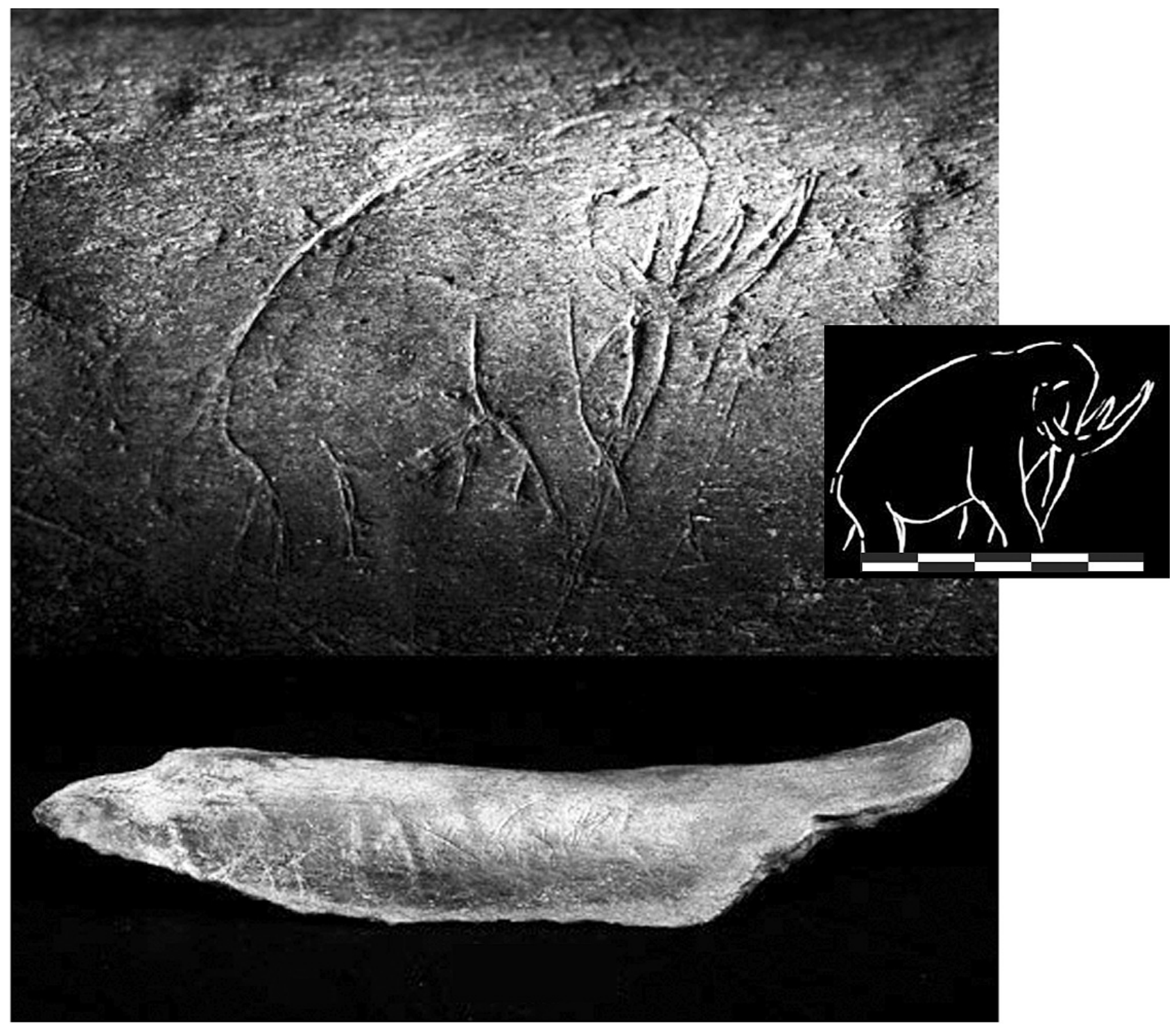

Figure 13 - « Mammouth » gravé sur os, Old Vero Site (Vero Beach, Floride, Etats-Unis). @ Cliché « news.nationalgeographic.com » (2009).

Figure 13 - engraved " mammoth » on bone, Old Vero Site Nero Beach, Florida, USA) () image " news.nationalgeographic.com » (2009). 
en énergie) lui ont été appliquées. L'os est ancien, il est même fossile, mais quid de la gravure ! Pour l'instant, aucun article scientifique n'a été publié à son sujet et nous attendons de Barbara A. Purdy, Professeur d'Anthropologie à l'Université de Floride et spécialiste des peuplements anciens de cette région, plus que quelques notes sur internet (2009) et certainement, ainsi qu'elle le souhaite, une reprise des fouilles sur ce site prestigieux.

En Europe, il semble aussi que le mammouth de La Madeleine ait inspiré les faussaires. Paul Raymond rappelle la découverte en 1904, dans une grotte sépulcrale des Cévennes, d'un maxillaire de cervidé gravé d'un protomé de mammouth (fig. 14). L'os était associé à des outils de silex, des éléments de parure, du pigment rouge et des ossements humains qui étaient pour partie authentiques mais provenaient des riches sépultures néolithiques de la région. ... L'animal avait été imité d'une façon parfaite. Le trait, à vrai dire, était malhabile, non quant au dessin qui dénotait, encore une fois, un véritable artiste, mais il était trop large ... Restait à savoir de quel modèle le faussaire s'était inspiré. Ce mammouth étant celui de La Madeleine, on pouvait penser que c'était le célèbre ivoire de cette station qui avait servi de modèle, mais il est représenté en sens inverse ... Feuilletant un jour les Eléments de zoologie de Paul Gervais (1871) ... je retrouvais transposé le mammouth de La Madeleine ... (Raymond 1907 - p. 316).

André Vayson de Pradenne (1932) indique que le SudOuest, fertile en trouvailles l'a été également en faussaires ... C'est surtout le Périgord qui a connu les succès des faussaires. L'intérêt soulevé par les œuvres d'art quaternaires et les hauts prix qu'elles atteignirent dès le début, rendaient la fraude bien tentante (p. 276). Afin d'illustrer son propos, il mentionne une pièce qui appartenait à Édouard Lartet et qui a été publiée par son fils (Louis Lartet 1874 - p. 33-36). II s'agit d'une plaque d'os gravée sur les deux faces de silhouettes de mammouths, conservée au Musée d'Archéologie Nationale (fig. 15). É. Lartet, qui a conservé cette pièce, y attache un intérêt particulier et ne la montre que dans l'intimité. II raconte cette histoire à Gabriel de Mortillet qui, dans la revue L'Homme (1885 - p. 518), en fait le récit suivant (également reproduit par Robert Munro 1905 - p. 41-42). Lors de leurs premières fouilles aux Eyzies et dans les environs, Édouard Lartet et Henry Christy logeaient à l'Hôtel du Midi aux Eyzies (propriété d'Alain Laganne, que Mortillet disait très intelligent et très bon vivant). Pendant de longues soirées d'automne, tout en se chauffant au coin du feu, on discourait ; Lartet et surtout Christy s'indignaient de voir certaines personnes douter de leurs découvertes et surtout supposer qu'ils étaient victimes d'une mystification.

- Nous parierons volontiers le champagne qu'on ne parviendrait pas à nous tromper.

\section{- Accepté, dit Laganne.}

"Quelques jours après, Laganne rentre à son hôtel tout couvert de boue, comme un homme qui a passé la journée à fouiller. II verse sur la table, devant Lartet et Christy, de nombreux os et des silex plus nombreux encore contenus dans un havresac. Les os sont triés, on les lave et l'on découvre la fameuse plaque aux silhouettes d'éléphant. Grandes exclamations ; tout le monde admire cette belle pièce quand Laganne tout triomphant s'écrie : Très bien, vous y êtes pris ; offrez-moi le champagne. C'est moi qui ai fabriqué la pièce devant laquelle vous vous extasiez.

Ce récit n'est pas pris au sérieux par Marcellin Boule (1905 - p. 319-320) ni par Henri Breuil (Breuil et al. - p. 282). Ils persistent à penser que ces deux mammouths sont authentiques. Boule invoque à l'appui de sa thèse le

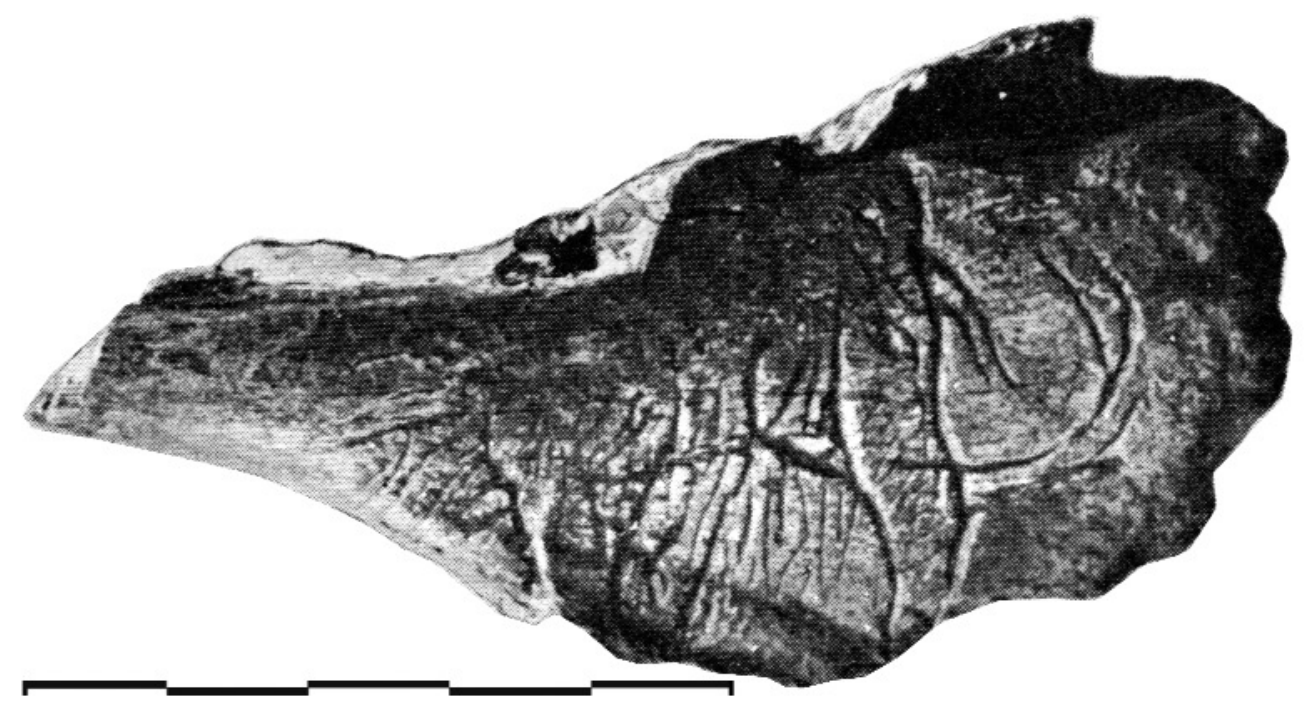

Figure 14 - Faux « mammouth » gravé sur os, Grotte sépulcrale des Cévennes. @ Cliché Paul Raymond (1907).

Figure 14 - Fake engraved " mammoth » on bone, burial cave in Cevennes () Image Paul Raymond (1907). 

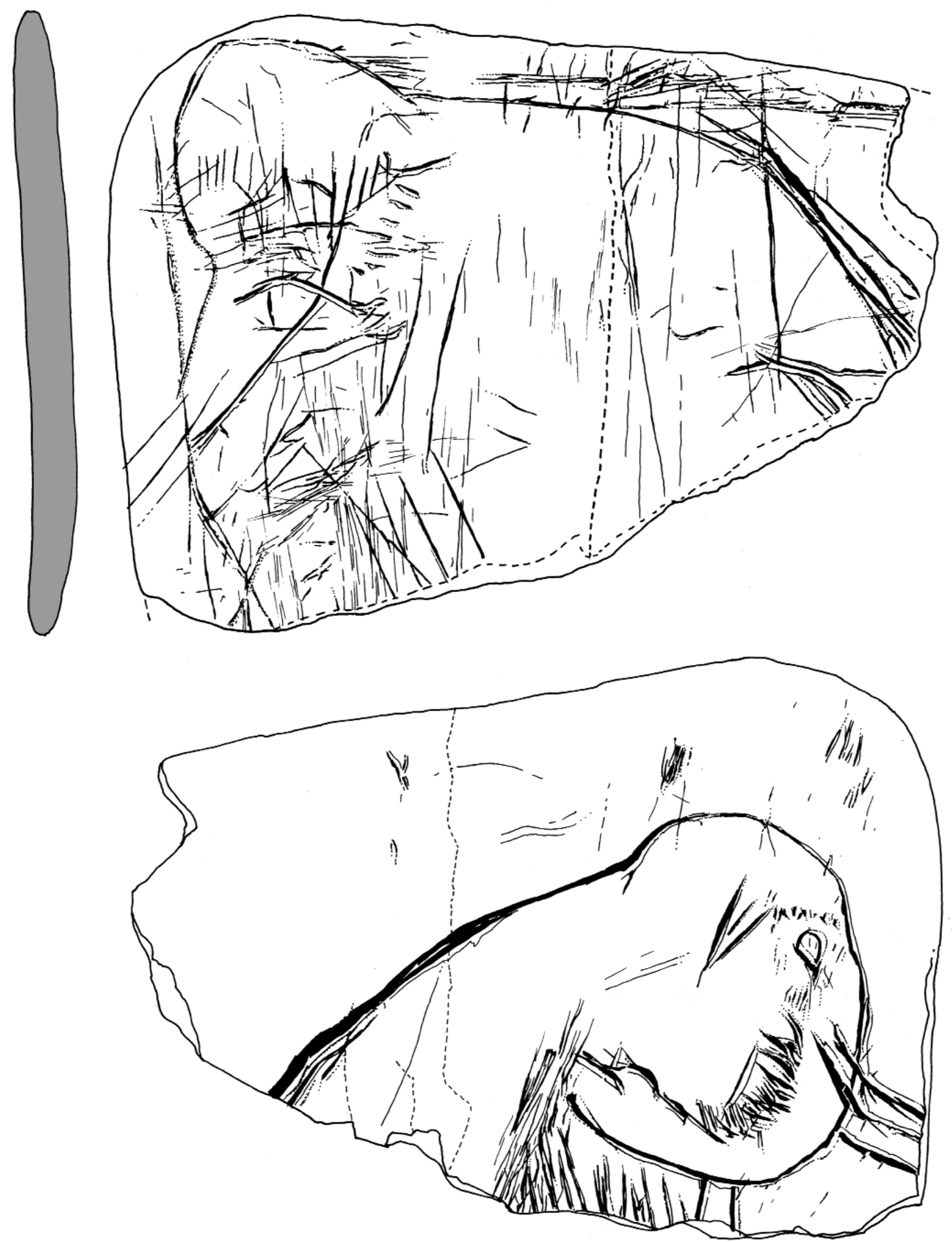

Figure 15 - «Mammouths » gravés sur os, Les Eyzies (Dordogne). Relevé Patrick Paillet (2010).

Figure 15 - « mammoths » engraved on bone, Les Eyzies (Dordogne). Tracing Patrick Paillet (2010). 


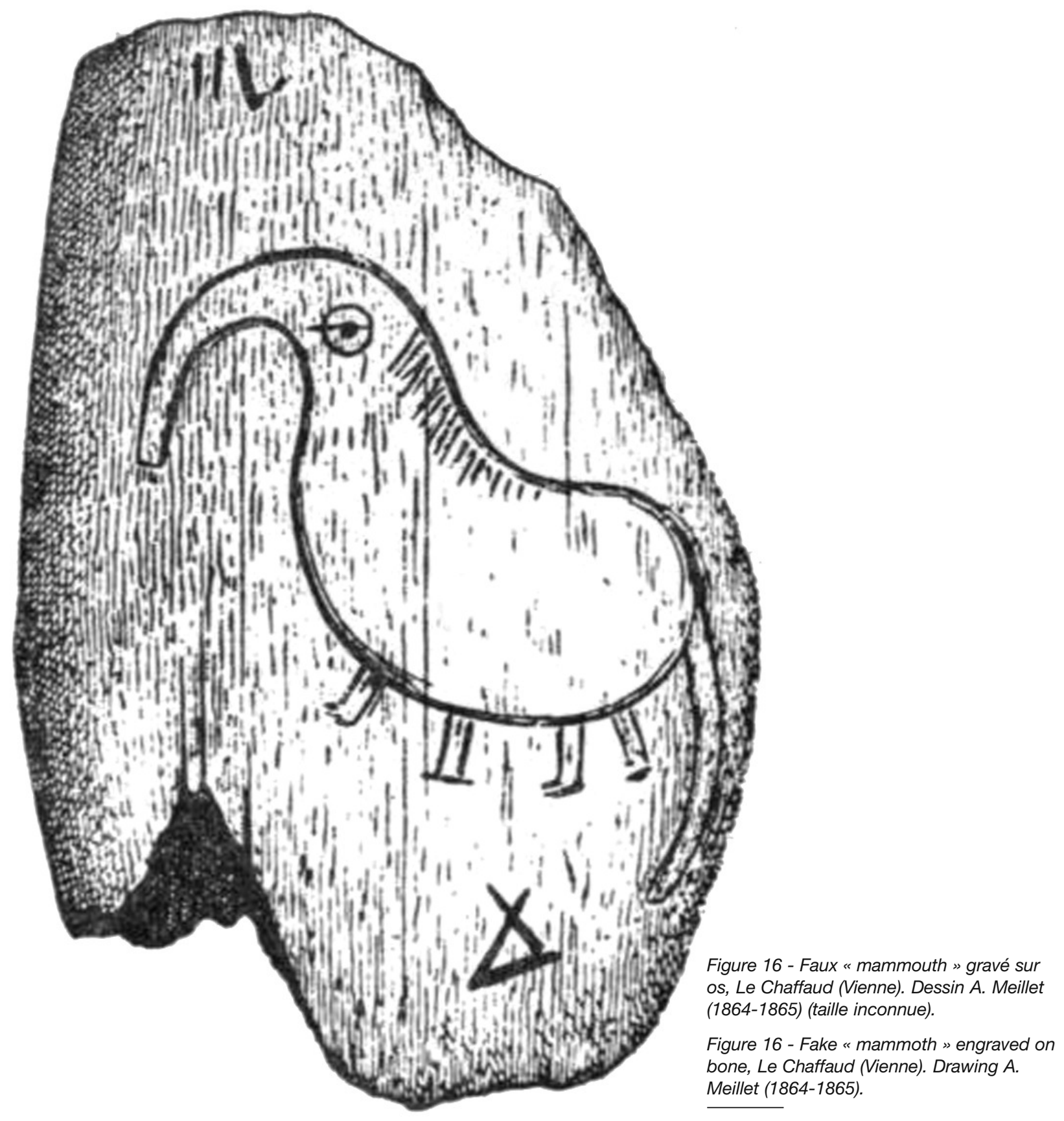

sérieux, la finesse d'esprit et la prudence scientifique de Louis Lartet. Dans la note que ce dernier consacre à l'objet, il ne lui fait aucun doute que les gravures sont préhistoriques. Une chose est certaine, au moins : Édouard Lartet attachait à cette mince plaque d'os polie un intérêt tout particulier. La pièce ne provenait pas de ses fouilles mais d'un " abri du Périgord ", sans plus de précision. Après une courte description des deux figures, Louis Lartet écrit que ... Nous avons cru, malgré l'incertitude qui plane encore sur l'origine précise de la gravure ... devoir la faire connaître, car son âge et son authenticité ne paraissent pas devoir être mis en doute ... (1874 - p. 35). II s'agit d'une œuvre très curieuse dans son style et son expression. Les conditions de sa découverte sont floues et l'historiette racontée par G. de Mortillet (Boule 1905) est troublante. Nous entreprendrons prochainement une nouvelle étude de cette pièce.

En revanche, le doute n'est pas permis devant ce « mammouth » si naif et tellement ridicule, supposé provenir de la grotte du Chaffaud et publié par A. Meillet comme nous l'avons rappelé plus haut dans le volume 2 des Époques antédiluviennes et celtiques du Poitou (18641865), parmi bien d'autres faux grossiers (fig. 16). Interrogeons-nous simplement sur l'honnêteté scientifique d'A. Meillet, ainsi que le suggère Gabriel de Mortillet 
(Leguay 1867 - p. 325-326), Paul de Vibraye et Adrien de Mortillet (Chenet 1929 - p. 78-80).

\section{8 - Le mammouth de La Madeleine aujourd'hui}

\section{1 - Brève anatomie d'une espèce disparue}

II est temps maintenant de se pencher un peu sur le modèle de l'artiste de La Madeleine et dégager ce qui en constitue les caractéristiques morphologiques remarquables. Denis Vialou (2004 - p. 154-159) parle d'un profil de rêve (fig. 17). Voilà à quoi le mammouth ressemble vraiment. Son profil est en courbes et ses trains avant et arrière sont asymétriques. L'animal est arrondi et il se distingue par sa masse bien campée, ses appuis massifs et sa dense toison laineuse. II oppose un certain statisme sculptural et une gracilité parfois animée par les défenses, la trompe et l'œil. L'animal est marqué par une forte disharmonie antéro-postérieure. L'arrière se dérobe sous les imposants thorax et abdomen. Le corps est porté vers l'avant en une masse unique qui englobe les antérieurs, le poitrail et la face. II est couronné par un dôme crânien saillant et assez étroit. Le garrot puissant surmonte le dos et les lombes en pente forte vers l'arrière-train. Entre le vertex et le garrot se loge une brisure cervicale ou dépression nucale plus ou moins anguleuse et profonde. $\mathrm{Ce}$ segment de la charpente anatomique signale le mammouth de loin dans son environnement et le caractérise également dans son expression graphique la plus schématique.

Les détails corporels les plus significatifs sont ceux qui donnent à la bête, naturellement statique sur ses quatre piliers (membres) achevés par des pieds en « champignon renversé », un semblant de mouvement ou de vie. L'œil est souvent expressif quand il est présent sous forme d'un cercle ou d'un ovale, inséré dans son orbite triangulaire ou en amande. Au niveau de l'orbite, le front est saillant. À l'opposé, la queue est naturellement petite. Elle se termine en fuseau garni de longs poils. C'est dans sa partie basale que se situe la valvule ou opercule anal qui fait défaut dans la très grande majorité des mammouths figurés. La queue n'a pas toujours fait l'objet d'une grande attention de la part des artistes préhistoriques. La trompe, dont la mobilité exprime une grande variété de comportements et qui est un organe majeur par ses multiples fonctions (Pales 1989 p. 62), est sporadiquement représentée en mouvement (tendue vers l'avant, enroulée ou rabattue sur le flanc). Beaucoup plus souvent, elle tombe à la verticale jusqu'au sol. Son extrémité est bilobée. Elle s'achève par deux appendices, l'un « digitiforme » et l'autre « labriforme », exceptionnellement figurés. Enfin, malgré la difficulté de représenter les défenses de profil, leur dimension remarquable et leur courbure sont souvent exagérées, apportant vigueur et emphase. Le mammouth possède de très petites oreilles qui n'ont pratiquement jamais été figurées. II est enfin très velu. Une toison laineuse ou bourre couvre le corps et se double de jarres longs et raides au niveau notamment des joues, de la lèvre inférieure, des pattes, du ventre, du dos, du poitrail et des épaules (Prud'homme et Mémoire 1990 ; Barrière 1993 ; Bahn et Lister 1995).

\section{2 - Le support}

Jusqu'à récemment, l'objet lui-même n'avait guère suscité l'intérêt des auteurs. Nous l'avons vu, l'ivoire a permis de prouver la coexistence de l'homme préhistorique et des animaux disparus. Mais rien n'est vraiment dit de précis sur le fragment de défense qui porte la gravure de mammouth. On apprend simplement qu'il s'agit d'une plaque ou d'une antique lame d'ivoire. Elle est ... brisée en plusieurs morceaux [fractures survenues lors de la découverte], dont quelques fragments étaient incrustés par la cuisson dans du lehm ossifère durci par une imprégnation de chaux (Büchner 1872 - p. 114). Lartet et Christy ajoutent qu'il s'agit de la partie de la couche externe d'une défense de mammouth. C'est une pièce mince et allongée, convexe d'un bord à l'autre suivant la rotondité de la défense et légèrement concave dans le sens de la longueur du fait de sa courbure (1865-1875 - p. 168). Selon Jean-Marc Bouvier, la gravure, parfaitement cadrée dans les limites du support et vraisemblablement exécutée sur le fragment de défense que nous connaissons actuellement, ne serait possible que sur de l'ivoire frais (1977 - p. 40).

Dans un article concernant les objets en ivoire $d u$ Paléolithique supérieur conservés au Muséum national d'Histoire naturelle, Denis Vialou (1995) consacre plusieurs lignes à cet objet. La pièce est composée de six morceaux, anciennement et imparfaitement collés [...] Les fractures proximales sont postérieures à la gravure du mammouth qu'elles interrompent. En revanche, le cadrage de l'animal indique que le support original n'était probablement guère plus large que l'actuel et que l'extrémité distale avait été fracturée avant l'exécution de la gravure (p. 88). Hormis quelques traces d'altérations, la face supérieure (face externe de la défense), lisse et compacte, est bien conservée. Selon Vialou, l'absence de texture contraignante et d'irrégularité de surface en fait un support particulièrement favorable à la gravure. Par ailleurs, la surface est large et faiblement convexe, meilleure encore que les omoplates de grands herbivores. Vialou décrit aussi la face interne de la défense qui conserve les traces du délitage de l'ivoire et sa structure naturelle rainurée. II en conclut que le support était déjà évidé ou exfolié quand il a été découpé. L'ivoire était donc fossile au moment de la gravure. Son épaisseur actuelle doit être proche de l'épaisseur d'origine.

Dans la même publication, François Poplin apporte des informations complémentaires et précises sur le délitage de l'ivoire (1995 - p. 17-27). En premier lieu, Poplin nous apprend qu'une telle plaque ou squame (fig. 18) ne peut être détachée de l'ivoire frais. Une défense fraîche ... invite au traitement dans la masse et en surface [...]. Les ... cornets ou cônes d'ivoire emboîtés [d'une défense en bon état] sont solidaires, de sorte qu'il n'apparaît qu'une masse homogène, dont la section transversale présente un motif en cœur de marguerite propre aux Proboscidiens (p. 20). L'ivoire frais et compact ne produit pas de squames. En vieillissant, les différentes couches constitutives de la défense se séparent ou se morcellent et en premier lieu la couche de cément, épaisse de près d'un centimètre. L'ivoire se délite ou se délamine. II se 


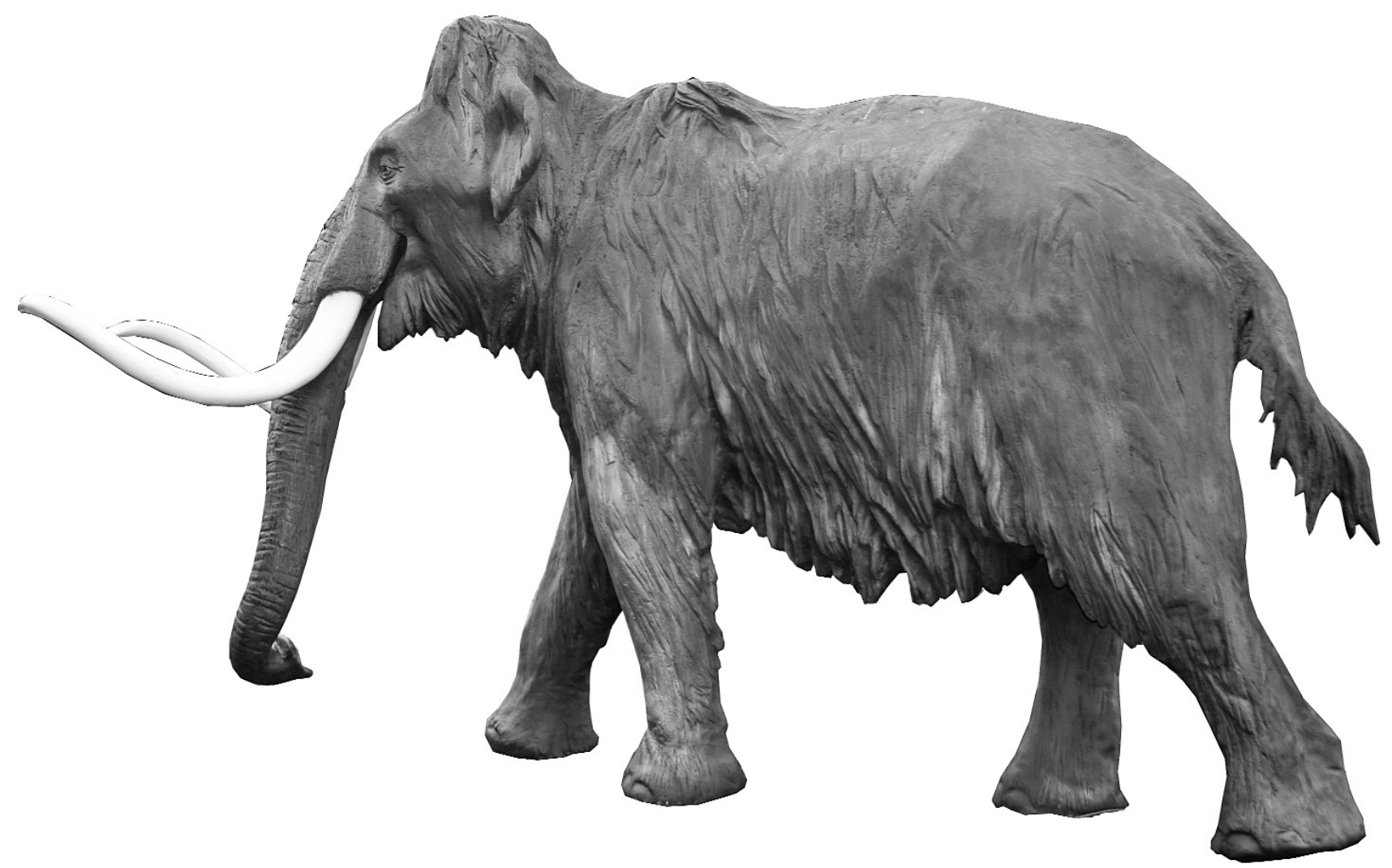

Figure 17 - Mammouth reconstitué (Muséum national d'histoire naturelle). () Cliché Patrick Paillet.

Figure 17 - Reconstitution of a mammoth (Muséum national d'histoire naturelle). () Image Patrick Paillet.

défait naturellement sous les effets de l'intempérisation et économise ainsi du travail à l'artiste qui dispose alors de préformes. En vieillissant [l'ivoire] se désagrège en donnant des éléments intéressants pour fabriquer des objets sans avoir à dégager ceux-ci par un long travail de la masse de la défense (1995 - p. 17). Dans les vieilles défenses collectées, soumises depuis longtemps aux intempéries, Poplin nous dit ... qu'on peut trouver de bons morceaux. Selon lui, le terme de lame, souvent utilisé dans la littérature ancienne à propos de l'ivoire de La Madeleine, ne convient pas car l'élément libéré n'est pas un lambeau plat, mais ... un cornet à axe recourbé qui s'emboîtait dans le cornet précédent et qui recevait le cornet suivant. La pièce est donc galbée ou légèrement cintrée en " tuile méditerranéenne » d'une épaisseur très régulière de $5 \mathrm{~mm}$ ou un peu plus (1995p. 19). La défense de La Madeleine montre clairement cette morphologie et laisse apparaitre des squames d'ivoire d'épaisseur plus ou moins égale (fig. 19). Mais le délitage n'est pas régulier ... à travers toute la masse de l'ivoire. Ici, une couche s'isole, là, deux ou trois le font d'un seul tenant. Et des fissures plus ou moins radiaires, comme dans les vieux troncs d'arbre, apparaissent, qui détachent les éléments de forme variée, allongés dans le sens de la défense, plus ou moins aplatis selon les squames ... (1995 - p. 22).

\section{3 - Le mammouth et ses relevés}

II n'existe pas beaucoup d'œuvres d'art mobilier paléolithique qui aient suscité autant d'intérêt que le mammouth de La Madeleine. Aujourd'hui encore, l'objet jouit d'une rare et légitime réputation que l'on doit aussi à l'abondance des publications et des reproductions de l'œuvre. Jean-Marc Bouvier recense cinquante articles ou livres comportant un relevé (inégal) de cette gravure. Et des dizaines d'autres en donnent la photographie (1977 - p. 57), ajoute-t-il. A de rares exceptions près (de Mortillet et de Mortillet 1881 ; Breuil et al. 1910 et surtout Pierre Laurent (in Bouvier 1977), les dessins publiés sont fort éloignés de l'œuvre et ne servent finalement que d'illustrations sans fondement et même sans prétention analytique et scientifique. On ne saurait reprocher aux anciens auteurs ces malfaçons alors que la pratique du relevé d'art (mobilier et pariétal) ne s'est systématisée que tard dans l'histoire de la discipline, avec les travaux de Henri Breuil notamment. Les dessins qui sont proposés jusqu'en 1910 (Breuil et al.) sont tous (ou presque) des copies plus ou moins interprétées, approximatives ou librement inspirées du relevé princeps publié en 1865. Elles sont plus éloignées encore de l'original qui n'a pas dû circuler beaucoup au moment où il a été déposé au service de Géologie du Muséum national d'histoire naturelle ${ }^{2}$ (Boule 1923 - p. 280-281).

(2) Avant d'être transféré en 1920 au service de Paléontologie, à la demande de Marcellin Boule et sur décision de l'ensemble des Professeurs du Museum. 


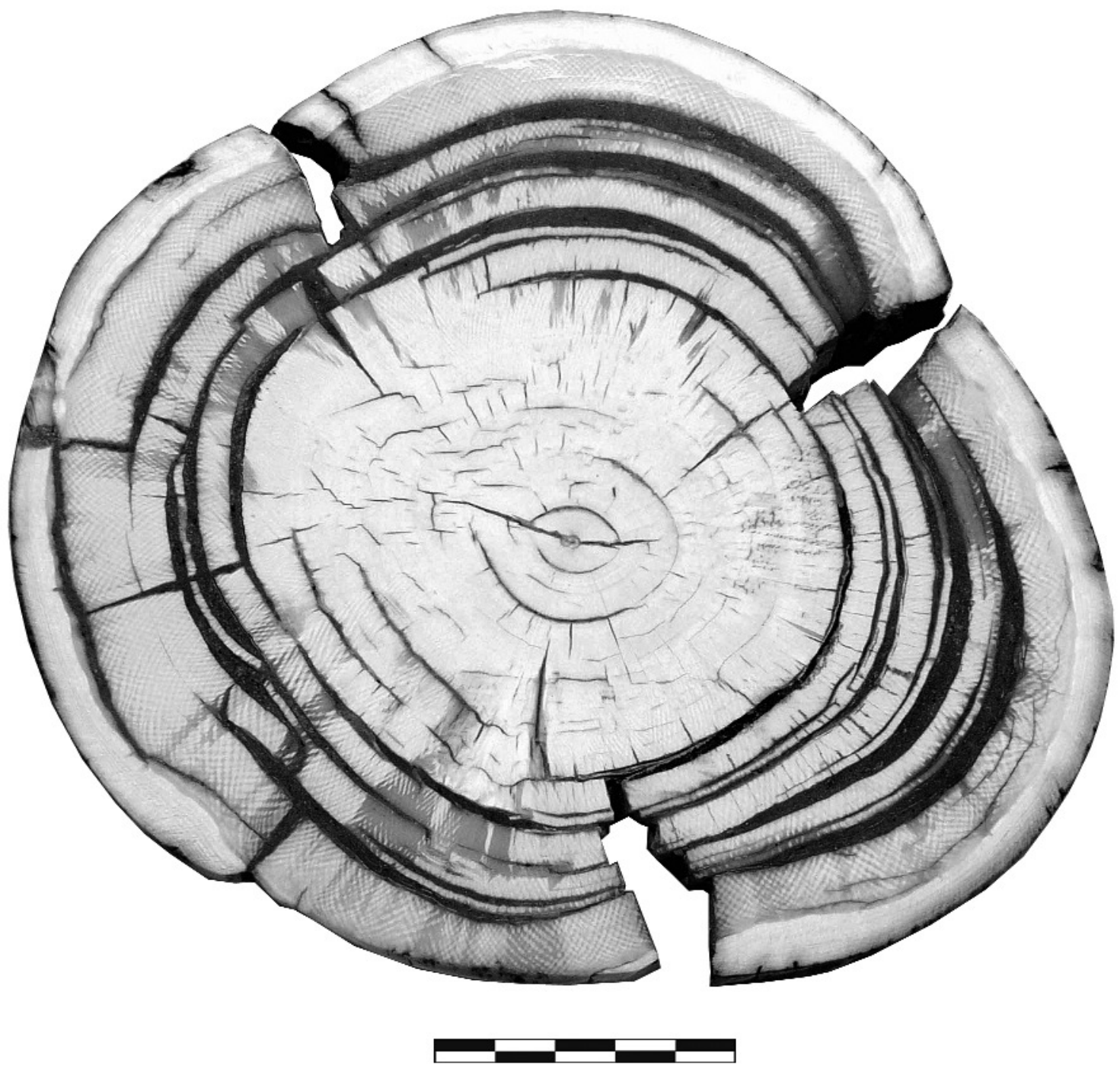

Figure 18 - Coupe de défense fossile de mammouth montrant le morcellement des squames. (C) Cliché Hannes Grobe, wikipedia.org (2009).

Figure 18 - Section of fossil mammoth defense showing the partition of the slates @ Image Hannes Grobe, wikipedia.org (2009).

L'essentiel est de figurer peu ou prou l'œuvre d'art par laquelle s'est produite la fameuse conversion du monde scientifique. II y aurait presque une étude à faire sur I'histoire des moulages de l'objet, si nombreux et souvent si mauvais (fig. 20). Le premier dessin a été effectué d'après une réplique de la pièce. On le voit précisément dans le traitement des contours et de la surface de l'objet (lissage et reconstitution des bords de la pièce, absence des détails relatifs aux recollages des cinq fragments), ainsi que dans le dessin lui-même, largement complété au niveau des recollages (fig. 21). Nous avons dit plus haut que les principaux tracés avaient été préalablement surlignés sur le moulage par Franks et avaient donc inspiré le dessinateur (Louveau). On ne saurait donc attendre de telles manipulations un rendu de l'original objectif et fidèle. C'est cette première chromolithographie, l'une des rares planches des Reliquiae Aquitanicae (Lartet et Christy 18651875) à avoir été confiée au bon soin des imprimeurs et lithographes anglais, M. et N. Hanhart, qui va être copiée des dizaines de fois, très rarement à l'identique, plus souvent dans des techniques, des styles ou des traitements personnalisés (fig. 22). Elle est parfois même reproduite à l'envers (Priem 1893-1894) (fig. 23). Quand ils ne simplifient pas le dessin ou quand ils ne négligent pas les caractères propres du support (fissures, écailles, collages, etc.), certains “ copistes » s'autorisent de curieuses libertés. Là, ils froncent un sourcil ou donnent à l'œil une pupille, ici ils effacent la saillie frontale et orbitaire ou dessinent une grande oreille, là encore ils accentuent le dôme crânien ou retracent le dos et le garrot. Le premier relevé publié par Breuil en 1906 (Cartailhac et al. 1906) et celui tiré de l'inventaire de l'art mobilier paléolithique du 


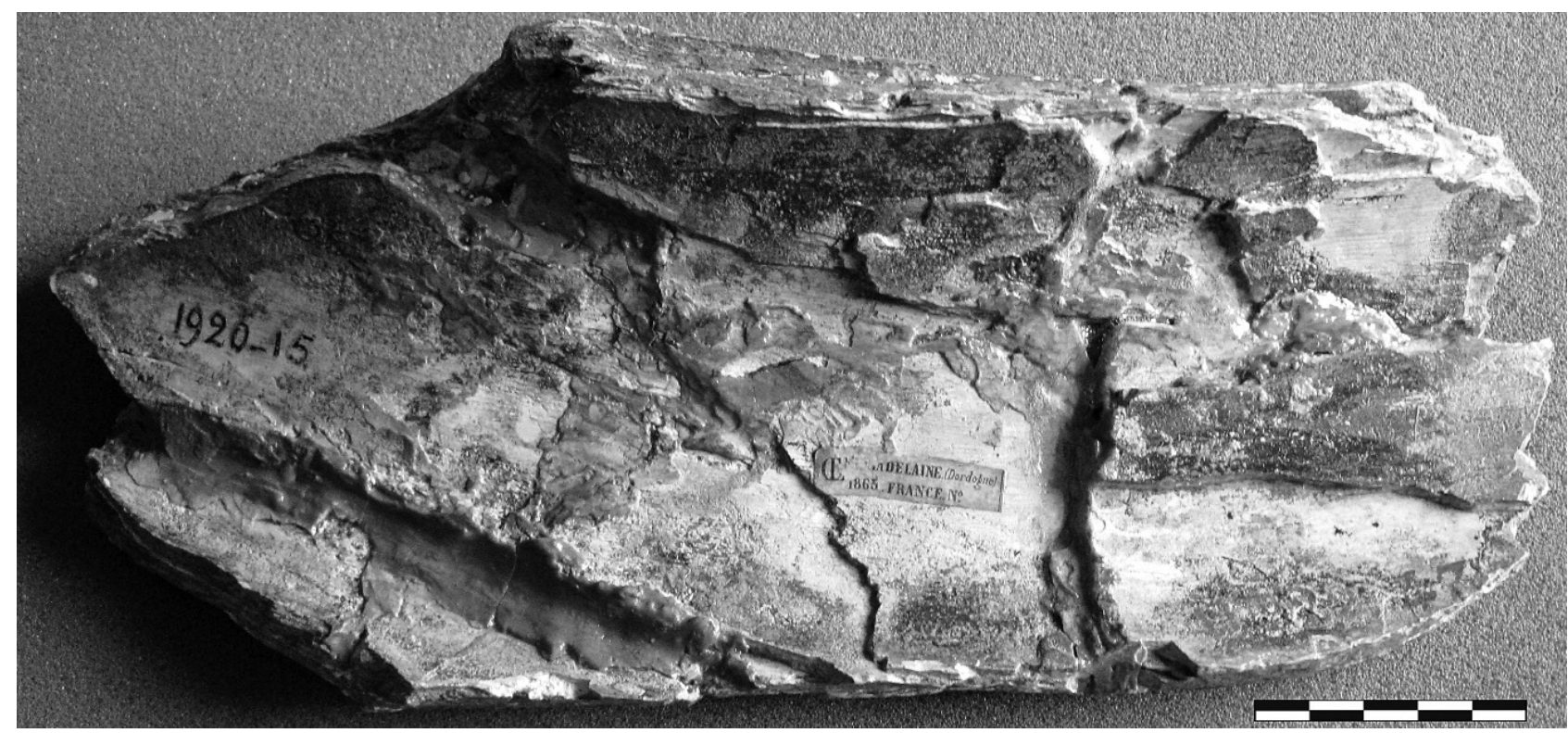

Figure 19 - Face interne de la défense de La Madeleine montrant des squames d'épaisseur différente. C Cliché Patrick Paillet (2009) avec l'autorisation du Département " Histoire de la Terre ", Muséum national d'histoire naturelle.

Figure 19 - Internal side of the La Madeleine defense showing the different thickness of the slates. (0) Image Patrick Paillet (2009) with authorization of the Department " Histoire de la Terre », Muséum national d'histoire naturelle.

Périgord publié par Suzanne de Saint-Périer en 1967 (fig. 24) ne sont que de pâles copies de la lithographie originale où le motif est isolé de son support. Finalement, les représentations qui s'affranchissent du modèle de 1865 sont rares. On notera au XIXe siècle l'excellent relevé (pour l'époque) exécuté par Adrien de Mortillet, vraisemblablement d'après un assez bon moulage, et publié dans Musée Préhistorique (G. et $A$. de Mortillet 1881, pl. XXVIII, $\mathrm{n}^{\circ}$ 212, p. 127-128) (fig. 25). Quelques détails comme la valvule anale, le pied arrière ou la pilosité traduisent la qualité d'analyse et d'interprétation du motif et du support. Ce relevé est repris dans de rares ouvrages plus récents (Wilson 1898) (fig. 26). A la même époque, une poignée d'auteurs publie un autre dessin inexact réalisé semble-t-il d'après la pièce originale, si l'on en juge par le tracé du bord droit de l'objet (fig. 27). Le mammouth, qui se dirige tantôt vers la gauche, tantôt vers la droite, présente un certain nombre de caractères originaux par rapport aux autres dessins. Les jarres du poitrail sont fortement soulignés. La tête, sur laquelle s'est focalisée l'attention du dessinateur, est partiellement dédoublée. Elle est complétée par une petite oreille inédite et un œil pupillé. Les autres détails sont réduits à des traits schématiques ou simplifiés sans respect de l'anatomie et du modèle.

Dans le fonds numérisé " Édouard et Louis Lartet 》 de la bibliothèque universitaire de Toulouse est publié un album iconographique non daté portant le monogramme de Louis Lartet. Un étonnant dessin du mammouth de La Madeleine y est reproduit (figure 15). Nous n'en avons pas retrouvé trace dans une quelconque publication. La bête, qui ne manque pas d'allure et son support d'ivoire sont traités avec une exceptionnelle liberté (fig. 28).
Dans la publication de Font-de-Gaume (Breuil et al. 1910), Henri Breuil donne un relevé détaillé du mammouth (fig. 29). Le contour de l'objet est très brièvement noté, mais fait plutôt penser à celui d'un moulage qu'à l'original. Le dessin semble présenté en déroulé, ce qui fait paraître l'animal haut sur pattes et en même temps ramassé sur luimême. On notera aussi l'absence de toutes indications plus précises concernant le support, comme les liaisons entre les fragments et enfin le fait qu'aucun trait du mammouth n'est interrompu dans les parties encollées.

Le relevé de Pierre Laurent, publié en 1977 (Bouvier - p. 55) (fig. 30), est excellent dans le rendu de la représentation. Cependant, toutes les incisions n'ont pas été relevées, loin s'en faut, et les limites des fractures ou des fissures n'apparaissent pas clairement. II manque également des coupes ou des sections.

Dans le cadre de cette publication, il nous a semblé nécessaire d'effectuer à notre tour une nouvelle analyse et un nouvel enregistrement graphique de l'œuvre et de son support.

\section{4 - Description et analyse}

\subsection{1 - Lieu de conservation}

Le mammouth de La Madeleine est actuellement conservé au département "Histoire de la Terre » (Galerie de Paléontologie) du Muséum national d'histoire naturelle (Paris). II appartient à la collection Édouard Lartet - Henry Christy (étiquette avec le monogramme CL collée sur la face inférieure) et porte un premier numéro d'inventaire 


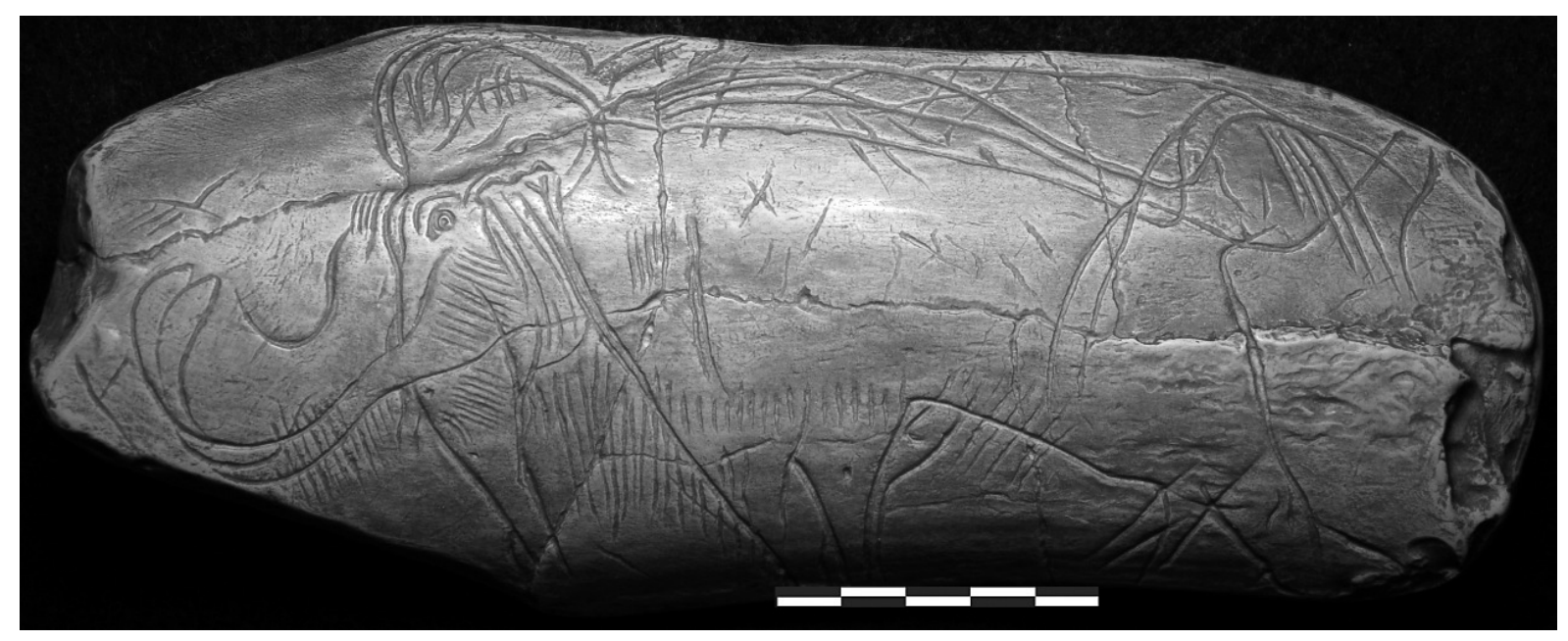

Figure 20 - Mauvais moulage du mammouth de La Madeleine. (C) Cliché Carole Vercoutère (2010).

Figure 20 - Poor casting of the La Madeleine mammoth. (C) Image Carole Vercoutère (2010).

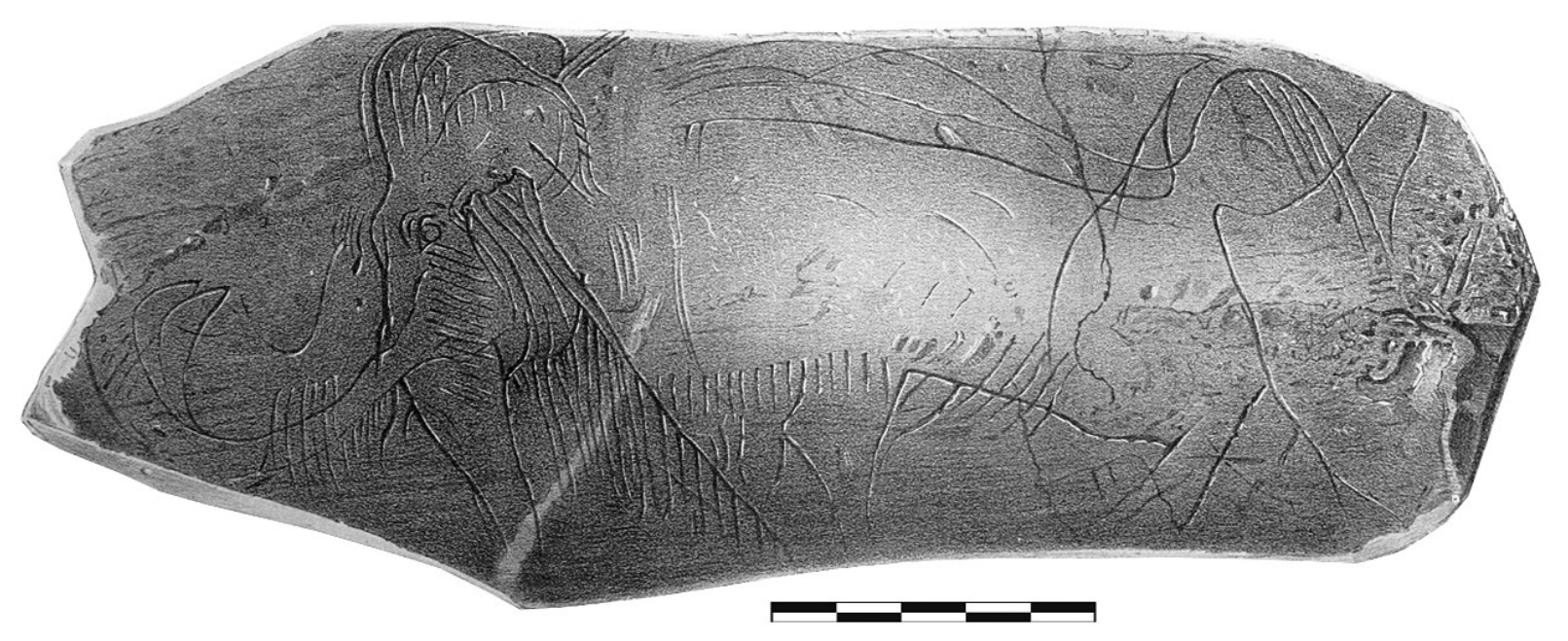

Figure 21 - Relevé du mammouth de La Madeleine d'après la réplique de M. Stahl. Relevé Édouard Lartet et Henry Christy (1865-1875).

Figure 21 - Tracing of the La Madeleine mammoth from M. Stahl replica. Tracing Edouard Lartet and Henry Christy (1865-1875).

( $\square$ 922-47) attribué par l'ancien « service » de Géologie du Muséum où l'objet a été déposé par Édouard Lartet (alors Paléontologue à la chaire de Paléontologie du Muséum) probablement entre 1865 et 1870 . Un autre numéro (192015 ) indique vraisemblablement la date et le numéro d'ordre d'entrée de l'objet dans les collections du " service " de Paléontologie, conformément à la demande de Marcellin Boule, évoquée plus haut, et à la décision de l'assemblée des Professeurs du Muséum (Boule 1923 - p. 280-281).

\subsection{2 - État de conservation}

Édouard Lartet nous apprend que l'objet a été découvert en cinq fragments. Leur assemblage et leur collage anciens sont imparfaits. Ils sont aujourd'hui particulièrement visibles. Les zones encollées sont envahissantes et débordent assez largement les lèvres des fractures, occultant certaines incisions. Par ailleurs, des morceaux sont en retrait de plusieurs millimètres par rapport au plan superficiel général. Des délaminations plus fines, peut-être plus récentes aussi, s'ajoutent à cette fracturation originelle in situ et portent à huit le nombre actuel de fragments réajustés et recollés. L'objet est dans un état de conservation très moyen. La surface gravée, qui semble correspondre à la première couche d'ivoire sous-jacente à la chemise de cément, est légèrement fissurée et montre de nombreuses marques d'altérations superficielles sous forme d'écaillages (micro-délitements), dont certains sont très récents, ou de ... micro-cupules de nature probablement géo-chimique en avant de la tête du mammouth et sur son arrièretrain (Vialou 1995 - p. 89) (fig. 31). Elles n'affectent pas la lisibilité de la gravure. En revanche, on observe aussi par 

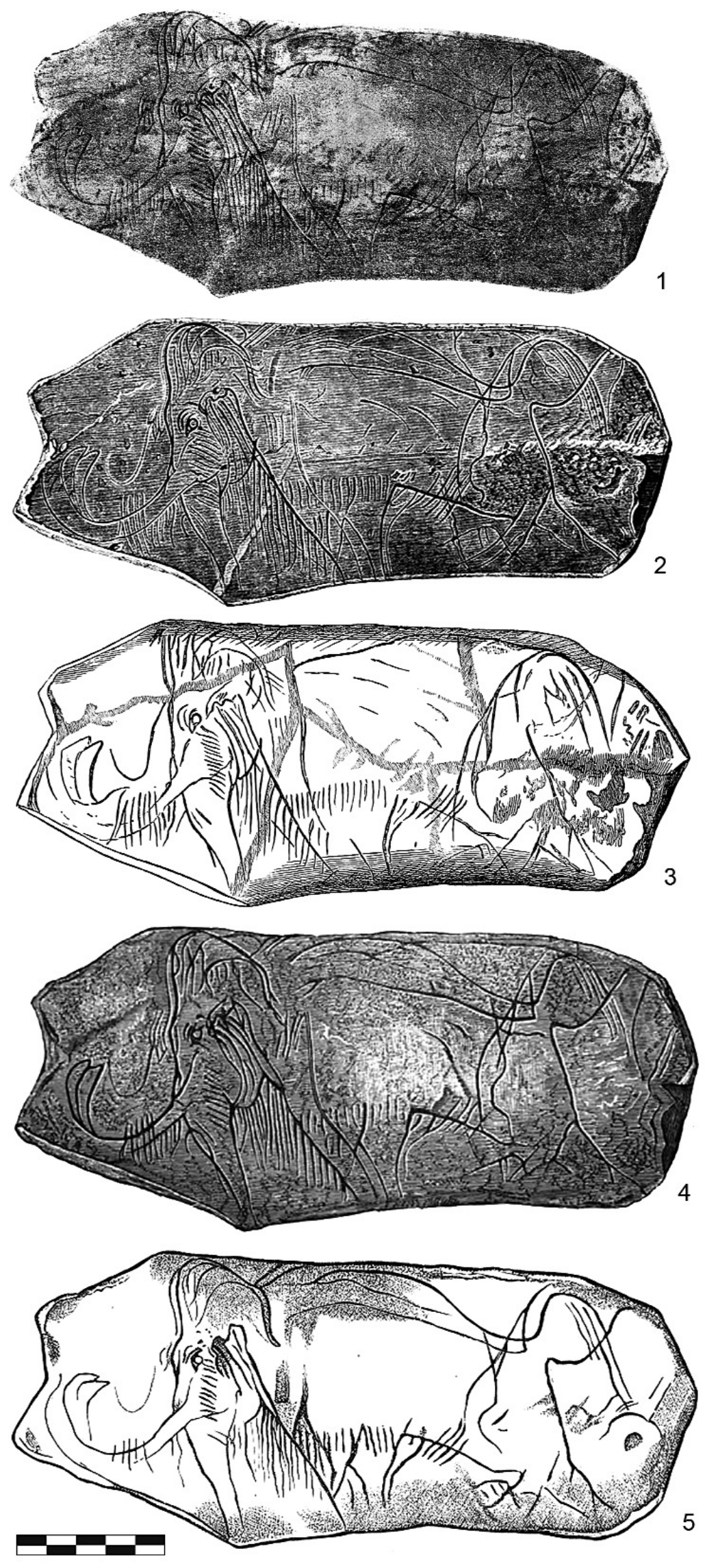

Figure 22 - Différents relevés du mammouth de La Madeleine.

1 - D’après John Lubbock (1872)

2 - D'après Charles Lyell (1873)

3 - D'après Charles Rau (1876)

4 - D’après François Lenormant (1881)

5 - D'après Henry Chapman Mercer (1885)

Figure 22 - Several tracings of the La Madeleine mammoth

1 - after John Lubbock (1872)

2 - after Charles Lyell (1873)

3 - after Charles Rau (1876)

4 - after François Lenormant (1881)

5 - after Henry Chapman Mercer (1885) 

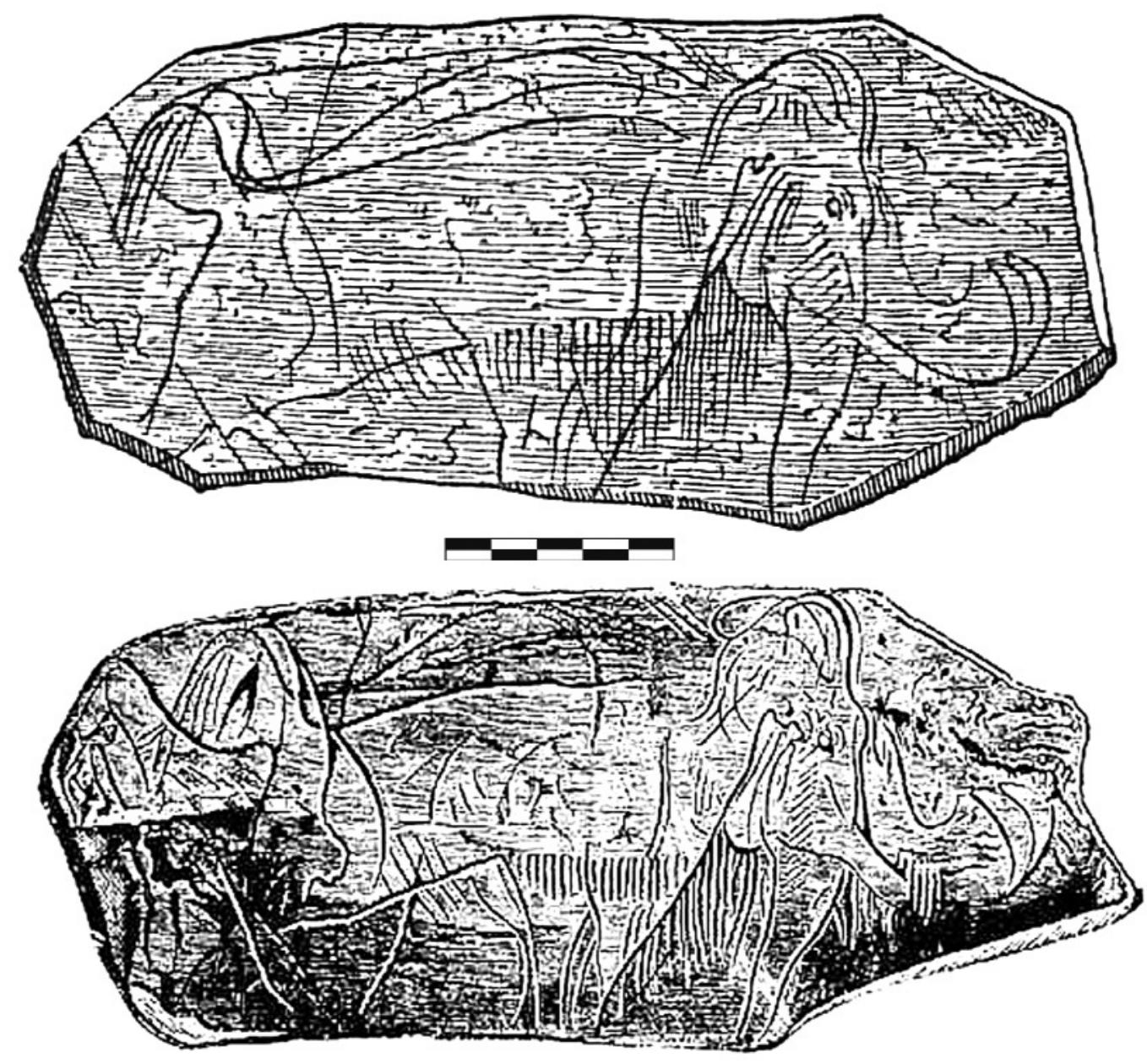

Figure 23 - Relevés du mammouth de La Madeleine reproduits à l'envers.

1 - Louis Figuier (1876) et René Verneau (1890) 2 - Ferdinand Priem (18931894)

Figure 23 - Tracings of the La Madeleine mammoth, reproduced in the wrong direction.

1 - Louis Figuier (1876) and René Verneau (1890)

2 - Ferdinand Priem (18931894)

endroits des vestiges des produits utilisés pour réaliser les empreintes et les moulages. Ils apparaissent en gris clair et occultent parfois des traits de gravures. II est d'ailleurs difficile d'analyser plus précisément (observations macroscopiques) les traits gravés tant ils sont encrassés par divers produits et notamment par du vernis dont la pièce est abondamment recouverte. Des imprégnations noirâtres sont également visibles sur les deux faces du support. Selon Denis Vialou (1995), leur origine est archéologique (milieu cendreux) ou taphonomique (dépôts minéraux).

Enfin, la surface gravée conserve assez nettement les cannelures ou les rainures serrées longitudinales qui correspondent à la structure naturelle de la surface d'une squame d'ivoire, plus particulièrement à l'interface cément-dentine (fig. 32). Ces rainures très régulières s'observent aussi sur la face interne du support et de toutes les squames qui le constituent.

Sur la face externe, elles se confondent avec des traces possibles de raclages intentionnels de la surface, antérieurs à la gravure.

Une expertise sanitaire de l'objet, préalable à une éventuelle restauration, nous semble nécessaire et pourrait être confiée à un spécialiste des matériaux organiques.

\subsection{3 - Description}

Dans ses dimensions actuelles, le fragment de défense de La Madeleine mesure $24,8 \mathrm{~cm}$ de longueur maximale et $10,6 \mathrm{~cm}$ de largeur maximale. Son épaisseur est de $1,8 \mathrm{~cm}$ sur la section du côté gauche et de $0,8 \mathrm{~cm}$ sur la fracture opposée (fig. 33).

Le mammouth, tourné à gauche, est cadré au maximum de la largeur et de la hauteur du support. Il est orienté vers l'extrémité apicale de la défense (plus grande épaisseur des squames) où une petite partie du dessin est interrompue par une fracture. On peut raisonnablement en conclure que la squame utilisée par l'artiste magdalénien de La Madeleine n'était guère plus longue que l'actuelle. Les fractures de droite sont certainement antérieures à la réalisation de la gravure. Nous disposons donc d'une œuvre complète. Le fait est rare dans le domaine de l'art mobilier, qui se caractérise bien souvent par sa fragmentation.

D'un point de vue strictement technologique, la morphologie (profils en $U$ ou en V), la largeur et la profondeur des tracés gravés varient en fonction des détails traités, mais également des parties du support. De nombreux traits trouvent ici un support favorable par une 

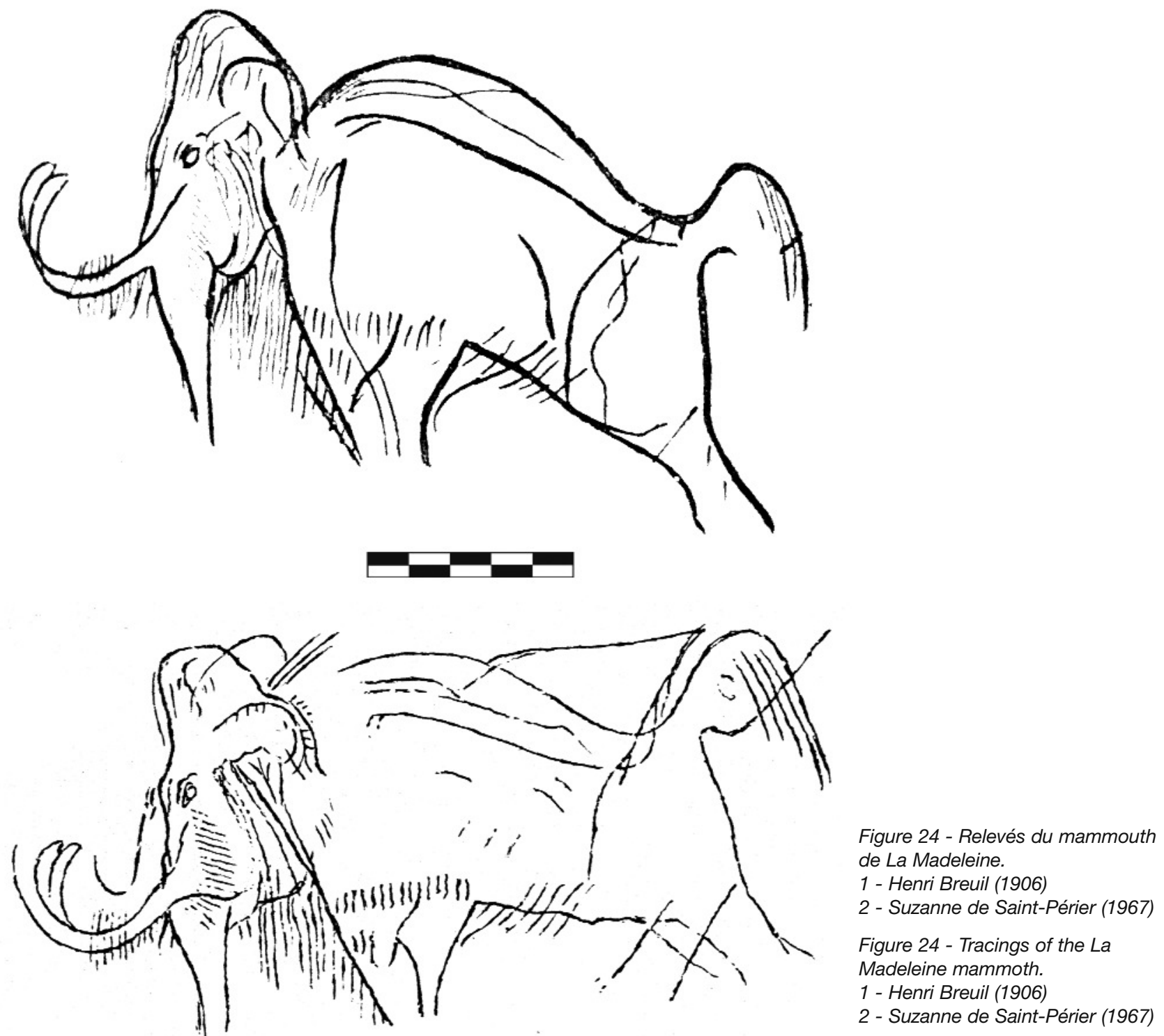

surface large, relativement plane et dépourvue d'irrégularité.

L'animal se lit sans difficulté malgré le grand nombre de traits, plus ou moins organisés, qui couvrent la surface. II est gravé dans une attitude campée mais dynamique. La queue est relevée en crosse ou «bras de pompe » et les membres sont rejetés en extension vers l'arrière. Le corps apparaît ainsi projeté vers l'avant, dans une attitude peu fréquente chez les mammouths figurés dans l'art pariétal et mobilier paléolithiques (fig. 34 et fig. 35). Cette attitude a fait écrire par certains auteurs que ce mammouth marchait à vive allure, qu'il fuyait ou bien encore qu'il chargeait. De plus, les nombreux repentirs qui affectent le dos et l'avanttrain contribuent à accentuer l'effet de mouvement.

Un soin tout particulier a été apporté à la tête (fig. 36) et à l'avant-train. II s'agit de la partie du corps la plus lisible sur la défense. Les détails anatomiques y sont nombreux et conformes au modèle. La tête est traitée d'une manière particulièrement réaliste dans sa forme générale ainsi que dans ses détails. Elle est d'abord massive, haute et plutôt courte d'avant en arrière. Elle est très prononcée au vertex (acrocéphalie) qui affecte la forme d'un dôme pointu en " pain de sucre ". Le front est vertical alors que le versant postérieur du vertex est incliné à environ $45^{\circ}$ vers l'échancrure cervicale.

À la base du front, l'artiste a nettement souligné la saillie, ou bosse orbitaire, que l'on voit fréquemment sur les mammouths figurés dans l'art paléolithique. Elle est dessinée à hauteur de l'œil.

Celui-ci est très finement incisé. II est piriforme (commissure interne anguleuse en forme de " caroncule " ou de larmier et angle temporal arrondi) et dépourvu de pupille. Trois traits en forme de demi-cercles le surmontent. Ce ne sont pas les sourcils, mais plutôt les replis cutanés que l'on observe chez le mammouth au-dessus des paupières. 


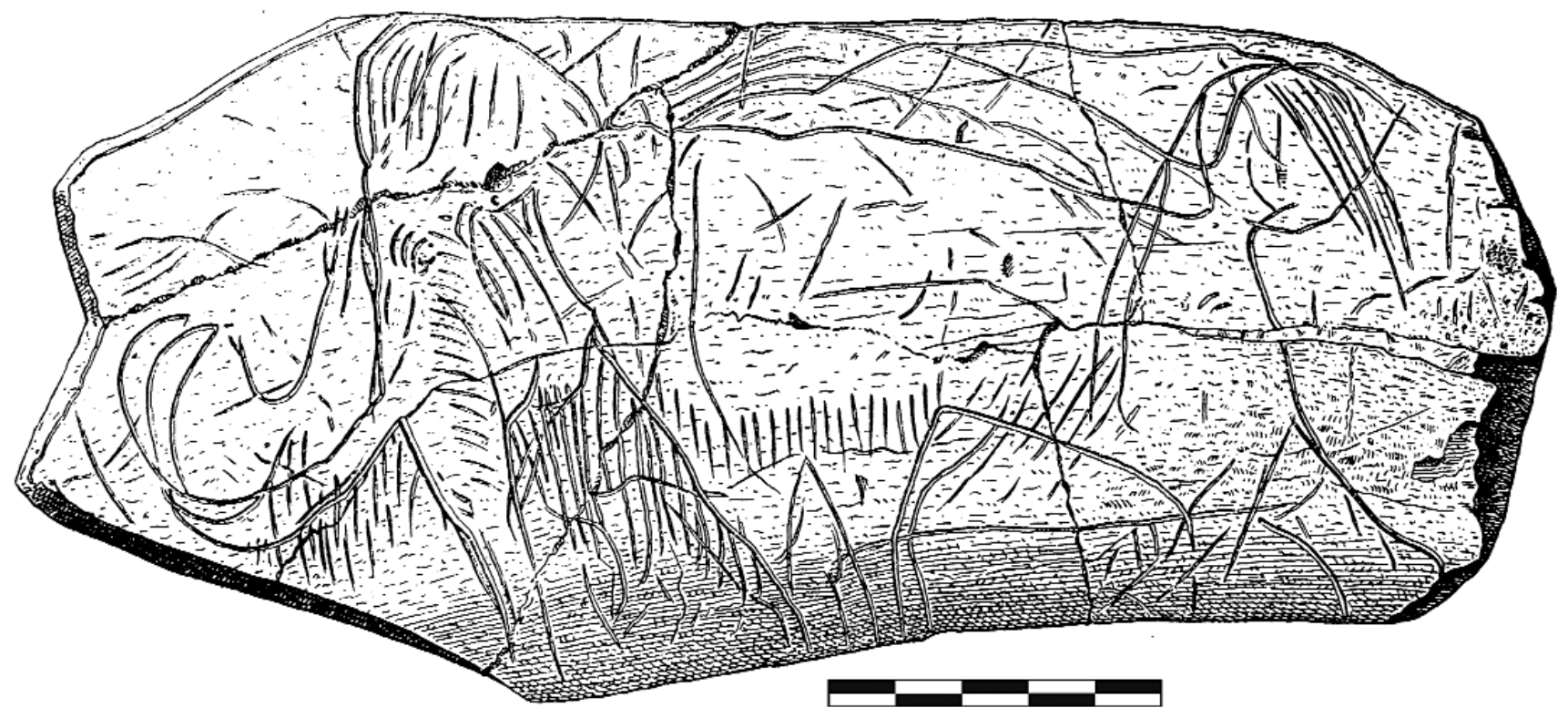

Figure 25 - Le mammouth de La Madeleine. Relevé Adrien de Mortillet (1881).

Figure 25 - La Madeleine mammoth. Tracing Adrien de Mortillet (1881).

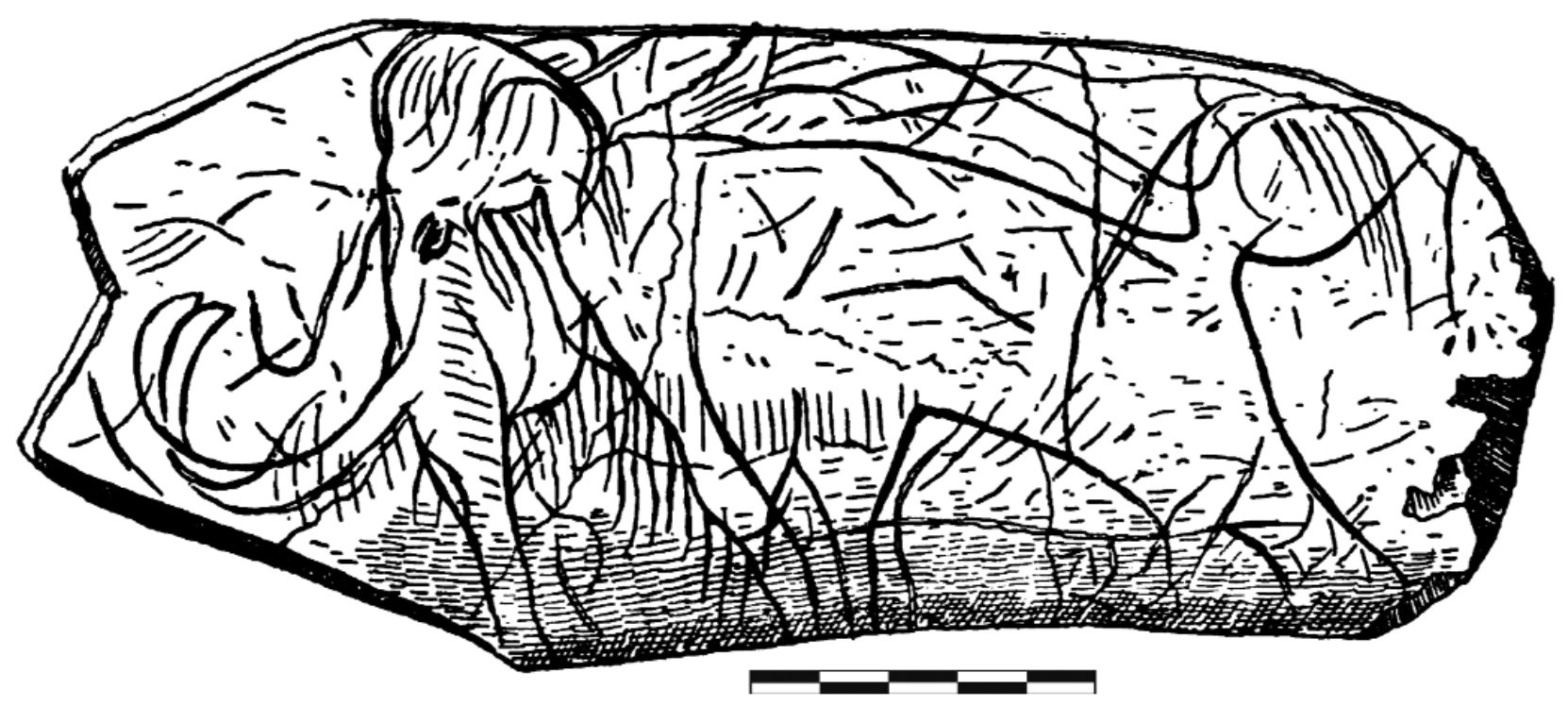

Figure 26 - Le mammouth de La Madeleine. Relevé d'après Thomas Wilson (1897).

Figure 26 - La Madeleine mammoth. Tracing after Thomas Wilson (1897). 

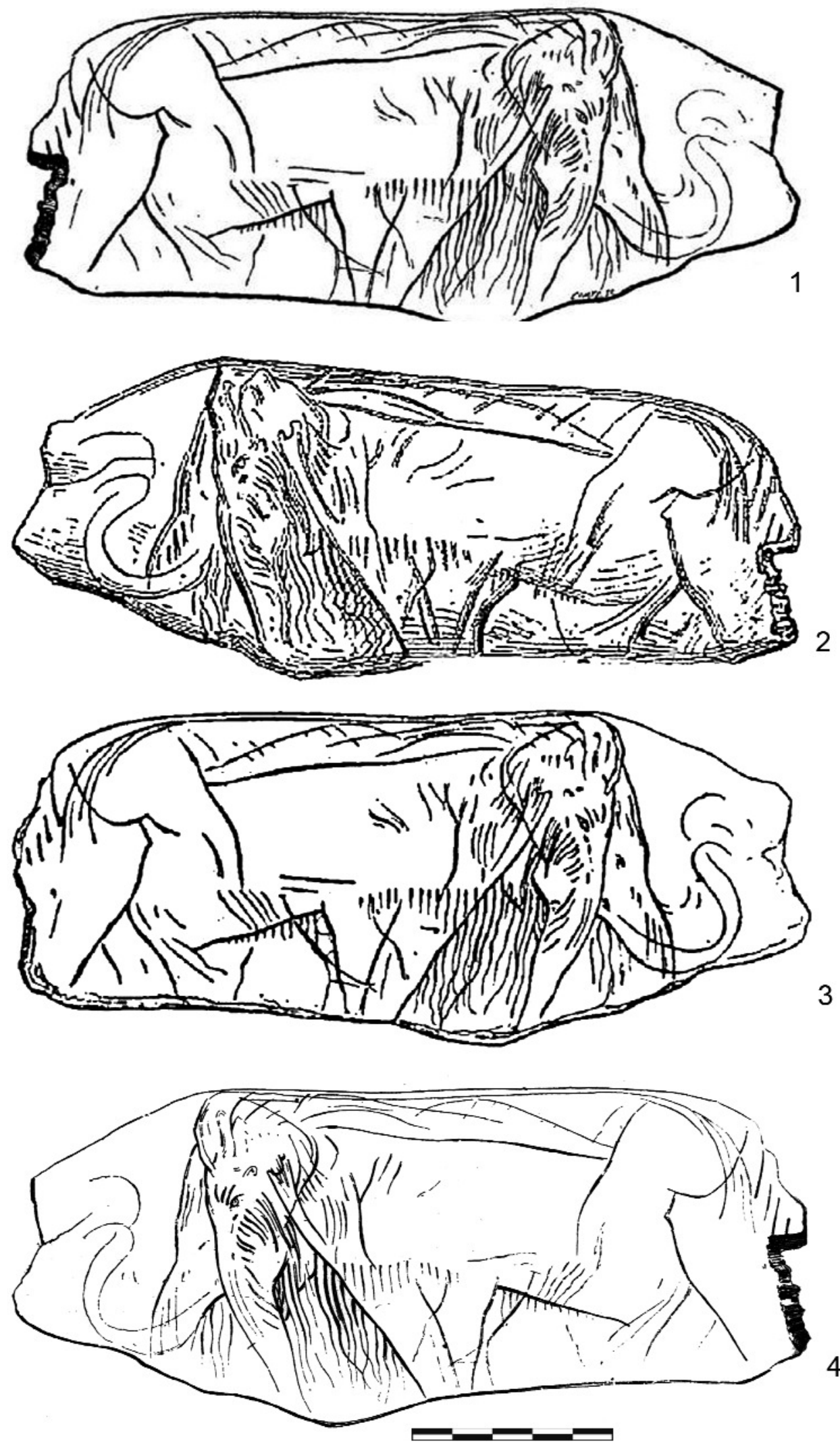

Figure 27 - Différents relevés du mammouth de La Madeleine.

1 - D'après la Gazette des Beaux-Arts (1867)

2 - D'après Victor Duruy (1881) 3 - D'après René Joseph Ménard (1882)

4 - D'après Emile Cartailhac (1889)

Figure 27 - Several tracing of the La Madeleine mammoth.

41 - after la Gazette des BeauxArts (1867)

2 - after Victor Duruy (1881)

3 - after René Joseph Ménard (1882)

4 - after Emile Cartailhac (1889) 


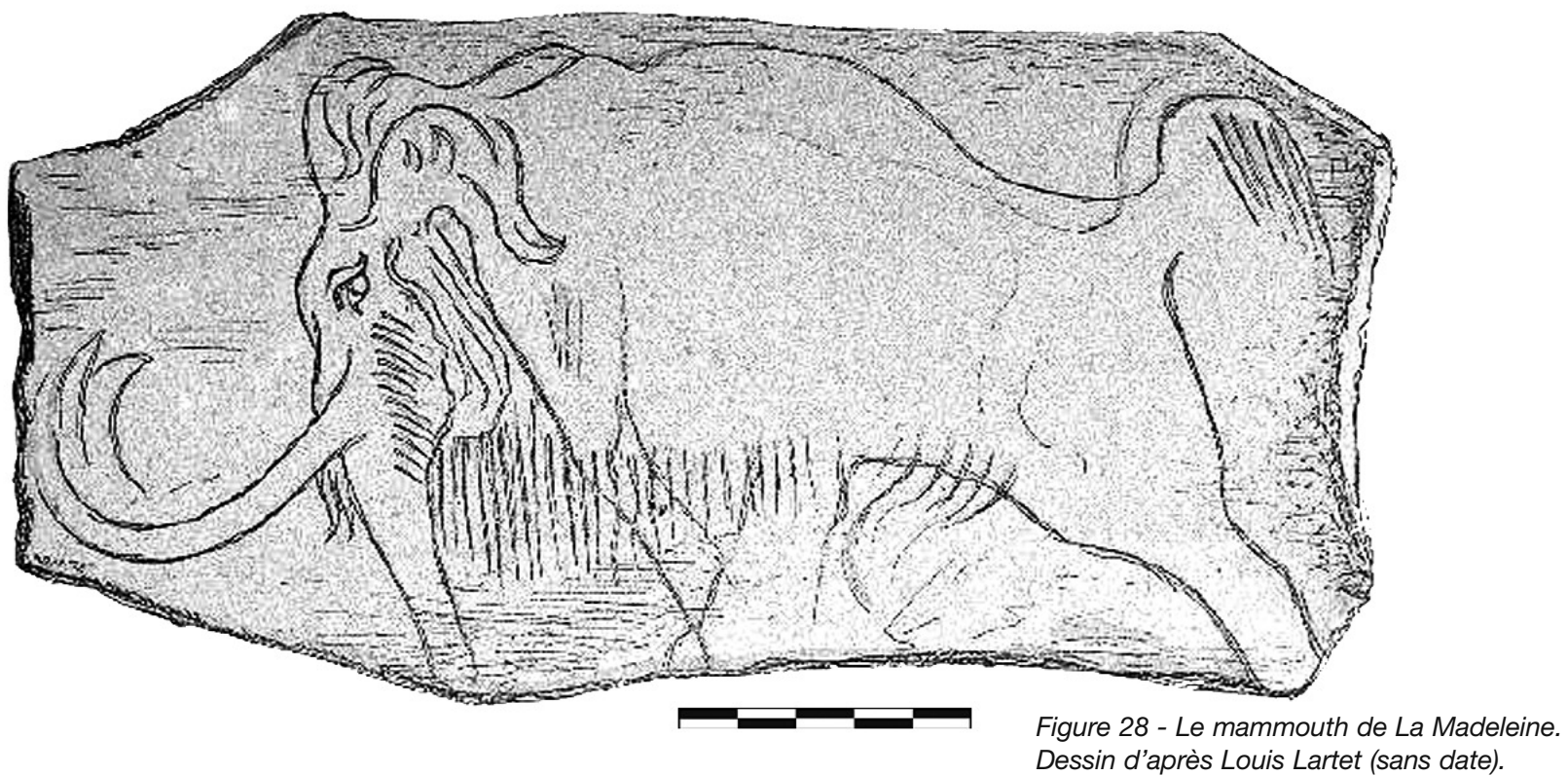

Figure 28 - La Madeleine mammoth. Drawing after Louis Lartet (undated).

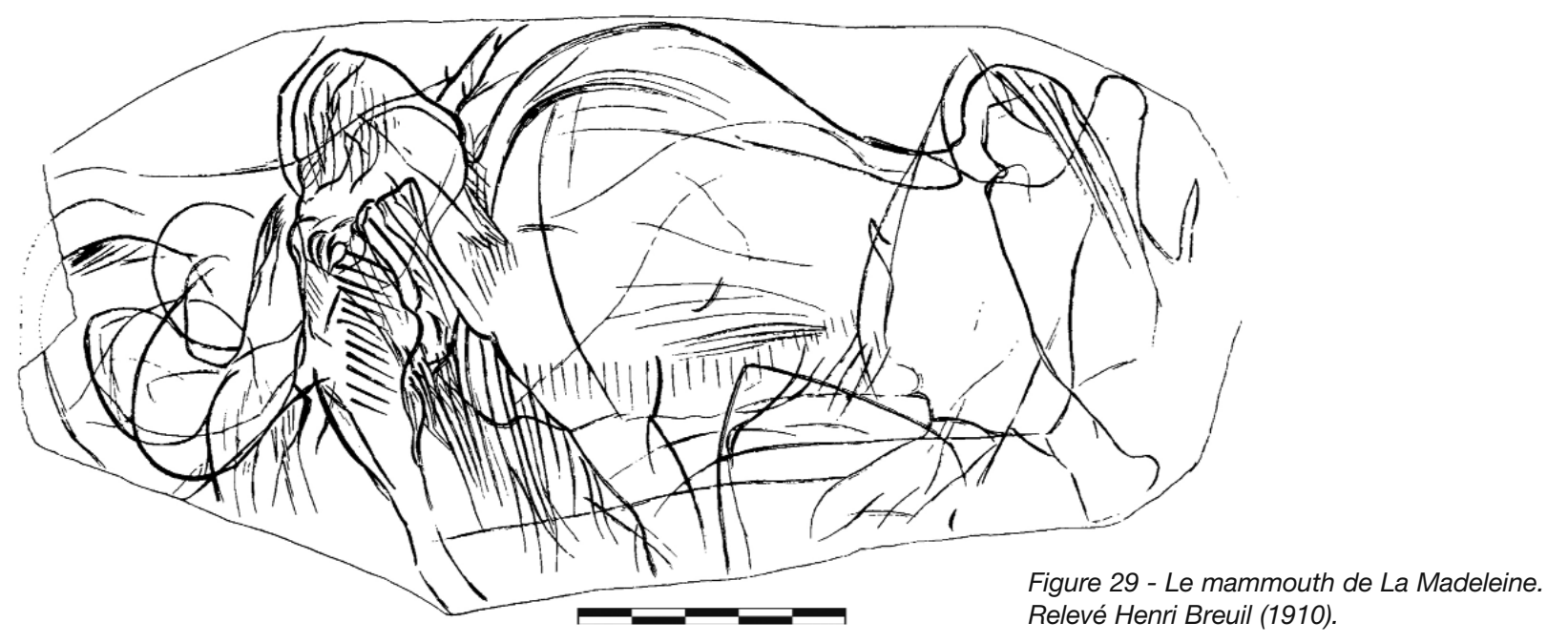

Figure 29 - La Madeleine mammoth. Tracing Henri Breuil (1910).

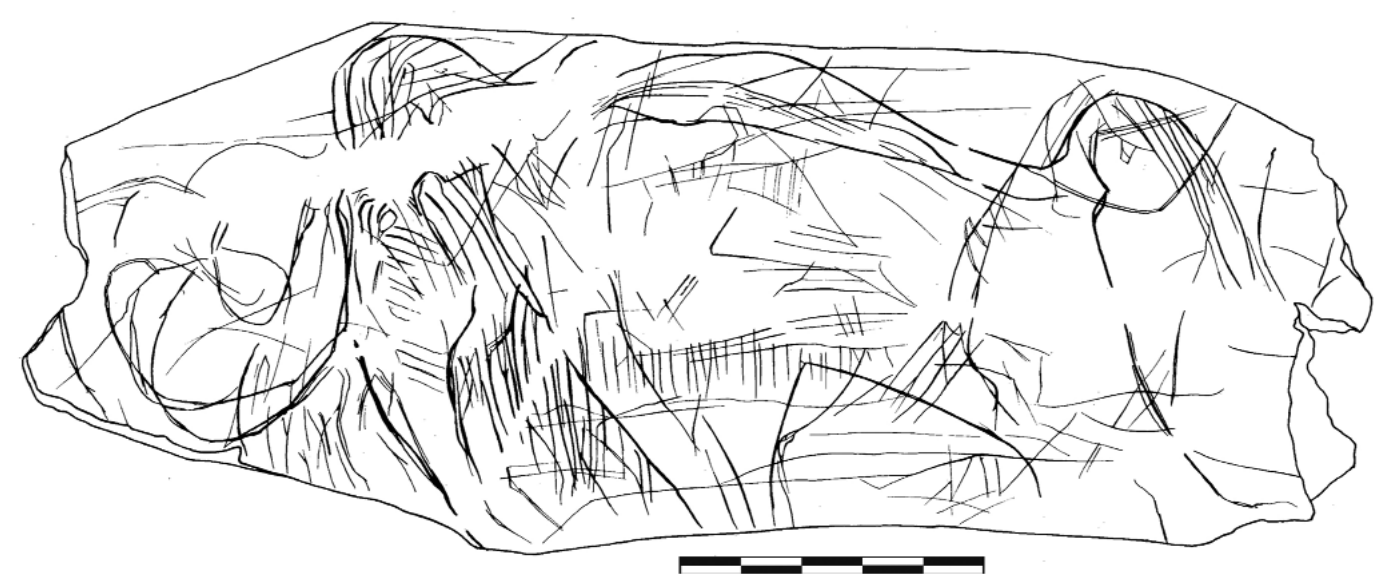

Figure 30 - Le mammouth de La Madeleine. Relevé Pierre Laurent (Bouvier 1977).

Figure 30 - La Madeleine mammoth. Tracing Pierre Laurent (Bouvier 1977). 


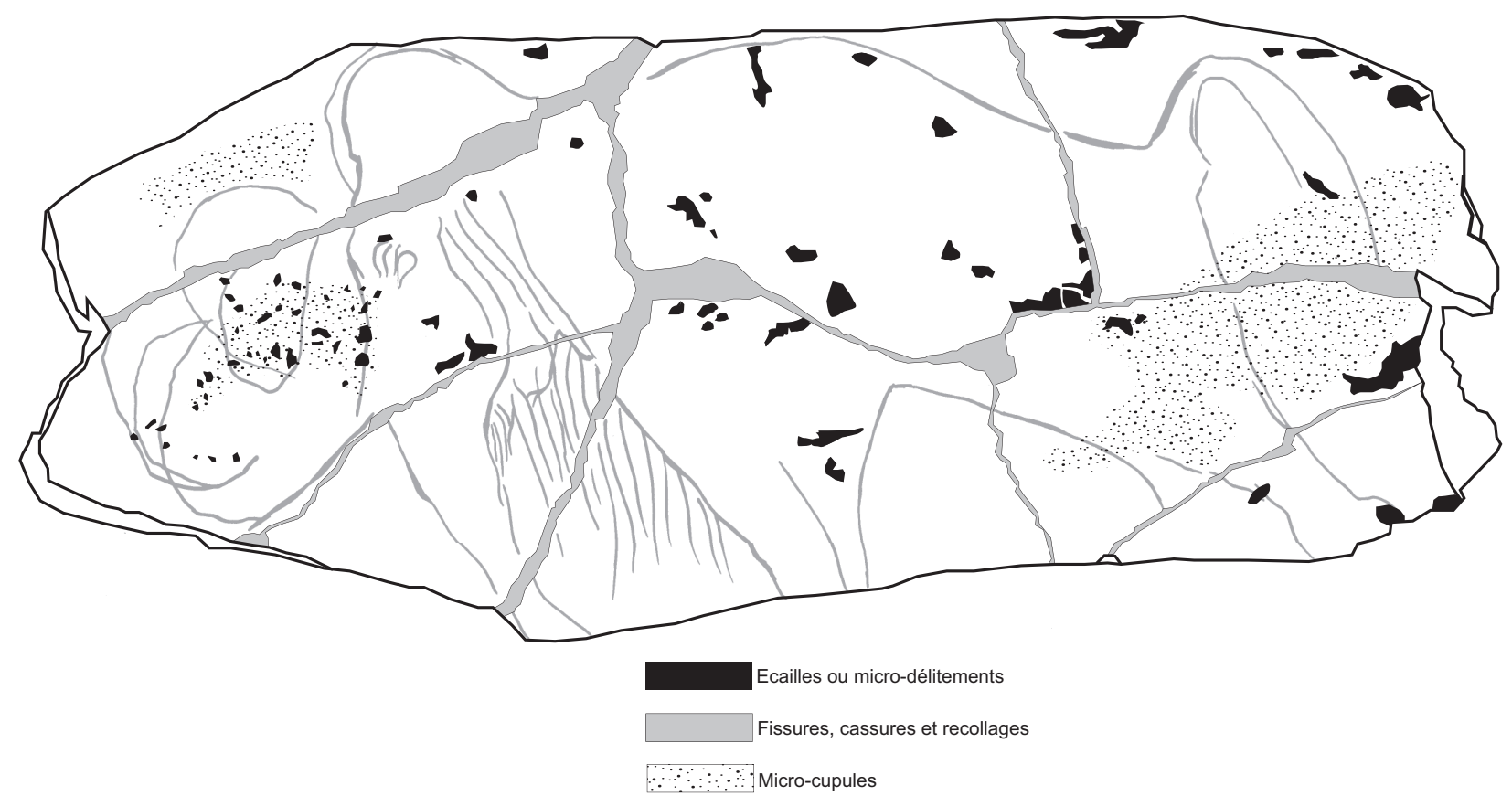

Figure 31 - Analyse taphonomique de la défense de La Madeleine. DAO Patrick Paillet.

Figure 31 - Taphonomic analysis of the La Madeleine defense. DrawingPatrick Paillet.

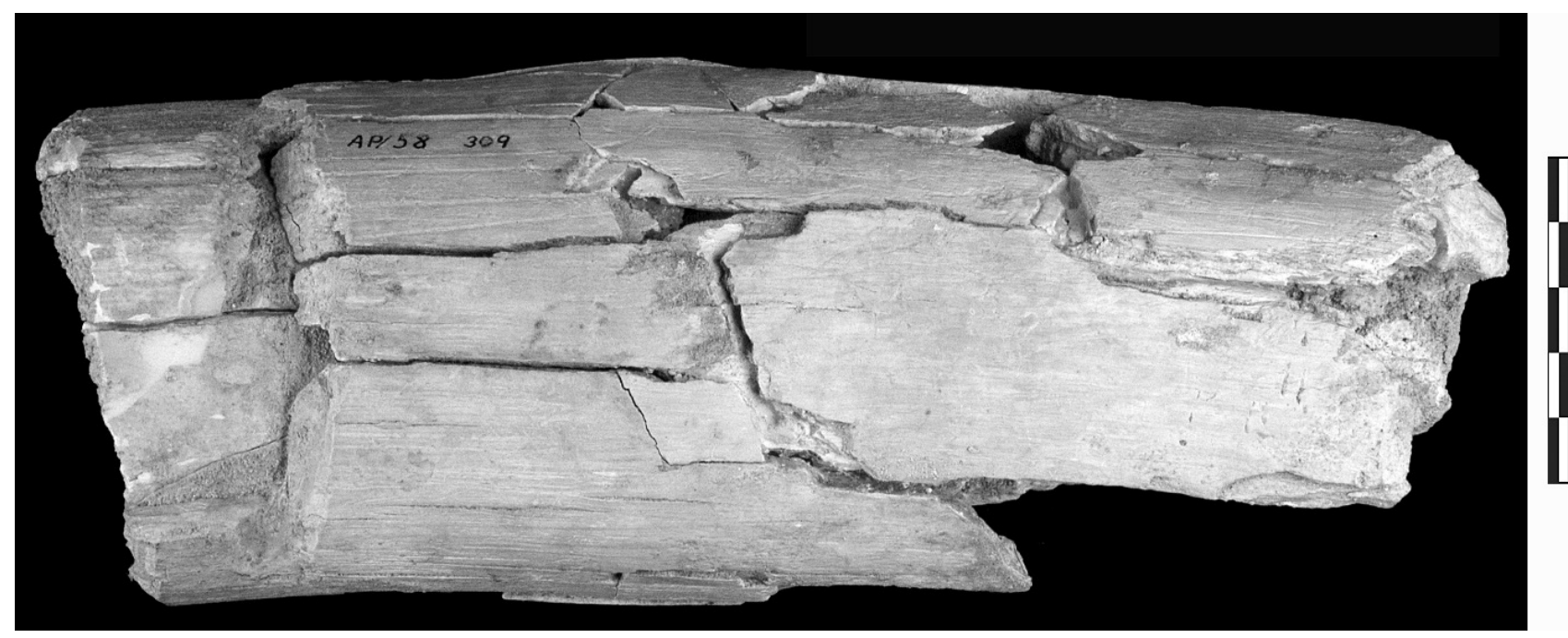

Figure 32 - Défense de mammouth, abri Pataud (Dordogne). () Cliché Roland Nespoulet et Laurent Chiotti.

Figure 32 - Mammoth defense, abri Pataud (Dordogne). (c) Cliché Roland Nespoulet and Laurent Chiotti.

La trompe est longue et épaisse. Elle est portée en position relâchée, c'est-à-dire presque verticale. Son extrémité distale forme un léger coude vers l'arrière. L'extrémité est ouverte sans indication des doigts préhensiles. Les incisions obliques et parallèles, qui se développent de l'œil à mi-hauteur de la trompe, semblent illustrer son aspect gaufré et annelé dû à l'alternance des rouleaux et des sillons cutanés qui la constituent. II pourrait aussi s'agir de l'épaisse toison qui couvre la partie supérieure de la trompe.
La bouche est fermée mais on aperçoit parfaitement la lèvre inférieure pointue accolée à la base de la trompe.

La toison, constituée de duvet ou de bourre laineuse et de jarres plus longs, recouvre une grande partie de la tête et plus particulièrement la joue arrondie et le vertex proéminent. Elle est traduite ici par de longues incisions courbes ou rectilignes qui sont parallèles ou entrecroisées. On remarque tout particulièrement le tablier de longs jarres accolés au menton et au poitrail. 


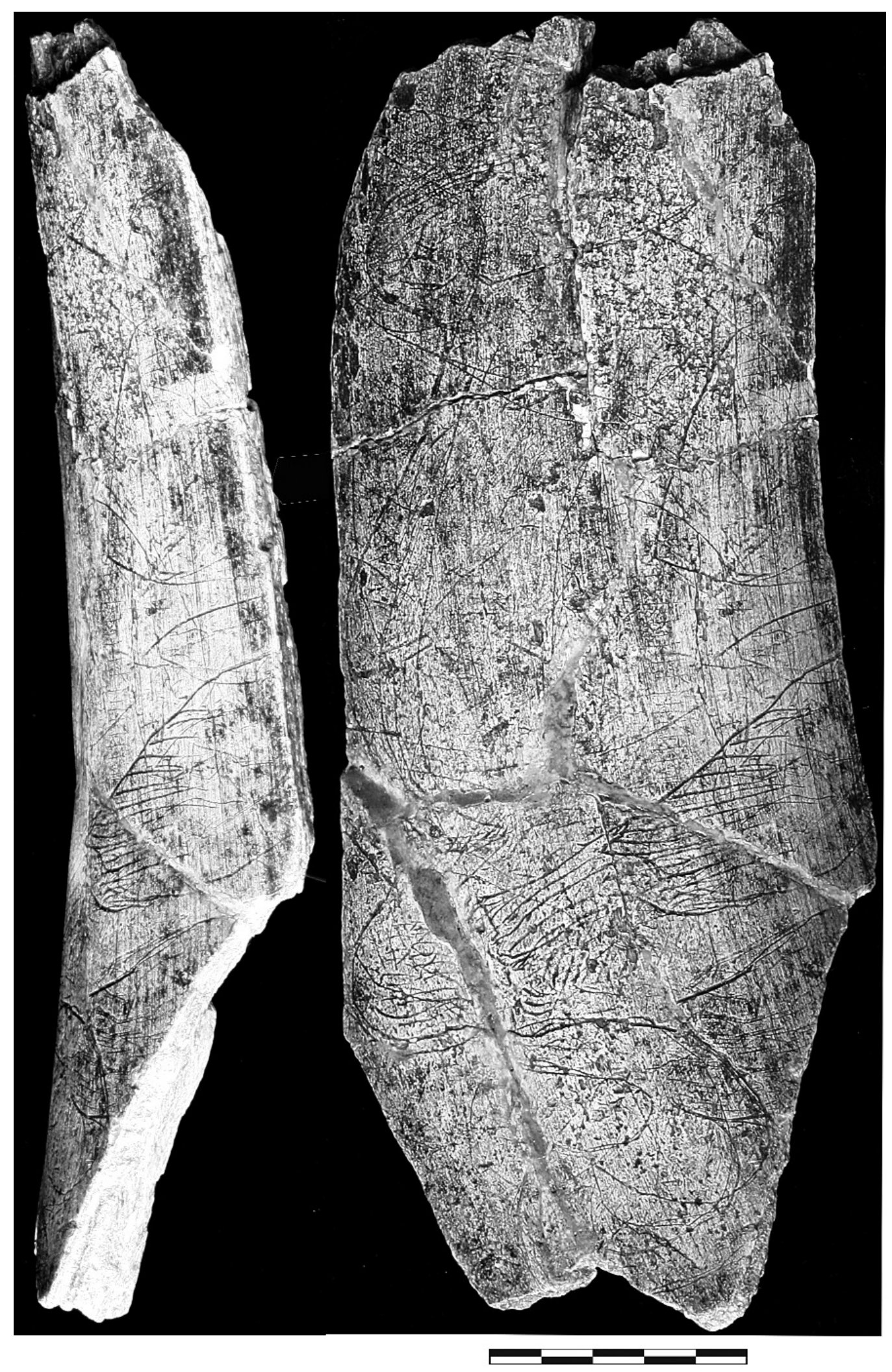

Figure 33 - Le mammouth de La Madeleine. @ Clichés Patrick Paillet (2009) avec l'autorisation du Département " Histoire de la Terre ", Muséum national d'histoire naturelle.

Figure 33 - La Madeleine mammoth. () Images Patrick Paillet (2009) with authorization of the Department " Histoire de la Terre ", Muséum national d'histoire naturelle. 

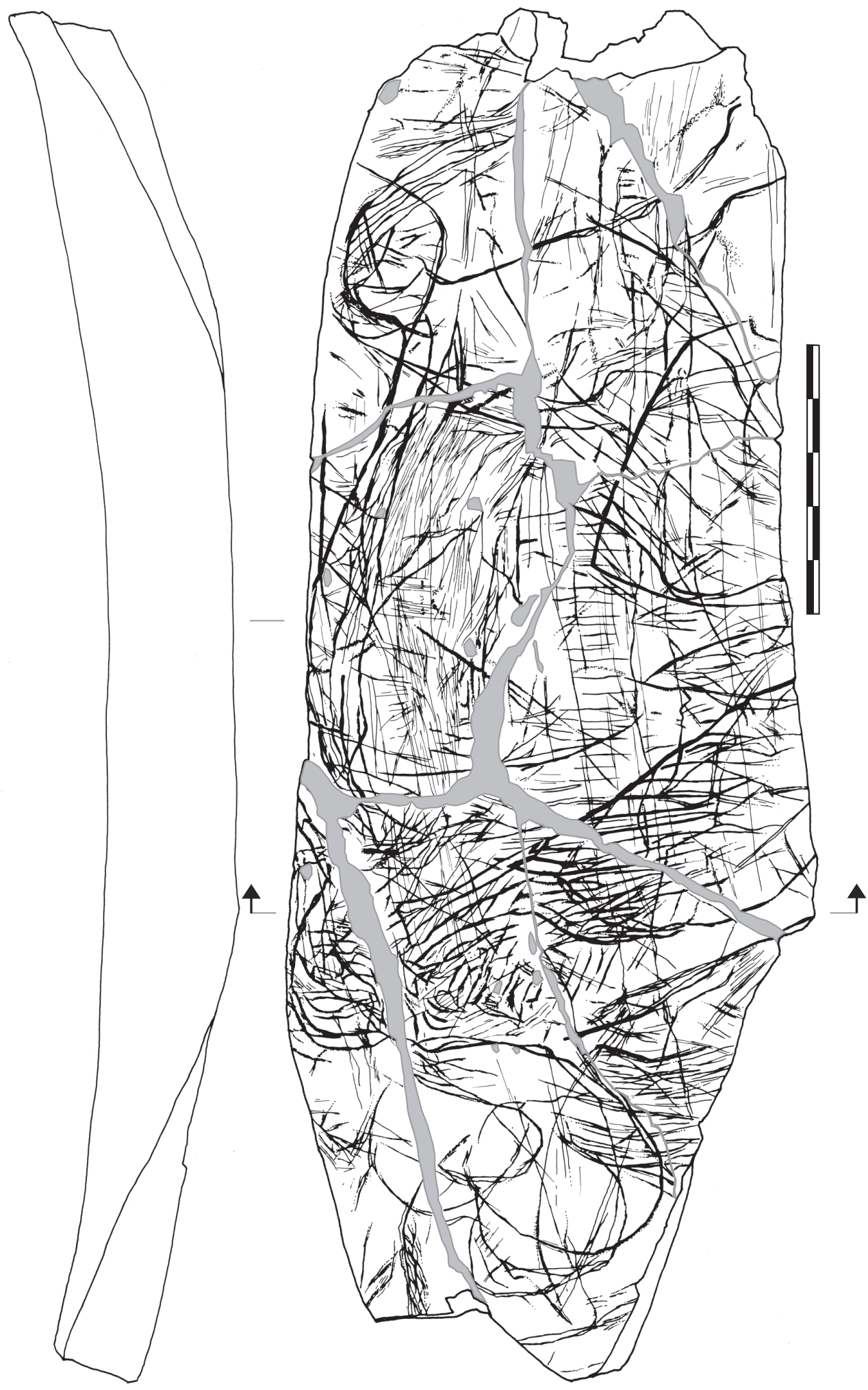

Figure 34 - Le mammouth de La Madeleine. Relevé Patrick Paillet

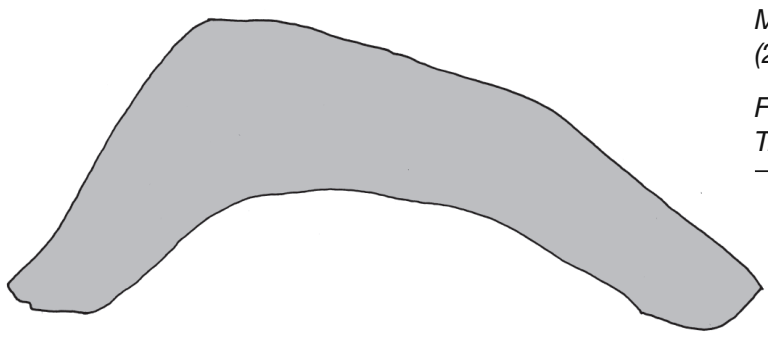
(2009).

Figure 34 - La Madeleine mammoth. Tracing Patrick Paillet (2009). 


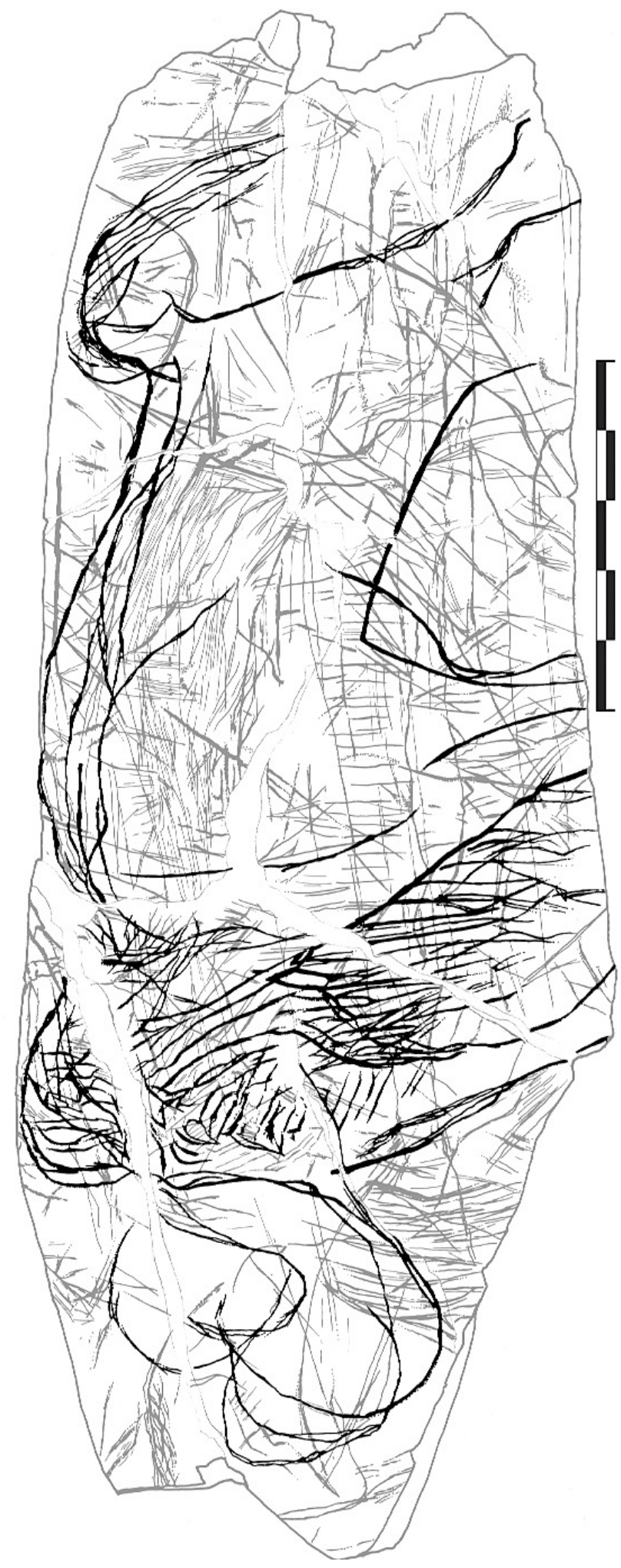

Figure 35 - Le mammouth de La Madeleine. Relevé sélectif Patrick Paillet (2009).

Figure 35 - La Madeleine mammoth. Selective tracing Patrick Paillet (2009).
II n'est pas exclu qu'une petite oreille ait été figurée en arrière et au-dessus de l'œil par des traits perpendiculaires aux jarres de la joue. Ils sont malheureusement interrompus au niveau de la fracture du support et occultés par l'épais enduit de colle. L'oreille semble ainsi perdue dans la toison. La figuration de cet organe du mammouth est exceptionnelle dans l'art paléolithique.Peut-être s'agitil de la sécrétion noirâtre (musth) produite par les glandes temporales des proboscidiens en période de rut?

Les défenses, exécutées en tracé unique et filiforme, sont longues et fortement spiralées. Leur insertion anatomique est conforme, mais leur dessin s'éloigne du réel par des enroulements excessifs. L'expression graphique est atypique. Mais finalement, elle traduit bien le développement et les courbures démesurées des incisives supérieures du mammouth. II y a également de nombreuses hésitations dans ces tracés et plusieurs repentirs, d'où l'illusion de plusieurs défenses. L'une d'entre-elles semble même s'insérer très haut vers le front et se lier à d'autres traits qui ont parfois été interprétés comme l'esquisse d'une première tête. La partie inférieure du support, au niveau de la principale défense, est couverte de stries et de tracés confus.

Projeté vers l'avant, le corps massif de l'animal apparaît assez allongé. C'est la conséquence d'une illusion induite par la convexité latérale du support. Par reconstitution en développé, il est aussi haut que long. Le cou est court et comprimé entre la tête et l'épaule. Le traitement graphique du corps et des membres est moins achevé que celui de l'avant-train. Le dessin, dans sa dimension stylisée ou synthétique, n'en est pas moins maîtrisé. L'échancrure de la nuque est assez profonde et montre un profil en $V$ évasé. Son articulation avec le rachis dorsal est interrompue par la fracture du support. Mais, on y voit encore plusieurs reprises de tracés. En ce sens, l'enchaînement avec la ligne du dos n'est pas parfait.

Le garrot est accentué par des traits multiples qui sont des repentirs. L'artiste a corrigé l'ondulation du dos en accentuant sa gibbosité. Le dos semble bien voûté. II est incliné vers l'arrière sans excès et montre même une légère inflexion au niveau des lombes.

Ces dernières se prolongent sur l'arrière par une queue épaisse et plutôt longue (fig. 37). Elle est redressée en crosse, synonyme d'une agitation particulière de l'animal (grande nervosité ?). Sa base charnue est plantée verticalement sur les reins. Ce sont les mèches de longues soies du toupet terminal qui donnent au membre son aspect anguleux. Elles sont rejetées vers l'arrière, en éventail, et contribuent à amplifier l'impression d'agitation.

Entre la base de la queue et le haut de la fesse, une saillie triangulaire indique le clapet anal. II s'agit d'un détail exceptionnellement reproduit dans l'art paléolithique.

Une seule patte postérieure est exécutée. Elle est relativement courte et en forte extension vers l'arrière. Elle s'achève à l'aplomb de l'extrémité de la queue. La cuisse est épaisse. La liaison avec le genou n'est pas claire. En revanche, la cheville est bien dessinée et le pied largement évasé vers la sole. La patte est en appui dynamique sur le 


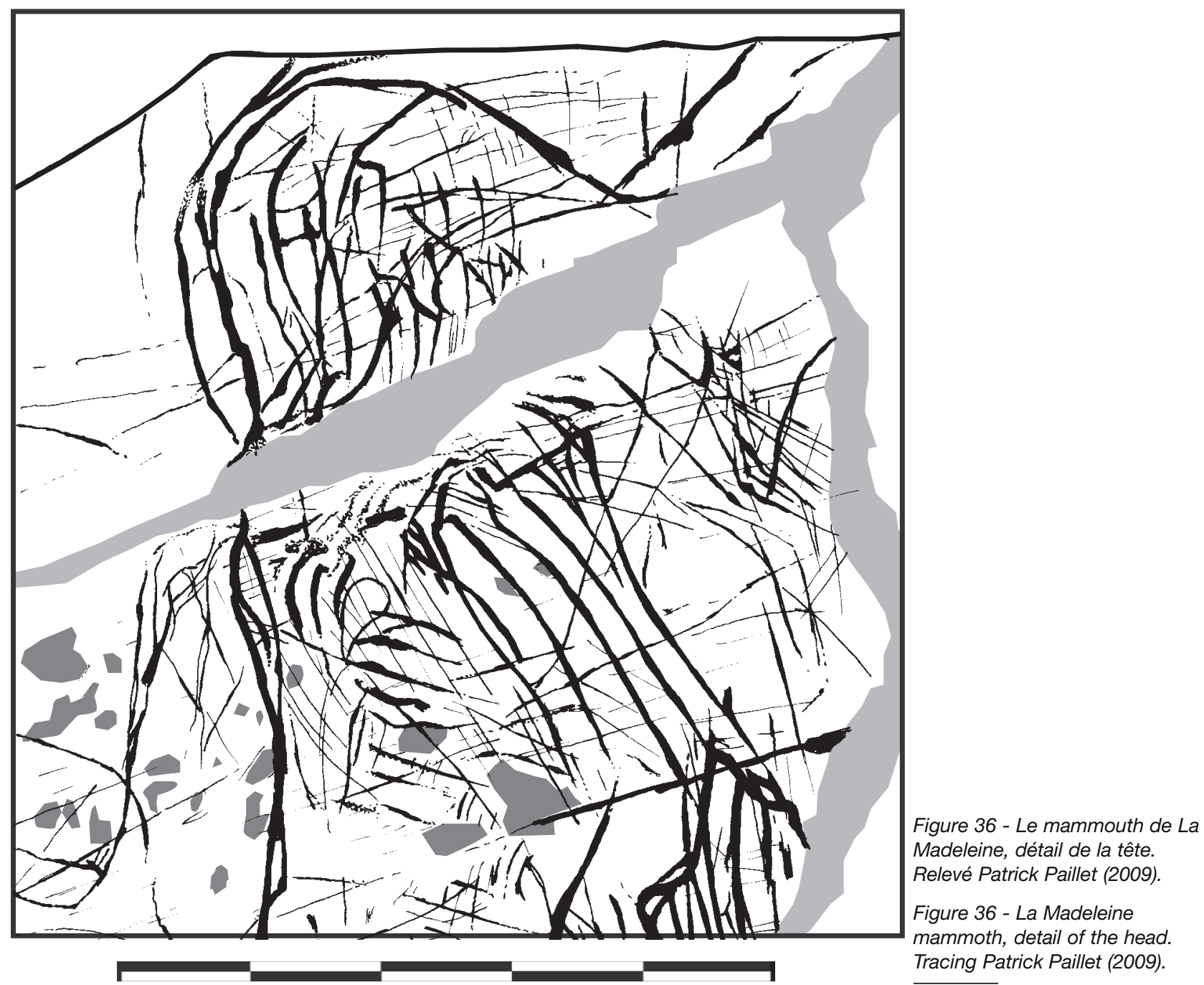

bord du support, comme les deux membres antérieurs qui sont juxtaposés. Ceux-ci forment deux colonnes jointives, légèrement inclinées vers l'arrière. Quelques inflexions des contours indiquent le coude et l'attache de l'épaule. Le rendu est cependant moins réaliste que pour le membre postérieur. Les deux pattes avant s'achèvent sur des pieds ouverts sans autre détail. Ces pattes apparaissent finalement un peu trop longues par rapport au tronc.

Les membres sont reliés par une ligne ventrale rectiligne, parallèle à la ligne dorsale. Ce parallélisme très net favorise une lecture dynamique de l'animal. Le ventre est incliné vers le bas et l'arrière. Son tracé est lié à celui d'une des pattes antérieures, formant avec elle un angle d'environ $70^{\circ}$, mais il est nettement dissocié de la patte postérieure. Sous le ventre, quelques longues incisions pourraient évoquer ces longs jarres pendant en houppelande connus sur quelques individus préservés dans les glaces de Sibérie.

Le poitrail et l'épaule sont enfin clairement indiqués mais ne semblent pas couverts d'une abondante pilosité comme chez l'animal modèle. Des séquences de tracés verticaux alignés sous l'épaule ou des traits moins organisés, des raclages et de nombreuses stries couvrent une grande partie du corps de l'animal. Nous ne saurions dire précisément où sont les signes linéaires simples associés à l'animal, les éléments figurant du pelage ou bien encore les traces d'une éventuelle préparation du support. Leur statut graphique reste imprécis.

\section{5 - Un autre mammouth à La Madeleine ?}

Le site de La Madeleine est connu pour la richesse et l'abondance de son art mobilier. Chevaux, cervidés, caprinés et bovinés se bousculent dans le bestiaire. Ils se comptent par centaines, gravés ou sculptés sur des supports lithiques ou organiques et sur des armes ou des outils. En revanche, les mammouths sont exceptionnels. Seulement deux représentations sont mentionnées dans la littérature. Celle que nous venons d'étudier et qui est entrée dans l'histoire de notre discipline par la grande porte et un arrière-train gravé sur une spatule en os découverte par Louis Capitan et Denis Peyrony (Collection Peyrony - Dépôt 


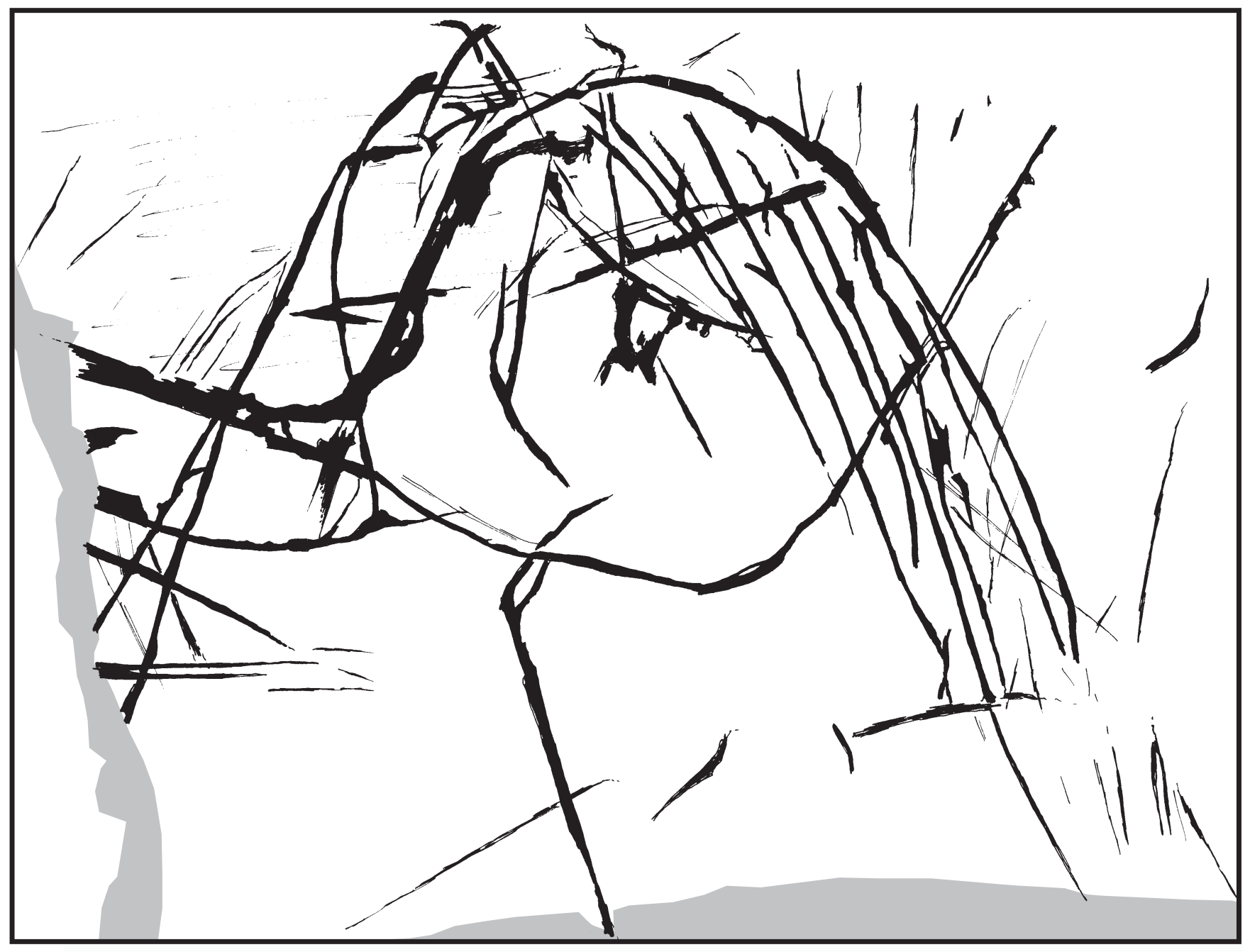

Figure 37 - Le mammouth de La Madeleine, détail de la queue. Relevé Patrick Paillet (2009).

Figure 37 - La Madeleine mammoth, detail of the tail. Tracing Patrick Paillet (2009).

du Musée d'Archéologie Nationale au Musée National de Préhistoire) (fig. 38). Cet objet provient des niveaux attribués au Magdalénien IV. II mesure $51 \mathrm{~mm}$ de long, $19 \mathrm{~mm}$ de large et $3 \mathrm{~mm}$ d'épaisseur. II est ainsi décrit par Louis Capitan et Denis Peyrony : Enfin le $n^{\circ} 6$, fig. 20, est l'arrière-train d'un mammouth, très reconnaissable à sa petite queue, à la forme du dos et au long poil qui le recouvre entièrement. II est dessiné sur un fragment de lame de poignard en os. Les deux croix placées en arrière sont des signes particuliers de l'auteur pour indiquer son œuvre; c'est, si on peut ainsi s'exprimer, sa signature, comme le disait Piette (1928 p. 43 , fig. $\left.20, n^{\circ} 6\right)$.

Cette représentation segmentaire ne nous convainc guère. Certes, les tracés linéaires évoquent un pelage mais cela est nettement insuffisant pour affirmer qu'il s'agit bien d'un arrière-train de mammouth. La représentation est confuse et reste indéterminée.
II nous faut aussi souligner que l'usage de l'ivoire et des restes osseux de mammouth en Europe occidentale est moins fréquent au Magdalénien que dans des périodes plus anciennes (Aurignacien et Gravettien notamment). II serait intéressant d'envisager une étude spécifique de ces matériaux et de leur utilisation (restes fauniques, industries sur matière dures d'origine animale, parures, objets d'art) dans les différents niveaux d'occupations de l'abri de La Madeleine.

\section{Conclusion}

Dans le vaste corpus des représentations paléolithiques de mammouths en Eurasie, tous supports confondus, le mammouth de La Madeleine est certainement l'un des plus achevés. On y trouve ce profil de rêve dont parle Denis Vialou, l'essence de la bête, et ces formes plus discrètes, ainsi que ces détails anatomiques, que l'artiste animalier et le chasseur a greffé çà et là sur les contours ou sur le 


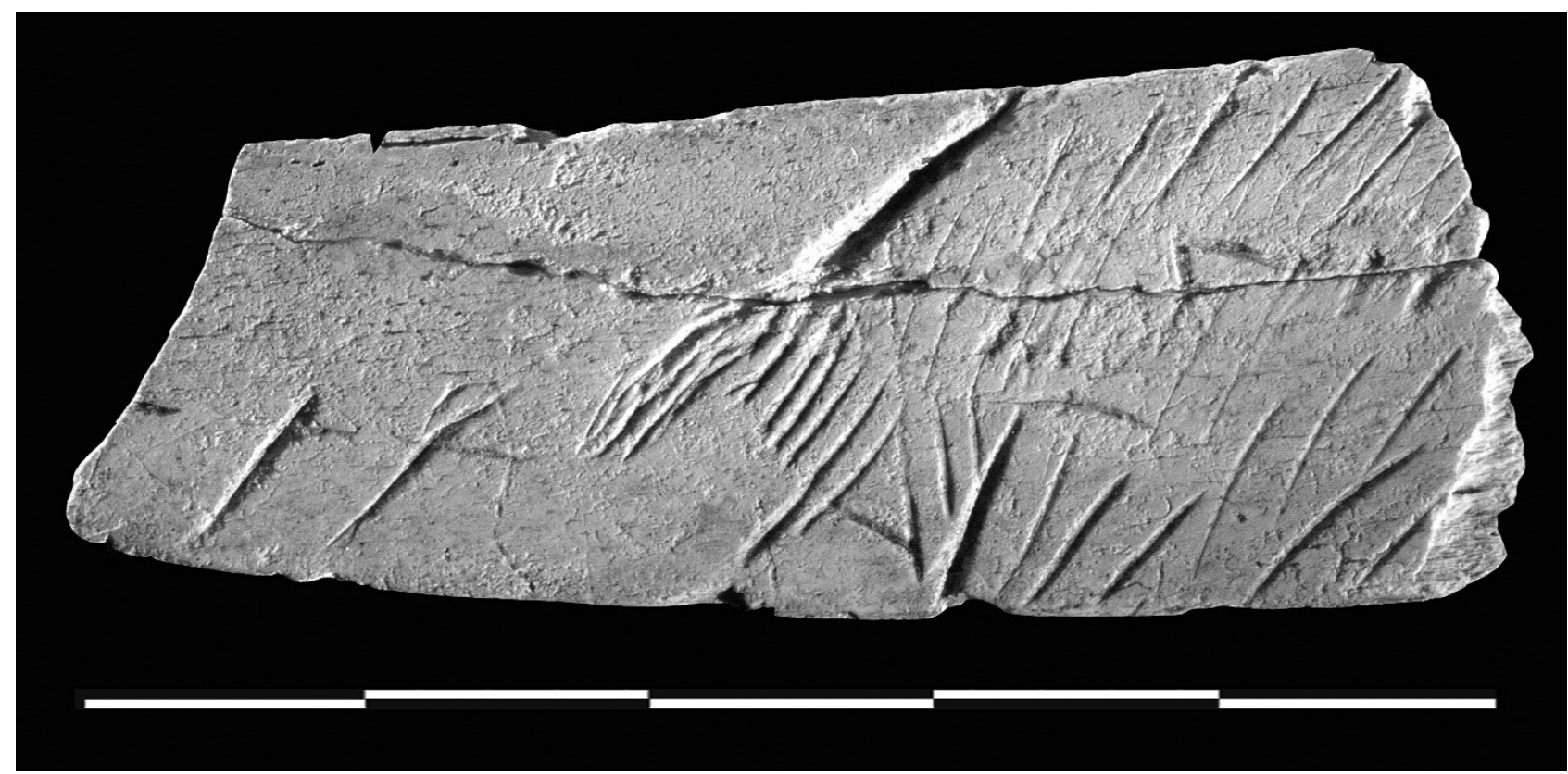

Figure 38 - Figure indéterminée (arrière-train de mammouth ?) sur lissoir en os, La Madeleine. ㄷ Cliché Musée National de Préhistoire (Les Eyzies-de-Tayac-Sireuil).

Figure 38 - Indetermined figure (mammoth hind-quarters ?) on bone smoother, La Madeleine @ Image Musée National de Préhistoire (Les Eyzies-de-Tayac-Sireuil).

corps. L'expression graphique est remarquable par ses propres conventions qui font écho à son extraordinaire liberté. L'animal est solidement planté sur ses pattes en colonnes et, en même temps, il est énergiquement projeté vers l'avant. Sa trompe, comme un cinquième pilier, est fermement ancrée dans le sol. Elle soutient l'animal dans son propre déséquilibre. À l'opposé, la queue se libère de toute entrave. Le mammouth est statique et dynamique à la fois. Voilà bien résumé ici le paradoxe du pachyderme, massif et gracieux. La représentation oscille également entre réalisme et expressionnisme. D'un côté, le répertoire est académique. L'œil, le front, le vertex, la bouche, l'opercule anal, le pelage, etc. sont au rendez-vous en lieu et place, en forme également. L'anatomie est scrupuleusement respectée. Le mammouth de La Madeleine rivalise avec les représentations les plus complètes et les plus réalistes de Rouffignac. Mais, si le trait suit souvent le modèle, il s'en affranchit parfois. En effet, d'un autre côté la manière est totalement libérée. Que dire effectivement de ces fines défenses sans fin enroulées, si ce n'est qu'elles fuient quelque peu la réalité. Mais leur rôle est important, puisqu'elles contribuent à parfaire l'équilibre de la composition. Leurs spirales dirigées vers le haut n'entrent-elles pas en résonnance avec les longues soies du pinceau terminal de la queue, à l'opposé, couchées ou plutôt projetées vers le bas et vers l'arrière ? La composition est parfaite et fait oublier les rares imperfections de la forme.

Nous avons vu le mammouth de La Madeleine entrer bruyamment dans l'Histoire des sciences. On comprend désormais qu'une telle représentation ne pouvait pas laisser indifférent. Le premier portrait connu du mammouth était en même temps l'un des meilleurs ou des plus fidèles qui soit, si l'on veut. L'histoire de notre science est parsemée de découvertes fortuites et de hasards heureux. Si en religion les miracles sont rares, ils sont encore moins fréquents en sciences. Mais nous devons reconnaître que la découverte du mammouth de La Madeleine relève bien de cette catégorie de faits extraordinaires, pour ne pas dire prodigieux. La probabilité de découvrir une gravure complète de mammouth sur cinq fragments d'ivoire (de mammouth) dans l'abri de La Madeleine en mai 1864, c'est-à-dire au plus fort des débats sur l'antiquité de l'homme et sur sa contemporanéité avec des espèces animales disparues et, de surcroît, lors d'une visite privée à laquelle participait Hugh Falconer, l'un des plus éminents spécialistes de l'époque des proboscidiens fossiles, était infime pour ne pas dire nulle. Enfin, mettre au jour un individu complet et aussi détaillé était tout simplement invraisemblable. En effet, si le mammouth est un acteur capital (plus de 300 individus dont 160 dans la seule grotte de Rouffignac) de l'iconographie pariétale paléolithique en Périgord, et pas seulement magdalénienne, il est presque absent de l'art mobilier de cette même région. À ce jour, nous ne connaissons qu'une quinzaine d'individus gravés ou sculptés sur supports mobiles. II y a à cela des raisons qui nous échappent. Si elles ne sont pas d'ordre paléoécologique, sont-elles symboliques ? Le fait est que cette pièce miraculée restera unique pour longtemps. Elle, qui n'avait aucune chance d'être ainsi découverte, n'en devient que plus remarquable encore. Son absence aurait bousculé un peu le cours de l'Histoire et aurait probablement retardé de quelques années la conversion du monde scientifique. Sa présence a rendu un immense service à la science et constitue un vibrant hommage à l'œuvre de tous les pionniers de la Préhistoire, en Périgord, en France et au-delà. 


\section{Remerciements}

Je dois de bons conseils et des corrections à des amis et des collègues. Je remercie Elena Man-Estier (Centre national de Préhistoire, Ministère de la Culture et de la Communication) qui s'est penchée sur le texte avec un grand sérieux et en a assuré une relecture critique. Ma gratitude va également à Carole Vercoutère et Stéphane Péan (Département “Préhistoire » du MNHN) qui m'ont apporté leur expertise en matière d'ivoire et d'archéozoologie. Enfin, Christine Argot, Pascal Tassy et Hervé Lelièvre (Département " Histoire de la Terre » du MNHN) m'ont permis d'accéder à cette œuvre illustre et bien protégée. Je leur en sais gré.

\section{Références bibliographiques}

ANONYME 1866 - La Voie Nouvelle, 1866. Revue philosophique, scientifique et Littéraire, Marseille, p. 50-51.

ANONYME 1867a - Gazette des Beaux-Arts, 1867. Courrier Européen de l'Art et de la Curiosité. Paris, Tome XXIII, $133^{\mathrm{èm}}$ livraison, $1^{\mathrm{er}}$ juillet 1867.

ANONYME 1867b - La Production Animale et Végétale, 1867. "Etudes faites à l'Exposition Universelle de 1867 ». Société impériale d'acclimatation, Paris.

ANONYME 1867c - Revue Catholique, 1867. $\mathrm{n}^{\circ}$ 11, Volume I, IX’̀ série, Novembre 1867, p. 638.

BAHN P. et LISTER A. 1995 - Encyclopédie complète des Mammouths. Delachaux et Niestlé, Paris.

BANDI H.-G. et MARINGER J. 1952 - L'art préhistorique. Editions Holbein, Bâle.

BARRIERE C. 1993 - «Les proboscidiens » (in) Groupe de réflexion sur l'art pariétal paléolithique (GRAPP). L'art pariétal paléolithique. Techniques et méthodes d'étude. Editions du CTHS, Documents préhistoriques 5, Paris, p. 151-156.

BEAUMONT E. (de) 1863 - (Intervention sans titre). Comptes Rendus des Séances de l'Académie des Sciences, Séance du lundi 18 mai 1863, Tome LVI, p. 935-937.

BON F. 2009 - Préhistoire. La fabrique de l'Homme. L'Univers Historique, Editions du Seuil, Paris.

BOUCHER DE PERTHES J. 1847, 1857 et 1864 Antiquités celtiques et antédiluviennes. Mémoires sur l'industrie primitive et les arts à leur origine. Paris (Trois tomes).

BOULE M. 1905 - (Compte-rendu de l'ouvrage de Robert Munro). L'Anthropologie, p.319-320.

BOULE M. 1923 - « Nouvelles entrées dans les collections de paléontologie du Muséum ». L'Anthropologie, Tome 33, p. $280-281$.

BOURLOT J. 1868 - Histoire de l'homme antédiluvien. Ages du mammouth, de l'ours des cavernes et du renne. Leiber, Paris.
BOUVIER J.-M. 1977 - Un gisement préhistorique : La Madeleine. Pierre Fanlac, Périgueux.

BREUIL H., CAPITAN L. et PEYRONY D. 1910 - La caverne de Font-de-Gaume aux Eyzies (Dordogne). Peintures et gravures murales des cavernes paléolithiques. Imprimerie A. Chêne, Monaco.

BREUIL H., MASKA Ch. et OBERMAIER H. 1912 - « La statuette de mammouth de Predmost ». L'Anthropologie, Tome XXIII, p. 273-285.

BROUILLET A. et MEILLET A. 1864-1865 - Époques antédiluviennes et celtiques du Poitou. 2 Tomes, Girardin Létang, Poitiers.

BÜCHNER L. (Traduction Charles Letourneau) 1872 L'homme selon la science, son passé, son présent, son avenir, (ou) D'où venons-nous ? - Qui sommes-nous ? - Où allons-nous ?. Exposé très simple suivi d'un grand nombre d'éclaircissements et remarques scientifiques. Reinwald, Paris.

CAPITAN L. et PEYRONY D. 1928 - La Madeleine. Son gisement - son industrie - ses œuvres d'art. Publications de I'Institut International d'Anthropologie, $n^{\circ} 2$, E. Nourry, Paris.

CARTAILHAC E. 1889 - La France préhistorique. Bibliothèque Scientifique Internationale, Paris.

CARTAILHAC E. 1907 - «L'œuvre du Marquis de Vibraye ». L'Anthropologie, Tome XVIII, p. 1-10.

CARTAILHAC E. et BREUIL H. 1906 - La caverne d'Altamira à Santillane, près Santander (Espagne). Imprimerie de Monaco, Monaco.

CHENET G. 1929 - «A propos de faussaires ». Bulletin de la Société Préhistorique Française, Volume 26, n 1, p. 78-80.

CLEUZIOU H. (du) 1887 - La création de l'homme et les premiers âges de l'humanité. Flammarion, Paris.

COHEN C. 2004 - Le destin du Mammouth. Série "Sciences », Editions du Seuil, Paris.

COHEN C. et HUBLIN J.-J. 1989 - Boucher de Perthes, Les origines romantiques de la préhistoire. Belin, Paris.

COYE N. 1997 - La Préhistoire en parole et en acte. Méthodes et enjeux de la pratique archéologique (18301950). Histoire des Sciences Humaines, l'Harmattan, Paris.

CUVIER G. 1985 (édit.) - Discours sur les révolutions de la surface du globe et sur les changements qu'elles ont produits dans le règne animal. Collection "Epistémè ", Christian Bourgois Editeur, Paris.

DARVILLE L. 1893 - Le roman de la Science. Hommes et Singes, Etude historique, géologique et archéologique. Ed. Albert Savine, Paris.

DARWIN C. 1859 - L'origine des espèces par le moyen de la sélection naturelle, ou la préservation des races favorisées dans la lutte pour la vie (Titre original en anglais : On the Origin of Species by Means of Natural Selection, or 
the Preservation of Favoured Races in the Struggle for Life). John Murray, London.

DESNOYERS J. 1863 - «Sur des indices matériels de la coexistence de l'Homme avec l'Elephas meridionalis dans un terrain des environs de Chartres, plus ancien que les terrains de transport quaternaires des vallées de la Somme et de la Seine ". Comptes Rendus des Séances de l'Académie des Sciences, Séance du 8 juin 1863, Tome LVI, p. 1073-1083.

DURUY V. 1881 - Histoire des romains depuis les temps les plus reculés jusqu'a l'invasion des barbares. Nouvelle édition revue, augmentée. Volume 3 , Hachette, Paris.

Exposition universelle de 1867 à Paris. Rapports du Jury international publiés sous la direction de $\mathrm{M}$. Michel Chevalier. (1868, 13 vol.)

Histoire du Travail. Rapport de M. E. du Sommerard, Commissaire délégué. Commission de l'Histoire du Travail à l'Exposition universelle de 1867, Tome 1, groupe 1 , p. $148-150$.

FIGUIER L. 1876 - L'Homme primitif. Hachette, Paris.

FOUCAULT A. 2005 - Des mammouths et des hommes. Collection «Planète vivante », Ed. Vuibert, Paris.

GERVAIS P. 1867 - Recherches sur l'ancienneté de l'homme et la période quaternaire. Arthus Bertrand, Paris.

GRIFFIN J. B., MELTZER D. J., SMITH B. D. and STURTEVANT W. C. 1988 - « A Mammoth Fraud in Science ». American Antiquity, Volume 53, n 3, (July 1988), p. $578-582$.

GROENEN M. 1994. Pour une histoire de la Préhistoire. Editions Jérôme Million, Grenoble.

KRAFT J. C. and THOMAS R. A. 1976 - «Early man at Holly Oak, Delaware ". Science, Volume 192, Issue 4241 (21 may 1976), p. 756-761.

LAMARCK J.-B. 1809 - Philosophie zoologique. Dentu, Paris.

LARTET E. 1861a - " Nouvelles recherches sur la coexistence de l'homme et des grands mammifères fossiles réputés caractéristiques de la dernière période géologique ». Bibliothèque universelle, Revue Suisse et étrangère, Tome XII, LXVle année, Novembre 1861, Genève, p. 203-209.

LARTET E. 1861b - «Nouvelles recherches sur la coexistence de l'homme et des grands mammifères fossiles réputés caractéristiques de la dernière période géologique ». Annales des Sciences Naturelles, 1861, Tome XV, $4^{\mathrm{ème}}$ série, Cahier $\mathrm{n}^{\circ} 3$, p. 177-253.

LARTET E. 1865a - « Une lame d'ivoire fossile trouvée dans un gisement ossifère du Périgord, et portant des incisions qui paraissent constituer la reproduction d'un Éléphant à longue crinière ". Comptes Rendus des Séances de l'Académie des Sciences, séance du lundi 21 août 1865 , $2^{\text {ème }}$ semestre, Tome LXI, n 8, p. 309-311.
LARTET E. 1865b - « Une lame d'ivoire fossile trouvée dans un gisement ossifère du Périgord, et portant des incisions qui paraissent constituer la reproduction d'un Éléphant à longue crinière ». Annales des Sciences Naturelles Zoologie et Paléontologie, 1865, V'̀me série, Tome IV, p. 353355, pl. XVI.

LARTET E. 1865c - « Une lame d'ivoire fossile trouvée dans un gisement ossifère du Périgord, et portant des incisions qui paraissent constituer la reproduction d'un Éléphant à longue crinière ". Matériaux pour l'histoire primitive et philosophique de l'homme, $2^{\text {ème }}$ année, Septembre 1865 Décembre 1866, p. 46-48.

LARTET E. et CHRISTY H. 1864 - " Sur des figures d'animaux gravées ou sculptées et autres produits d'art et d'industrie rapportables aux temps primordiaux de la période humaine. (Cavernes du Périgord. Objets gravés et sculptés des temps pré-historiques dans l'Europe occidentale) ». Revue archéologique, Nouvelle série, $5^{\text {ème }}$ année, Volume IX, p. 233-267.

LARTET E. et CHRISTY H. 1865-1875 - Reliquiae Aquitanicae ; being contributions to the archaeology and palaeontology of Perigord and the adjoining provinces of southern France. Edit. Thomas Rupert Jones, London.

LARTET L. 1874 - « Gravures inédites de l'âge du Renne, paraissant représenter le mammouth et le glouton ". Matériaux pour l'Histoire naturelle et primitive de l'Homme, Volume IX, $\mathrm{n}^{\circ}$ 2, p. 33-36.

LEGUAY L. 1867 - « Sur divers objets de l'âge de la pierre provenant de divers ateliers du département de la Vienne, offerts par M. Meillet ». Bulletin de la Société d'Anthropologie de Paris, Volume 2, p. 304-326.

LE HON H. 1867 - L'homme fossile en Europe - Son industrie, ses mœurs, ses œuvres d'art. Reinwald, Paris.

LENORMANT F. 1881-1888 - Histoire ancienne de l'orient jusqu'aux guerres médiques. Les premières civilisations : Etudes d'histoire et d'archéologie. Tome 1, Ed. Maisonneuve, Paris.

LE QUELLEC J.-L. 2009 - Des martiens au Sahara. Chroniques d'archéologie romantique. Collection « Histoire », Actes Sud/Errance.

LINAS C. (de) 1868 - L'Histoire du travail à l'exposition universelle de 1867. Paris.

LUBBOCK J. 1872 - Pre-Historic times, as illustrated by ancient remains and the manners and customs of modern savages. D. Appleton and company, New-York.

LYELL C. 1860 - " On the occurrence of works of human art in post-Pliocene deposits ». Report of the 29th meeting of the British Association for the advancement of science (Aberdeen, Sept.1859), Volume 29, Notices and Abstracts, London, p. 93-95.

LYELL C. 1873 - The geological evidences of the antiquity of man. $4^{\text {ème }}$ édition, J. Murray, London. 
MERCER H. Ch. 1885 - The Lenape Stone or the indian and the mammoth. The Knickerbocker, G.P. Putnam's sons, New Yok ans London.

MENARD R.-J. 1882 - La vie privée des anciens : le travail dans l'Antiquité (dessins d'après les monuments antiques par Cl. Sauvageot), Volume 3, p. 545-546, fig. 675.

MILNE EDWARDS H. 1863 - « Note sur les résultats fournis par une enquête relative à l'authenticité de la découverte d'une mâchoire humaine et de haches en silex, dans le terrain diluvien de Moulin-Quignon ». Comptes Rendus des Séances de l'Académie des Sciences, séance du lundi 18 mai 1863, Tome LVI, p. 921-933.

MILNE EDWARDS H. 1864 - «Sur de nouvelles observations de MM. Lartet et Christy, relative à l'existence de l'homme dans le centre de la France à une époque où cette contrée était habitée par le Renne et d'autres animaux qui n'y vivent pas de nos jours ". Comptes Rendus des Séances de l'Académie des Sciences, séance du 29 février 1864, Tome LVIII, p. 401-408.

MORTILLET G. (de) 1865 - Les Mystifiés de l'Académie des Sciences. Défi adressé à MM. Decaisne et Elie de Beaumont. Paris.

MORTILLET G. (de) 1867a - Promenades préhistoriques à l'exposition universelle. Paris, p. 24-27.

MORTILLET G. (de) 1867b - Promenades préhistoriques à l'exposition universelle. Revue des cours scientifiques de la France et de l'étranger (M. Eug. Yung), p. 701-702.

MORTILLET G. (de) 1868 - «Promenade au Musée de Saint-Germain ". Matériaux pour l'Histoire primitive et philosophique de l'Homme, Quatrième année, p. 465-466.

MORTILLET G. (de) 1885 - «Faux paléoethnologiques ».

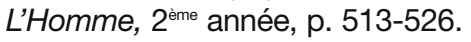

MORTILLET G. (de) 1890 - «Origines de la chasse, de la pêche et de l'agriculture ". Bibliothèque anthropologique, Tome 1, N XII, Lecrosnier et Babé, Paris, p. 24-29.

MORTILLET G. et A. (de) 1881 - Musée préhistorique. C. Reinwald éditeurs, Paris.

MUNRO R. 1905 - Archaeology and false antiquities. Methuen and Co, London.

PALES L. 1989 - Les gravures de la Marche, IV.-Cervidés, mammouths et divers. Editions Ophrys, Gap et Paris.

PIVETEAU J. 1928 - «A propos de Glozel ». Revue de Paris, $1^{\text {er }}$ mai 1928.

POPLIN F. 1995 - « Délitage et débitage dans le travail de l'ivoire vrai sur des exemples du début du Paléolithique supérieur ". (in) Le travail et l'usage de l'ivoire au Paléolithique supérieur, Actes de la Table Ronde de Ravello (29-31 mai 1992), Edit. Hahn J., Menu M., Taborin Y., Walter P., Widemann F., Ravello, Istituto poligraphico e zecca dello stato, Libreria dello stato, p. 17-27.

PRIEM F. 1893-1894 - La terre avant l'apparition de l'homme. Périodes géologiques, faunes et flore fossiles, géologie régionale de la France. Collection « Les merveilles de la nature ", Baillière et fils, Paris.

PRUD'HOMME J. et MEMOIRE N. 1990 - Eléphant, Mammouths ... et les autres. Catalogue d'exposition, Muséum d'Histoire Naturelle de Bordeaux, Bordeaux.

PUTMAN F.W. 1890 - [Untitled Comments at the General Meeting] - 5 february 1890 - Remarks on early man in America. Proceedings of the Boston society of natural history, Volume 24, 1888-1890, p. 467-469.

QUATREFAGES A. (de) 1896 - L'espèce humaine. $12^{\text {ème }}$ édition, F. Alcan, Paris.

RAU Ch. 1876 - Early man in Europe. Harper and Brothers, New-York.

RAYMOND P. 1907 - « Les faux en Préhistoire. Deux pièces rares ". La Revue Préhistorique, Annales de Palethnologie, Tome II, $\mathrm{n}^{\circ}$ 10, Novembre 1907, p. 314-317.

REINACH S. 1928 - Ephémérides de Glozel. KRA éditeur, Paris.

RICHARD N. 1992 - L'invention de la Préhistoire. Une anthologie. Agora-Les Classiques, Presses-Pocket, Paris.

ROBERT E. 1863a - «Sur la non-contemporanéité de l'homme primitif et des grandes espèces perdues de Pachydermes ". Comptes Rendus des Séances de l'Académie des Sciences, séance du 18 mai 1863, Tome LVI, p. 955-957.

ROBERT E. 1863b - «Sur la non-contemporanéité de l'homme et des grandes espèces éteintes de Mammifères ". Comptes Rendus des Séances de l'Académie des Sciences, séance du 15 juin 1863, Tome LVI, p. 1121-1122.

ROBERT E. 1863c - «Sur l'origine récente des traces d'instruments tranchants observées à la surface de quelques ossements fossiles ". Comptes Rendus des Séances de l'Académie des Sciences, séance du 22 juin 1863, Tome LVI, p. 1157-1158.

ROBERT E. 1864 - Nouvelles observations relatives à la prétendue contemporanéité de l'homme et des grands Pachydermes éteints. Comptes Rendus des Séances de l'Académie des Sciences, séance du 11 avril 1864, Tome LVIII, p. 673-675.

SAINT-PERIER S. (de) 1967 - « Inventaire de l'art mobilier paléolithique en Périgord ». Centenaire de la Préhistoire en Périgord (1864-1964). № spécial du Bulletin de la Société Historique et Archéologique du Périgord, Fanlac, Périgueux, p. 139-151.

SAINT-PERIER R. (de) 1920 - « Les gravures quaternaires du Mammouth rapprochées des attitudes de l'Eléphant actuel ». Bulletin de la Société Préhistorique Française, Volume 17, $\mathrm{n}^{\circ} 12$, p. 283-285.

SELLARDS E. H. 1916 - Human Remains and Associated Fossils from the Pleistocene of Florida. 8th Annual Report of Florida Geological Survey, Tallahassee, p. 123-160.

VAYSON DE PRADENNE A. 1932 - Les fraudes en archéologie préhistorique. Emile Nourry, Paris. (1993, Editions Jérôme Million, Grenoble). 
VERNEAU R. 1890 - L'enfance de l'humanité. 1- L'âge de pierre. Bibliothèque des merveilles, Hachette, Paris.

VIALOU D. 1995 - « Objets en ivoire du Paléolithique supérieur conservés au Muséum national d'Histoire naturelle, Paris ». (in) Le travail et l'usage de l'ivoire au Paléolithique supérieur, Actes de la Table Ronde de Ravello (29-31 mai 1992), Edit. Hahn J., Menu M., Taborin Y., Walter P., Widemann F., Ravello, Istituto poligraphico e zecca dello stato, Libreria dello stato, p. 8889.

VIALOU D. 2004 - « Le mammouth dans l'art pariétal. Un profil de rêve ». (in) Catalogue de l'exposition «Au temps des mammouths ", (dir. Alain Foucault et Marylène PatouMathis), Les éditions du Muséum et Philéas Fogg, Paris, p. 154-159.

VIBRAYE P. (de) (Marquis) 1864 - « Notes sur de nouvelles preuves de l'existence de l'homme dans le centre de la France à une époque où s'y trouvaient aussi divers animaux qui de nos jours n'habitent pas cette contrée ». Comptes Rendus des Séances de l'Académie des Sciences, séance du 24 février 1864, Tome LVIII, p. 409-416.

VIBRAYE P. (de) (Marquis) 1865a - « Sur la reproduction en bois de Renne d'une tête (présumée) de Mammouth et sur quelques morceaux d'ivoire travaillé provenant plus particulièrement des stations du Périgord ». Comptes Rendus des Séances de l'Académie des Sciences, séance du 04 septembre 1865, Tome LXI, p. 399-404.

VIBRAYE P. (de) (Marquis) 1865b - « Sur la reproduction en bois de Renne d'une tête (présumée) de Mammouth et sur quelques morceaux d'ivoire travaillé provenant plus particulièrement des stations du Périgord ".Annales des Sciences Naturelles, II-Zoologie, $5^{\text {ème }}$ série, Tome IV, p. 356-362.
WILSON T. 1898 - Prehistoric art ; or the origin of art as manifested in the works of prehistoric man. Smithsonian Institution, United States National Museum, Washington.

WOODWARD H. 1864 - " Discovery of a cranium of Elephas primigenius at Ilford in Essex ». The Geological Magazine, $\mathrm{N}^{\circ} 1$, July-December 1864, p. 241-244, 1 fig.

WOODWARD H. 1868 - " On the curvature of the tusks in the Mammoth, Elephas primigenius (Blumenbach) ". The Geological Magazine, $\mathrm{N}^{\circ}$ 5, January-December 1868, p. 540-543, pl. XXII et XXIII.

WOODWARD H. 1869 - « Man and the mammoth; Being an account of the animals found associated with early man in Pre-historic times ». The Geological Magazine, $\mathrm{N}^{\circ} 6$, Issue 56, February 1869, p. 58-72.

RESSOURCES NUMERIQUES (Old Vero Site), 2009.

1. http://remotecentral.blogspot.com/2009/06/verobeach-ice-age-engraving-mammoth.html,

2. http://news.nationalgeographic.com/news/2009/06/090610oldest-art-mammoth-picture.html,

3. http://www.maxisciences.com/pal\%E9ontologie/lesdebuts-de-I-art-americain-sur-un-os-demammouth_art2432.html 
